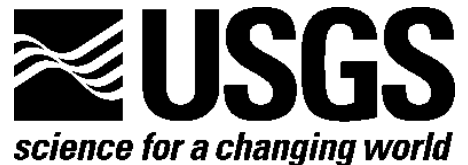

\title{
Geodesy- and Geology-Based Slip-Rate Models for the Western United States (Excluding California) National Seismic Hazard Maps
}

By Mark D. Petersen, Yuehua Zeng, Kathleen M. Haller, Robert McCaffrey, William C. Hammond, Peter Bird, Morgan Moschetti, Zhengkang Shen, Jayne Bormann, and Wayne Thatcher

Open-File Report 2013-1293

U.S. Department of the Interior

U.S. Geological Survey 


\section{U.S. Department of the Interior \\ SALLY JEWELL, Secretary}

\section{U.S. Geological Survey \\ Suzette M. Kimball, Acting Director}

U.S. Geological Survey, Reston, Virginia: 2014

For more information on the USGS-the Federal source for science about the Earth,

its natural and living resources, natural hazards, and the environment-visit

http://www.usgs.gov or call 1-888-ASK-USGS

For an overview of USGS information products, including maps, imagery, and publications, visit $h$ ttp://www.usgs.gov/pubprod

To order this and other USGS information products, visit $h$ ttp://store.usgs.gov

Suggested citation:

Petersen, M.D., Zeng, Yuehua, Haller, K.M., McCaffrey, Robert, Hammond, W.C., Bird, Peter, Moschetti, Morgan, Shen, Zhengkang, Bormann, Jayne, and Thatcher, Wayne, 2014, Geodesy- and geology-based slip-rate models for the Western United States (excluding California) national seismic hazard maps: U.S. Geological Survey Open-File Report 2013-1293, 80 p., http://dx.doi.org/10.3133/ofr20131293.

ISSN 2331-1258 (online)

Any use of trade, firm, or product names is for descriptive purposes only and does not imply endorsement by the U.S. Government.

Although this information product, for the most part, is in the public domain, it also may contain copyrighted materials as noted in the text. Permission to reproduce copyrighted items must be secured from the copyright owner. 


\section{Contents}

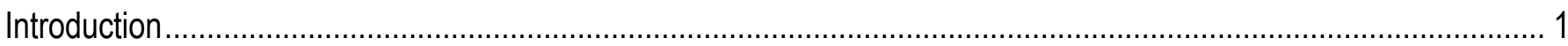

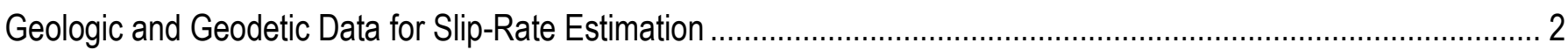

Methodology for Constructing Combined-Inversion Slip-Rate Models ................................................................. 4

Methodology for Implementing Combined-Inversion on Fault Slip-Rate Models into Hazard Maps .......................... 8

Methodology for Constructing Combined-Inversion Off-Fault Seismicity-Rate Models ...........................................14

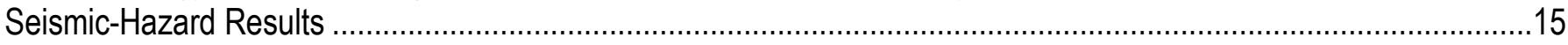

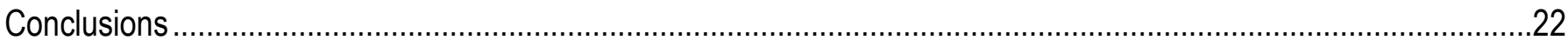

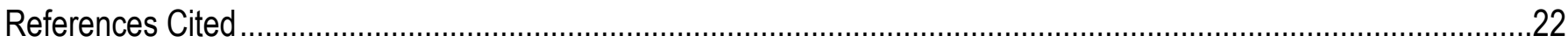

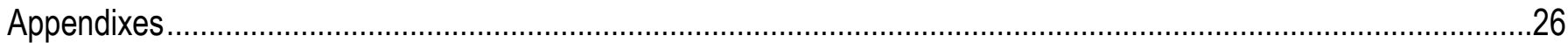

Appendix A-NSHMP Block Model of Western United States Active Tectonics ...................................................27

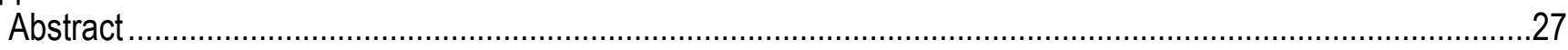

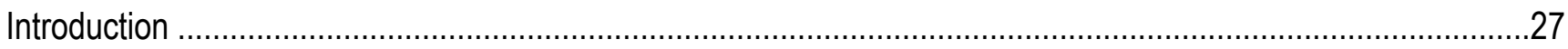

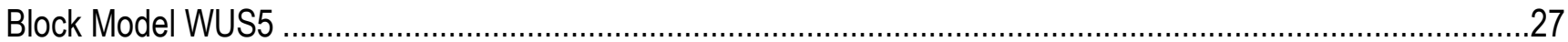

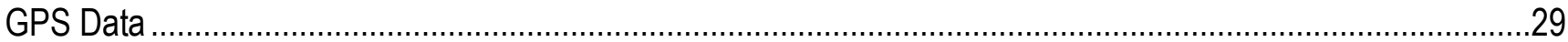

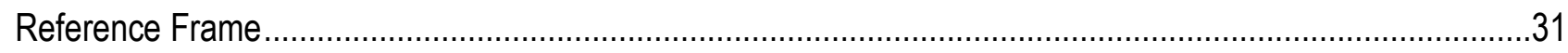

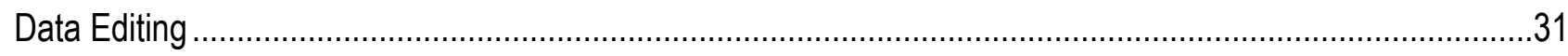

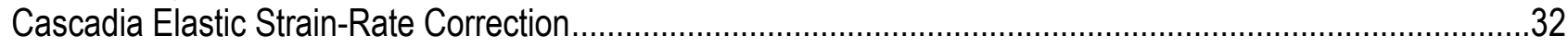

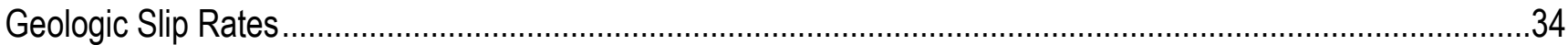

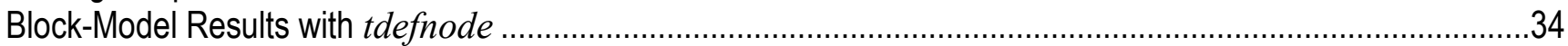

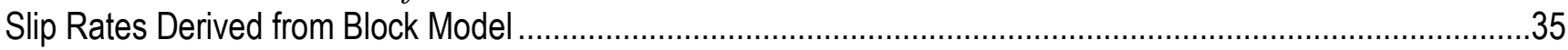

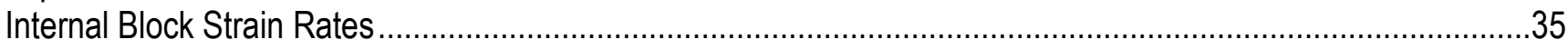

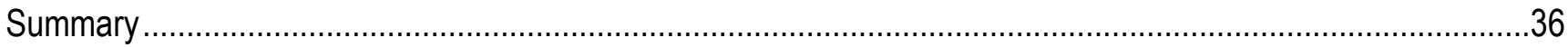

References Cited.........................................................................................................................

Appendix B-A Block Model of Western United States Tectonic Deformation for the 2014 National Seismic

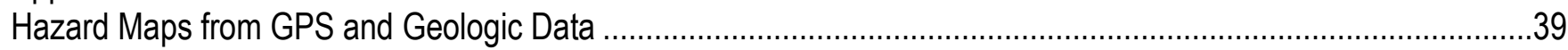

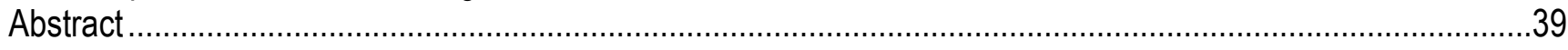

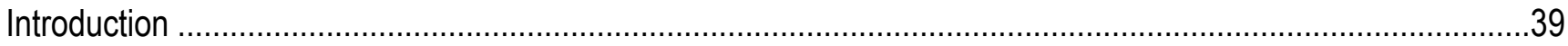

Data

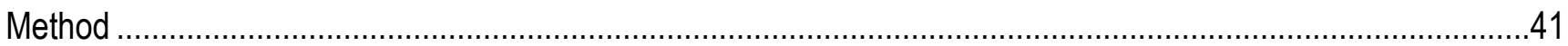

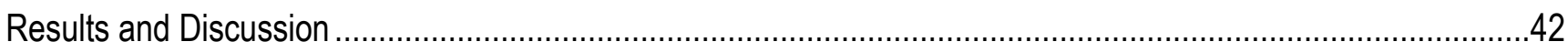

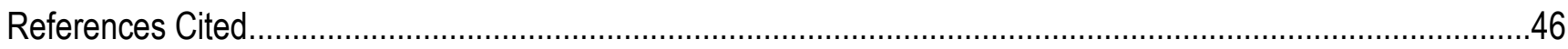

Appendix C-Estimation of Fault Slip Rates in the Conterminous Western United States with Statistical and

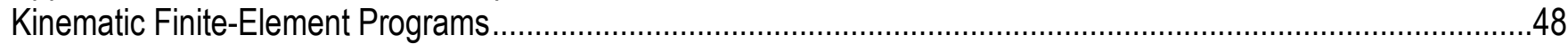

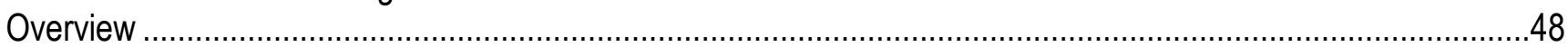

Statistical Modeling of Geologic Offset Rates with Program Slippery ..........................................................48

Joint Geologic and Geophysical Inversion for Offset Rates with Program NeoKinema......................................51

Manual Adjustments to Some Slip Rates in California.........................................................................55

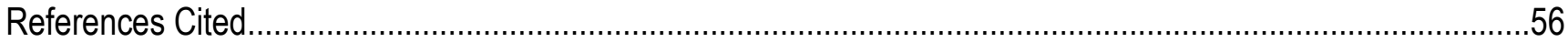

Appendix D—A Fault-Based Model for Crustal Deformation in the Western United States ....................................58

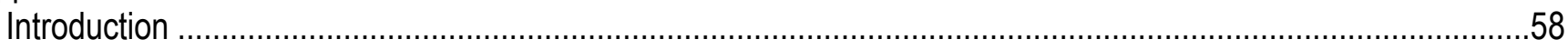

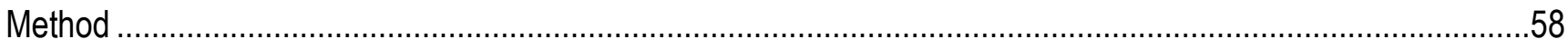

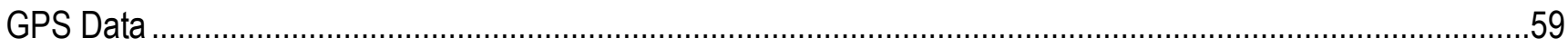

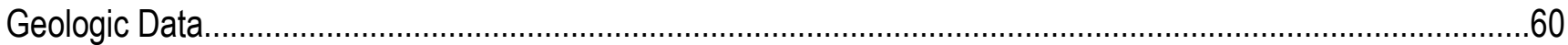

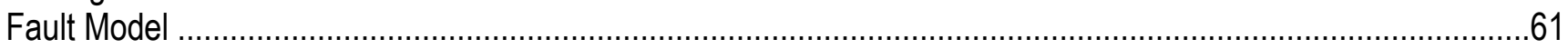

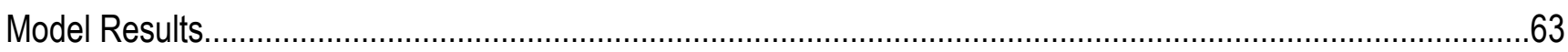

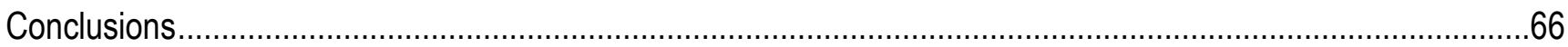


References Cited.

Appendix E-Consideration of the Use of Off-Fault Strain Rates from Combined Inversions of Geodetic (GPS)

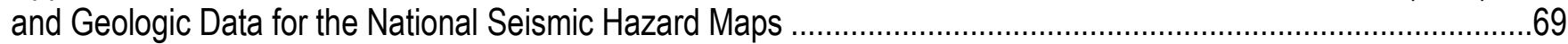

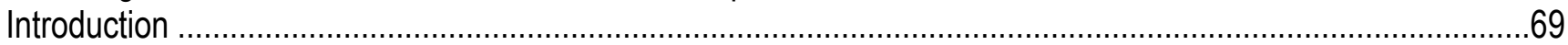

Off-Fault Strain Rates from Combined-Inversions ....................................................................................69

Calculation of Seismicity Rates from Off-Fault Strain Rates......................................................................71

Seismic Hazard from Off-Fault Strain Rates .......................................................................................

Input and Guidance from NSHMP Steering Committee........................................................................79

Updates to Combined-Inversion Models_Zeng and Shen.....................................................................79

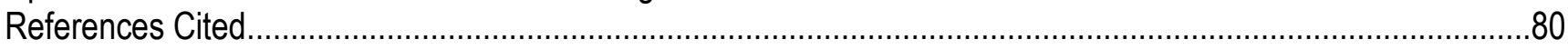

\section{Figures}

Figure 1. Map of modified fault sources in the Western United States excluding California ................................... 1

Figure 2. Comparison of model slip rates ........................................................................................... 9

Figure 3. Frequency plot of assigned slip rates for the geologic-based and geodetic-based block models............. 10

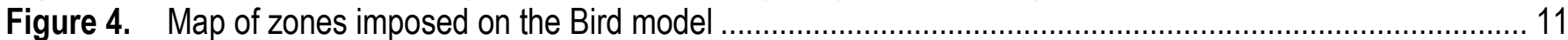

Figure 5. Cumulative on-fault slip along east-west profiles.......................................................................... 13

Figure 6. Difference maps of 1-hertz spectral acceleration for geodetic-based block models ................................ 16

Figure 7. Difference maps of 5-hertz spectral acceleration for geodetic-based block models ................................ 17

Figure 8. Ratio maps of 1-hertz spectral acceleration for geodetic-based block models ....................................... 18

Figure 9. Ratio maps of 5-hertz spectral acceleration for geodetic-based block models ...................................... 19

Figure 10. Difference and ratio maps of 5-hertz and 1-hertz (1-Hz) spectral acceleration for final model ................. 21

Figure A-1. Map of block boundaries in the Western United States.................................................................. 28

Figure A-2. Map of block-model boundaries and National Seismic Hazard Map Project fault sources....................... 29

Figure A-3. Maps of global positioning system velocity field data for the Western United States ............................... 30

Figure A-4. Corrections to velocity field for locking at the Cascadia subduction zone ……....................................... 33

Figure A-5. Comparison of fault slip rates (total rate) for geologic-based and block models ................................... 35

Figure A-6. Maps of areal strain rate and shear strain rate within blocks of McCaffrey model................................... 36

Figure B-1. Map of rotation of blocks in the Hammond and Bormann model....................................................... 42

Figure B-2. Residual misfit from the Hammond and Bormann block model..................................................... 43

Figure B-3. Hammond and Bormann model details in southern California and northern Walker Lane ...................... 43

Figure D-1. Maps of global positioning system velocity field in the Western United States ......................................60

Figure D-2. Map of fault sources in the Western United States and geologic sites in California ................................... 61

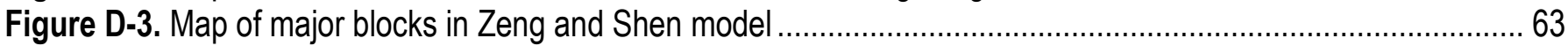

Figure D-4. Comparison of velocity vectors and residual velocities for Zeng and Shen model..................................... 64

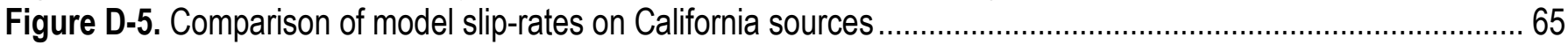

Figure D-6. Comparison of model slip rates on Intermountain West and Pacific Northwest sources.......................... 65

Figure E-1. Comparison of maximum horizontal strain rates from the combined-inversion models............................ 70

Figure E-2. Fraction of grid cells from three combined-inversion models with binned strain rates............................. 71

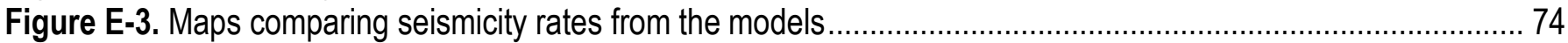

Figure E-4. Maps showing difference in seismicity rates between the models................................................... 75

Figure E-5. Comparison of smoothed seismicity model and calculated seismicity rates from Bird model................... 78

Figure E-6. Plot of updated off-fault strain rates from the Zeng and Shen model .................................................. 80 


\section{Tables}

Table 1. Modifications to the 2008 national seismic hazard map project fault-source parameters ......................... 6

Table 2. Comparison of modified 2008 fault-sources and Bird model slip rates ..............................................12

Table A-1. Velocity fields used and rotation into North American reference frame ..............................................30

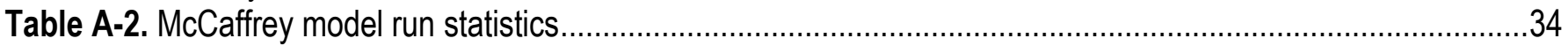

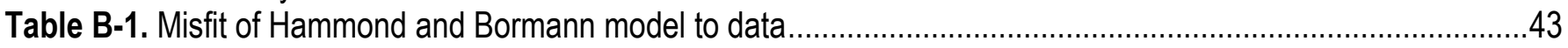

Table C-1. Residual N2 misfits for final preferred Hammond and Bormann models ................................................55

Table E-1. Total moment rate in the study area from the combined-inversion models ...........................................72 


\section{Conversion Factors}

Inch/Pound to SI

\begin{tabular}{lcl}
\hline & \multicolumn{1}{c}{ Multiply } & \multicolumn{1}{c}{ To obtain } \\
\hline & Length & \\
\hline inch (in.) & 2.54 & centimeter (cm) \\
inch (in.) & 25.4 & millimeter (mm) \\
foot (ft) & 0.3048 & meter (m) \\
mile (mi) & 1.609 & kilometer (km) \\
mile, nautical (nmi) & 1.852 & kilometer (km) \\
yard (yd) & 0.9144 & meter (m) \\
\hline
\end{tabular}

\section{Initialisms and Abbreviations}

$\begin{array}{ll}\text { ABM } & \begin{array}{l}\text { average block model } \\ \text { average acceleration produced by gravity at the Earth's surface } \\ \text { global positioning system }\end{array} \\ \text { IMW } & \text { Intermountain West } \\ \text { M } & \text { moment magnitude } \\ \text { NSHMP } & \text { National Seismic Hazards Mapping Project } \\ \text { PDF } & \text { probability density function } \\ \text { RMS } & \text { root mean square } \\ \text { UCERF3 } & \text { Uniform California Earthquake Rupture Forecast, version } 3 \\ \text { WUS } & \text { Western United States }\end{array}$




\title{
Geodesy- and Geology-Based Slip-Rate Models for the Western United States (Excluding California) National Seismic Hazard Maps
}

By Mark D. Petersen, Yuehua Zeng, Kathleen M. Haller, Robert McCaffrey, William C. Hammond, Peter Bird, Morgan Moschetti, Zhengkang Shen, Jayne Bormann, and Wayne Thatcher

\begin{abstract}
The 2014 National Seismic Hazard Maps for the conterminous United States incorporate additional uncertainty in fault slip-rate parameter that controls the earthquake-activity rates than was applied in previous versions of the hazard maps. This additional uncertainty is accounted for by new geodesy- and geology-based slip-rate models for the Western United States. Models that were considered include an updated geologic model based on expert opinion and four combined inversion models informed by both geologic and geodetic input. The two block models considered indicate significantly higher slip rates than the expert opinion and the two fault-based combined inversion models. For the hazard maps, we apply 20 percent weight with equal weighting for the two fault-based models. Off-fault geodetic-based models were not considered in this version of the maps. Resulting changes to the hazard maps are generally less than $0.05 \mathrm{~g}$ (acceleration of gravity). Future research will improve the maps and interpret differences between the new models.
\end{abstract}

\section{Introduction}

The national seismic hazard maps for the conterminous United States (Frankel and others, 1996, 2002; Petersen and others, 2008) rely on (1) earthquake source models that characterize the sizes and rates of earthquakes across a region and (2) ground-motion models that describe the potential shaking levels from these earthquakes. The hazard maps are incorporated in public policy applications such as building-design codes and risk assessments. Therefore, it is important that the models implement the best available science and that they consider random uncertainty as well as alternatives that account for the range of scientifically defensible models available within the science community. Regional and topical workshops are held to assess such alternatives.

One valuable input to the hazard maps is the slip rate that is used to define the rate of earthquakes on known faults, and it is essential that the hazard maps consider reasonable alternative values for this influential parameter. In past versions of the USGS National Seismic Hazard Mapping Project (NSHMP) maps, we depended primarily on expert analysis of geologic-based slip-rate data to model earthquake rates on faults. In addition to the geologic data, modelers also considered available geodetic data in constraining rates of distributed deformation across both broad and narrow zones. For example, in developing seismic source models for California, geologic slip rates were summed across a broad zone along southwest- to northeast-oriented profiles to compare with the total geodetic-based rates obtained from large-scale plate tectonic models (Petersen and others, 1996). These comparisons were used to constrain slip rates on individual faults and to ensure that the models were consistent with 
were used to constrain slip rates on individual faults and to ensure that the models were consistent with general plate tectonics. In addition to these geodetic constraints, we also considered the geodetic data across smaller zones (shear zones) in eastern California and western Nevada to model earthquakes across areas where estimated low geologic slip rates on faults were inconsistent with high geodeticbased rates. Earthquake rates in these source zones were based on a relatively dense distribution of global positioning system (GPS) velocity data. For calculating these rates, we considered 50 percent of the total geodetic slip rate. This reduction was implemented because we assumed that not all the modeled geodetic-based slip rate generates large damaging earthquakes. For example, some offset will naturally occur through aseismic creep, smaller earthquakes, or from foreshocks and aftershocks that are not considered in this analysis. The resulting slip rate was converted to the rate of earthquakes across a zone using Kostrov's (1974) formula, and this earthquake rate was incorporated in a Gutenberg-Richter magnitude-frequency distribution for use in the hazard calculations (Petersen and others, 2008). Within the modeled zones, we characterized (moment magnitude, M) M6.5-M7.6 earthquakes on sources that uniformly fill the zone.

Recently, several modeling teams have combined geologic and geodetic slip-rate data (known as combined-inversion models) to estimate slip rates on individual faults. These models have now advanced to the point that the science community recommends that the combined-inversion models should be considered more directly in calculating hazard. For the 2014 update of the hazard maps, we considered four modeling approaches to develop combined-inversion earthquake source models for the NSHMP maps. The four teams describe their models and data in appendixes A-D. This study incorporates systematic use of interseismic GPS benchmark velocities across the region for the first time. These data have promise of becoming an important alternative dataset in assessing earthquake rates.

The purpose of this report is to show the geologic and geodetic (GPS) input data, methodology, geologic input models, combined geologic- and geodetic-based slip-rate models (combined-inversion models), and hazard results obtained when implementing the new models. Three steps were important in constructing the final combined-inversion models for the maps: (1) compiling, processing, and editing GPS-based velocity data and preserving these data in a database that is available for use by all model developers, (2) computing new combined-inversion slip rates for fault sources in the NSHMP maps, and (3) implementing the resulting combined-inversion and the traditional geology-based slip-rate models in the hazard analysis. We discuss each of these components in this report. We do not consider California in this study, because it has already been implemented in the Uniform California Earthquake Rupture Forecast (version 3) model (WGCEP, 2013). In addition, we do not concentrate on the Cascadia subduction zone and have attempted to remove the velocities caused by this major earthquake source so that we could focus on the slip rates on other faults. The Cascadia subduction zone is modeled using a variety of paleotsunami and historic information in the national seismic hazard maps (Petersen and others, in press).

\section{Geologic and Geodetic Data for Slip-Rate Estimation}

The NSHMP maps for the Western United States (WUS) have historically relied on either an assigned slip rate or paleoearthquake recurrence rate from studies of dated offset features, geomorphology, or fault trenching studies for each fault source in the model. Observed geologic displacements record long-term average rates (typically over several hundreds or thousands of years) that are essential for assessing the activity rates needed for seismic-hazard analyses. These assigned slip rates are used to forecast the rate of earthquakes on the modeled fault with higher slip rates implying higher activity rates and lower slip rates implying lower activity rates for the same magnitude range. 
Paleoseismic trenching studies provide additional details that identify timing and displacement of earthquakes on faults; therefore, they are direct evidence of past earthquake activity and provide ground-truth that compares with our modeled earthquake rates.

There are several limitations in using the geologic data for assessing hazard. First, slip rates on a fault may vary over time and space. Therefore, it is difficult to determine which of these rates is most appropriate for a 50-year period for which the maps are made. We typically prefer geologic slip rates that span several of the most recent seismic cycles (where available) to assess the hazard. Second, faults are often characterized by one or a few slip rates along the entire length of the fault; thus, the data may not be average or representative. These factors also inhibit a robust assessment of the slip-rate uncertainty, especially if the measurements do not represent a uniform sampling of the fault. Third, fault slip rate has substantial uncertainties associated with the measurement of fault displacements and the timing of those displacements. The associated uncertainties are rarely documented. Thus, geologic sliprate uncertainties often span more than a factor of two, especially for poorly studied faults. Fourth, although paleoseismic data provide our most direct estimate of earthquake rates, it is difficult to know if the record of past earthquakes is complete leading to an inaccurate estimate of earthquake rates.

Nevertheless, geologic slip rates and paleoseismic-recurrence observations have thus far constrained our estimate of earthquake rates on faults.

Modern GPS data have good spatial coverage and span more than 25 years (from 1987-2012). They record the most recent motions with submillimeter per year precision, which is often more precise than data provided by geology studies. Slip rates based on combined-inversions of geologic and geodetic data are generally consistent with the assigned slip rates we have considered in the prior version of the NSHMP maps (considering its uncertainties), with exceptions that may be important for assessing hazards. Some of these differences are due to the influence of the GPS data, and others are due to differences in analysis methods (for example, expert analysis versus algorithmic). Each of the modelers reports their normalized or reduced chi-squared uncertainties in their respective appendix. This is one measure that defines how well the model predicts the observed geodetic data.

Geodetic data also have limitations for use in hazard analysis. For example, these data do not cover the 100- or 1,000-year time spans that we generally need to assess long-term hazard, and current data may include transient strains or aseismic strains, which are difficult to identify and eliminate (Hearn and others, 2013; Chuang and Johnson, 2011). In addition, geodetic data also do not provide sufficient resolution in places where there are many closely spaced faults, because uncertainties of individual fault slip rates in such regions trade off with one another (although the total amount of slip across several faults may be constrained). For the deformation models, it is unclear how to distribute the modeled strain rates across the regions between the modeled faults even though we know there are numerous unmodeled and unidentified faults within these zones. In addition, with geodetic data (and with geologic data), it is difficult to constrain the depth of the seismogenic zone for use in hazard calculations. Further research will improve the combined-inversion models for estimating slip rate on faults in the future.

The estimates of off-fault strain-rate models should provide a wealth of new information regarding the location of future earthquakes that do not occur on the modeled faults. However, these models have wide moment-rate variability, and scientists attending our workshops and the NSHMP Steering Committee felt that these models are not ready for use in the NSHMP maps. The off-fault strain-rate models are described in appendix E.

Using the geodetic and geologic data together for hazard analysis makes sense given the limitations and uncertainties associated with each of the datasets. The geologic data that were used to inform the geodetic models are based on the NSHMP 2008 fault-source model (Haller and Wheeler, 
2008a,b) with updates that are described below. An alternative (automated statistical) analysis of these geologic data is discussed in appendix C. Appendix A is a compilation of GPS velocities from a variety of sources and includes corrections for the elastic strain from the Cascadia subduction zone.

\section{Methodology for Constructing Combined-Inversion Slip-Rate Models}

In this report, we consider the slip rates for fault sources based on expert analysis of geologic slip-rate data and from two types of combined-inversion models for assessing fault slip rates. The first type is referred to as combined-inversion "block models" consisting of rigid or uniformly straining blocks bounded by major active faults. These models include elastic strain during interseismic times. The second type of combined-inversion models are referred to as "fault-based models" that consider slip on all faults. These models permit nonuniform strain rates off the specified faults but at much shorter wavelengths than in the block models.

Fault sources in the 2008 NSHMP model (fig. 1) were updated to incorporate newly published geologic and paleoseismic studies that characterize activity rate and fault geometry to inform the combined-inversion models. Table 1 identifies source-specific changes made to the 2008 NSHMP model. In summary they include the following:

- Normal faults are updated with three-dimensional geometry.

- Five new sources are added based on recent studies.

- Three sources are updated with two-dimensional geometry.

- Nine sources are constrained by annual rate.

- Fifteen sources are updated with revised vertical throw rate.

- Two sources are updated with revised horizontal slip rate. 


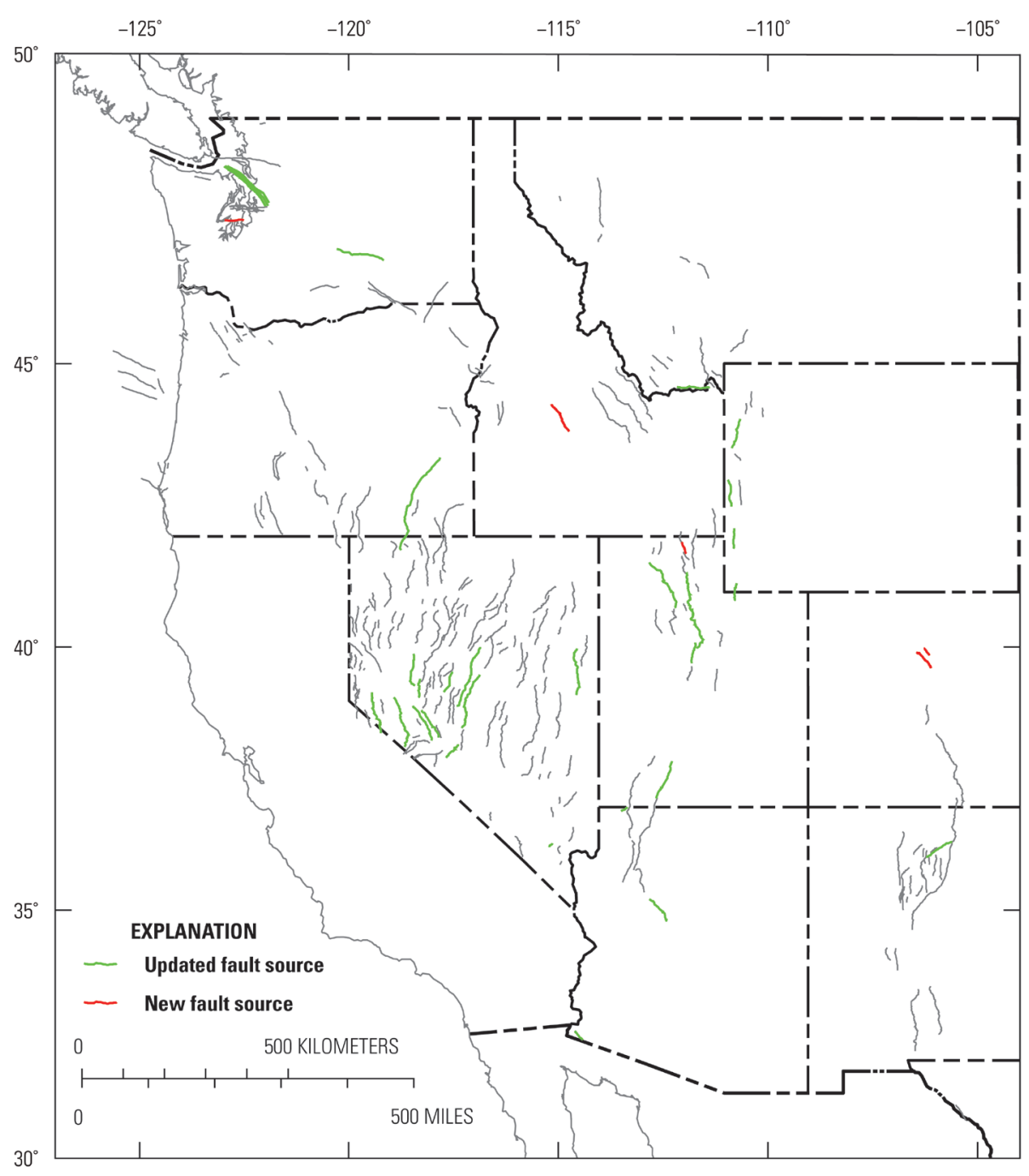

Figure 1. Map showing location of modified 2008 national seismic hazard map project fault sources in the study area (Western United States excluding California). Green sources have updated parameters; red sources are new sources. 
Table 1. Modifications to the 2008 national seismic hazard map project fault-source parameters.

[2008 value and 2014 value refer to the updated parameter column. Fault length in kilometers; vertical throw rate and horizontal slip rate in millimeters per year; $\mathbf{M}$, moment magnitude]

\begin{tabular}{|c|c|c|c|c|c|}
\hline Fault name & State & Updated parameter & $\begin{array}{l}2008 \\
\text { value }\end{array}$ & $\begin{array}{l}2014 \\
\text { value }\end{array}$ & Citation \\
\hline Algodones fault zone & Arizona & $\begin{array}{l}\text { extend length of } \\
\text { source }\end{array}$ & 19.17 & 26.57 & $\begin{array}{l}\text { U.S. Bureau of } \\
\text { Reclamation (2009) }\end{array}$ \\
\hline $\begin{array}{l}\text { Big Chino-Little Chino } \\
\text { fault }\end{array}$ & Arizona & $\begin{array}{l}\text { extend length of } \\
\text { source to include } \\
\text { Little Chino fault }\end{array}$ & 49.00 & 64.61 & $\begin{array}{l}\text { Gootee and others } \\
\text { (2010), Ferguson and } \\
\text { others (2012), } \\
\text { Pearthree and } \\
\text { Ferguson (2012) }\end{array}$ \\
\hline Gore Range frontal fault & Colorado & new source & & & $\begin{array}{l}\text { Derouin and others } \\
\text { (2010) }\end{array}$ \\
\hline $\begin{array}{l}\text { Williams Fork Mountains } \\
\text { fault }\end{array}$ & Colorado & new source & & & Kirkham (2004) \\
\hline Sawtooth fault & Idaho & new source & & & $\begin{array}{l}\text { Thackray and others } \\
\text { (2009), Johnson } \\
\text { (2010) }\end{array}$ \\
\hline Centennial fault & Montana & vertical throw rate & 0.9 & 0.7 & Petrik (2008) \\
\hline Benton Spring fault & Nevada & $\begin{array}{l}\text { horizontal slip } \\
\text { rate }\end{array}$ & 0.27 & 0.5 & $\begin{array}{l}\text { Bell (1995), } \\
\text { Wesnousky (2005) }\end{array}$ \\
\hline $\begin{array}{l}\text { Desatoya Mountains fault } \\
\text { zone }\end{array}$ & Nevada & vertical throw rate & 0.1 & 0.04 & $\begin{array}{l}\text { Koehler and } \\
\text { Wesnousky (2011) }\end{array}$ \\
\hline Lone Mountain fault zone & Nevada & vertical throw rate & 0.13 & 0.2 & $\begin{array}{l}\text { Hoeft and Frankel } \\
\text { (2010) }\end{array}$ \\
\hline $\begin{array}{l}\text { Rainbow Mountain fault } \\
\text { zone }\end{array}$ & Nevada & vertical throw rate & 0.15 & 0.2 & $\begin{array}{l}\text { Caskey and others } \\
(2004)\end{array}$ \\
\hline Sand Springs Range fault & Nevada & vertical throw rate & 0.1 & 0.2 & Bell and others (2004) \\
\hline $\begin{array}{l}\text { Schell Creek Range fault } \\
\text { system }\end{array}$ & Nevada & vertical throw rate & 0.01 & 0.1 & $\begin{array}{l}\text { Koehler and } \\
\text { Wesnousky (2011) }\end{array}$ \\
\hline Smith Valley fault & Nevada & vertical throw rate & 0.38 & 0.25 & $\begin{array}{l}\text { Hayes (1985), } \\
\text { Wesnousky and Caffee } \\
\text { (2011) }\end{array}$ \\
\hline Toiyabe Range fault zone & Nevada & vertical throw rate & 0.22 & 0.06 & $\begin{array}{l}\text { Koehler and } \\
\text { Wesnousky (2011) }\end{array}$ \\
\hline Wassuk Range fault zone & Nevada & vertical throw rate & 0.55 & 0.7 & $\begin{array}{l}\text { Bormann and others } \\
\text { (2012) }\end{array}$ \\
\hline $\begin{array}{l}\text { Western Toiyabe Range } \\
\text { fault zone }\end{array}$ & Nevada & vertical throw rate & 0.2 & 0.07 & $\begin{array}{l}\text { Koehler and } \\
\text { Wesnousky (2011) }\end{array}$ \\
\hline Embudo fault & $\begin{array}{l}\text { New } \\
\text { Mexico }\end{array}$ & $\begin{array}{l}\text { horizontal slip } \\
\text { rate }\end{array}$ & 0.09 & 0.13 & $\begin{array}{l}\text { Bauer and Kelson } \\
\text { (2004) }\end{array}$ \\
\hline Steens fault zone & Oregon & vertical throw rate & 0.3 & 0.27 & $\begin{array}{l}\text { Personius and others } \\
\text { (2007) }\end{array}$ \\
\hline
\end{tabular}


Table 1. Modifications to the 2008 national seismic hazard map project fault-source parameters. - Continued [2008 value and 2014 value refer to the updated parameter column. Fault length in kilometers; vertical throw rate and horizontal slip rate in millimeters per year; $\mathbf{M}$, moment magnitude]

\begin{tabular}{|c|c|c|c|c|c|}
\hline Fault name & State & Updated parameter & $\begin{array}{l}2008 \\
\text { value }\end{array}$ & $\begin{array}{l}2014 \\
\text { value }\end{array}$ & Citation \\
\hline $\begin{array}{l}\text { Great Salt Lake fault } \\
\text { zone, Antelope Island } \\
\text { section }\end{array}$ & Utah & $\begin{array}{l}\text { annual-rate } \\
\text { constraint }\end{array}$ & 0.000651 & 0.000238 & Lund (2006) \\
\hline $\begin{array}{l}\text { Great Salt Lake fault } \\
\text { zone, Fremont Island } \\
\text { section }\end{array}$ & Utah & $\begin{array}{l}\text { annual-rate } \\
\text { constraint }\end{array}$ & 0.000746 & 0.000238 & Lund (2006) \\
\hline $\begin{array}{l}\text { Great Salt Lake fault } \\
\text { zone, Promontory section }\end{array}$ & Utah & $\begin{array}{l}\text { annual-rate } \\
\text { constraint }\end{array}$ & 0.000511 & 0.000238 & Lund (2006) \\
\hline $\begin{array}{l}\text { Sevier/Toroweap fault } \\
\text { zone (northern) }\end{array}$ & Utah & vertical throw rate & 0.36 & 0.04 & $\begin{array}{l}\text { Lund and others } \\
\text { (2008) }\end{array}$ \\
\hline $\begin{array}{l}\text { Wasatch fault zone, Nephi } \\
\text { section }\end{array}$ & Utah & $\begin{array}{l}\text { annual-rate } \\
\text { constraint }\end{array}$ & $4.00 \mathrm{E}-04$ & $1.11 \mathrm{E}-03$ & Lund (2013) \\
\hline $\begin{array}{l}\text { Wasatch fault zone, Provo } \\
\text { section }\end{array}$ & Utah & $\begin{array}{l}\text { annual-rate } \\
\text { constraint }\end{array}$ & 4.17E-04 & 7.69E-04 & Lund (2013) \\
\hline $\begin{array}{l}\text { Wasatch fault zone, Salt } \\
\text { Lake City section }\end{array}$ & Utah & location modified & & & \\
\hline $\begin{array}{l}\text { Wasatch fault zone, } \\
\text { Weber section }\end{array}$ & Utah & $\begin{array}{l}\text { annual-rate } \\
\text { constraint }\end{array}$ & $7.14 \mathrm{E}-04$ & 7.69E-04 & Lund (2013) \\
\hline $\begin{array}{l}\text { Wasatch fault zone } \\
\text { floating M7.4 }\end{array}$ & Utah & M distribution & M7.4 & M6.5-7.4 & \\
\hline $\begin{array}{l}\text { West Cache fault, } \\
\text { Junction Hills section }\end{array}$ & Utah & new source & & & Lund (2006) \\
\hline Southern Whidbey Island & Washington & $\begin{array}{l}\text { extend length of } \\
\text { source }\end{array}$ & & & $\begin{array}{l}\text { Dragovich and others } \\
(2007)\end{array}$ \\
\hline Tacoma fault & Washington & new source & & & \\
\hline Grand Valley fault & Wyoming & vertical throw rate & 1.1 & 0.8 & reevaluation of data \\
\hline Rock Creek fault & Wyoming & vertical throw rate & 1.7 & 0.62 & Lund (2013) \\
\hline Teton fault & Wyoming & vertical throw rate & 1.3 & 0.7 & $\begin{array}{l}\text { O'Connell and others } \\
\text { (2003), Hampel and } \\
\text { others (2007), White } \\
\text { and others (2009) }\end{array}$ \\
\hline
\end{tabular}

Four modeling teams participated in developing combined geologic and geodetic slip-rate models for the 2014 update of the NSHMP maps; we refer to the block model described in appendix A as the McCaffrey block model. Descriptions of the fault slip-rate models are included as appendixes showing the McCaffrey block model (appendix A), the Hammond and Bormann block model (appendix B), the Bird fault-based model (appendix C), and the Zeng and Shen fault-based model (appendix D). 
Each of these models was developed using a methodology that had previously been applied in developing one of the UCERF3 (Uniform California Earthquake Rupture Forecast, version 3) models (WGCEP, 2013). The differences between these combined-inversion models provide some sense of the epistemic uncertainty in estimating slip rates, which is an important consideration in constructing robust probabilistic seismic hazard assessments.

\section{Methodology for Implementing Combined-Inversion on Fault Slip-Rate Models into Hazard Maps}

In order to determine whether or not to use combined-inversion slip-rate models in the 2014 NSHMP maps and how we should apply these slip-rate models in the calculations, we convened two open workshops to discuss models and hazard implications, a meeting for the four geodetic modeling teams to evaluate data and methods, and an expert-panel meeting to determine whether geodetic- and geologic-based models and the associated hazard implementations were mature enough for this hazard application. The majority of participants at these workshops and panels agreed that the combinedinversion models provided new estimates of fault slip rate that should be considered in future hazard maps. They felt that some of the combined-inversion slip-rate models were appropriate for the update scheduled for 2014, but additional research on relevant input parameters and models would be required to make them more useful in hazard assessment. Therefore, they indicated that the models should be carefully scrutinized and given lower weight in this update of the hazard maps. This lower weight will prevent the hazard values from fluctuating as the geodetic models mature.

In order to directly compare the slip rates assigned in the modified 2008 fault-source model and horizontal velocities derived from GPS data, we divide the horizontal slip rate by the cosine of the dip angle to derive the down-dip slip rate, as recommended by workshop participants. All of the model rates were converted using this same method (either implicitly or explicitly). Some combined-inversion models suggest slip rates that are significantly different from the modified NSHMP fault sources (fig. 2). For this analysis, we consider factors of 2 and $1 / 2$ of the mean down-dip slip rate to encompass the 95-percent confidence range for geologic slip rates (fig. 2) (see for example, Petersen and others, 1996). We do not understand these differences or which of these rates is more appropriate, because both datasets have limitations as discussed above. 

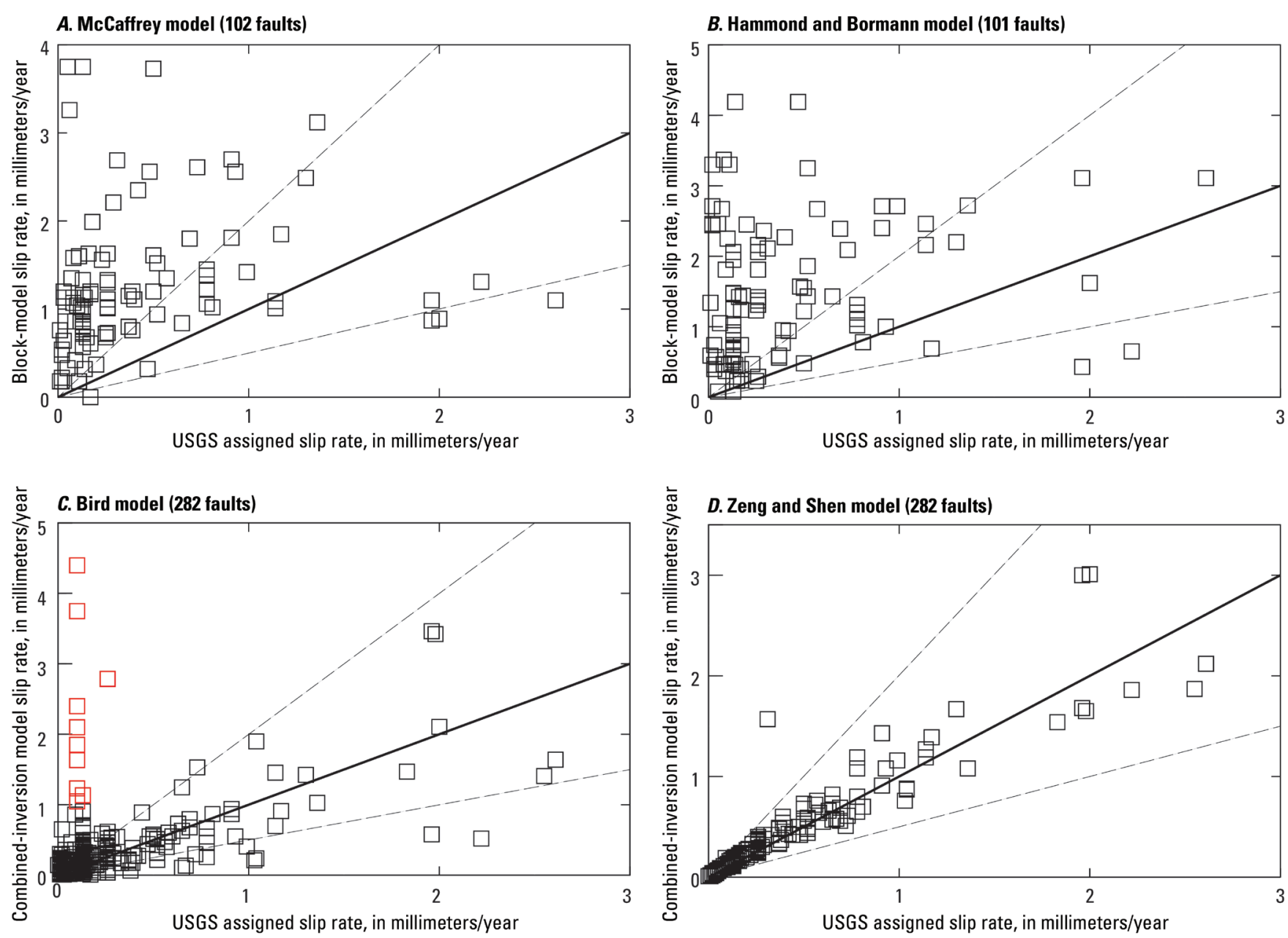

Figure 2. Comparison of the slip-rate models of $A, M c C$ affrey block model (appendix $A$ ), $B$, Hammond and Bormann block model (appendix B), C, Bird fault-based model (appendix C), and D, Zeng and Shen faultbased model (appendix D) versus the 2008 NSHMP fault sources. Solid line represents equality between the geology and geodesy slip rates; dashed lines represent factors of 2 and $1 / 2$ compared to the equality line. Red symbols on the Bird (appendix C) graph represent fault slip rates that were modified in the hazard assessment.

The combined-inversion slip rates of McCaffrey block model (fig. $2 A$, appendix A) and Hammond and Bormann block model (fig. $2 B$, appendix B) are typically higher than the modified 2008 fault-source slip rates. It is important to point out that we cannot determine if the block-model rates are right or wrong from this comparison - only that the rates differ from the assigned geologic rates that have been applied in past hazard maps. The block models use block boundaries that are interpreted from the earthquake data, fault data, and strain-rate orientations; hence, slip rates in these models are constrained to occur only on the block boundaries (faults within the blocks are modeled as uniform strain rates). Thus, the block models only include about one-third of the faults that are in the modified 2008 fault-source model. Figure 3 shows the modified 2008 fault-source slip rates for the faults included and excluded from the block models. About half of the faults that are not included in the block models have slip rates less than 0.3 millimeters per year $(\mathrm{mm} / \mathrm{yr})$; however, a few of the geologically faster slipping faults are also excluded from the block models due to their locations compared to the block 
boundaries. For this hazard map implementation, we used block-model data to assess the general geodetic trends, but we were not able to arrive at consensus on an appropriate method to distribute slip rate within blocks. Therefore, the block models were not applied directly in the final hazard maps. Further studies will help us understand these discrepancies and determine how to use these data in future applications.

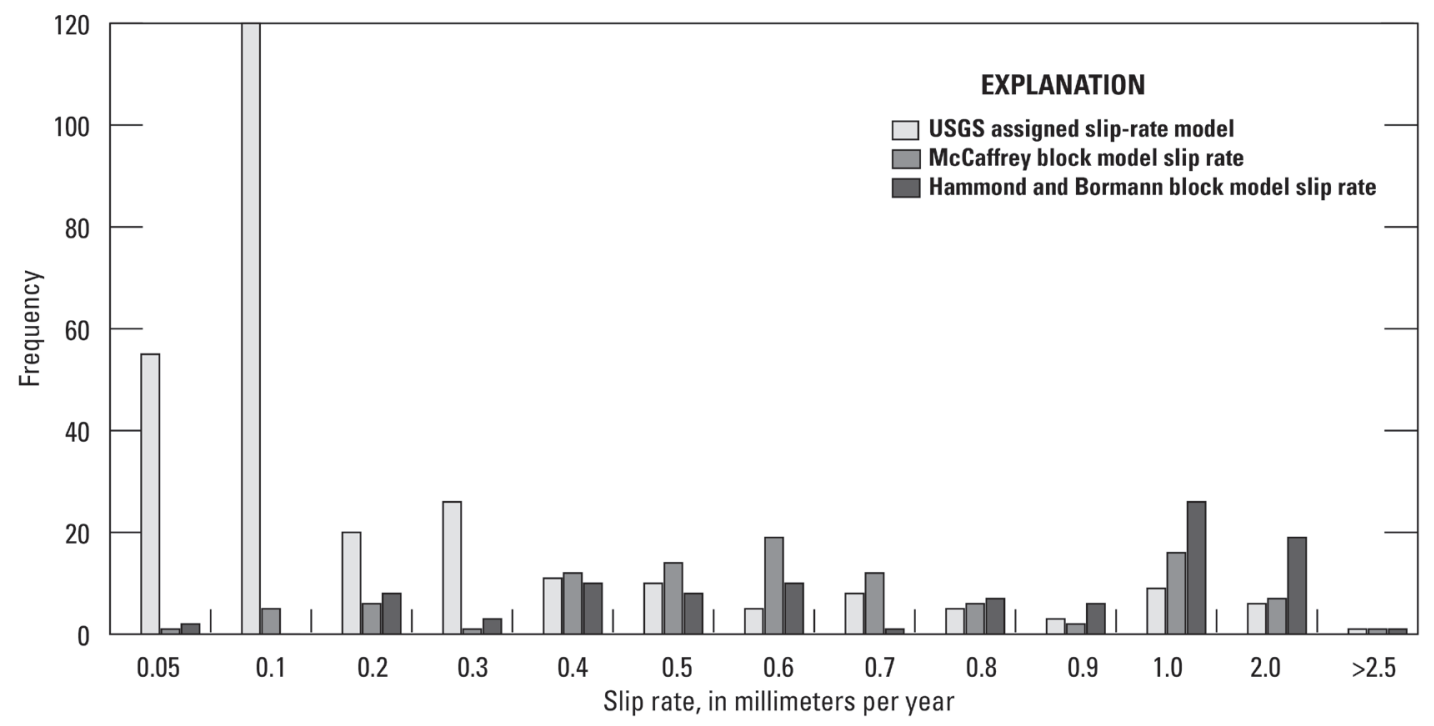

Figure 3. Frequency plot of assigned slip rates for the modified 2008 fault-source model and geodetic-based block models.

The combined-inversion slip rates of Bird fault-based model (fig. $2 C$, appendix $C$ ) and the Zeng and Shen fault-based model (fig. $2 D$, appendix D) slip-rate models also differ from the modified 2008 fault-source slip rates, though the differences are not as large as they are for the block models. The general agreement of these two models with the modified 2008 fault-source slip rates does not mean that they are more correct than the results of the block models. The Bird slip-rate model differs significantly (by a factor of two or more) from the modified 2008 fault-source slip rates for 10 faults (table 2) in western and central Nevada. The modified 2008 fault-source slip rates on these faults are low (about 0.1 $\mathrm{mm} / \mathrm{yr}$ ), and the combined-inversion rates are higher by factors of 10 or more (these are shown as red symbols on fig $2 C$ ). We model these higher rates in our hazard analysis by using 50 percent of the slip rate indicated by the Bird model and by spreading the reduced slip rate over a region extending about 10 $\mathrm{km}$ around the group of faults modeled with high slip rates (fig. 4). We reduce the slip rates on these central Nevada faults because we do not understand the first-order differences between the slip rates assigned in the modified 2008 fault-source model and combined geologic-geodetic slip rates. Further research is needed to define the range of acceptable rates before we implement such a major change that will cause a significant hazard hotspot over these faults. These faults are mostly located in central Nevada in the vicinity of some past large earthquakes. It is possible that transient deformation (Hammond and others, 2009), groundwater withdrawal, or some other nontectonic effects are contributing to the unusually high slip rates for these closely spaced faults. In addition, the combinedinversion slip rates may not be well resolved and have large uncertainties. Another possibility is that poorly dated offset features are not reliable, and the geodetic data is more appropriate for hazard in the 
next 50 years. Additional combined-inversion slip rates near Portland, Oreg., also are higher than the modified 2008 fault-source slip rates (table 2, fig. 4). Therefore, we have also spread the slip rates for these faults over a zone to account for our uncertainty in the location of future earthquakes in this region.

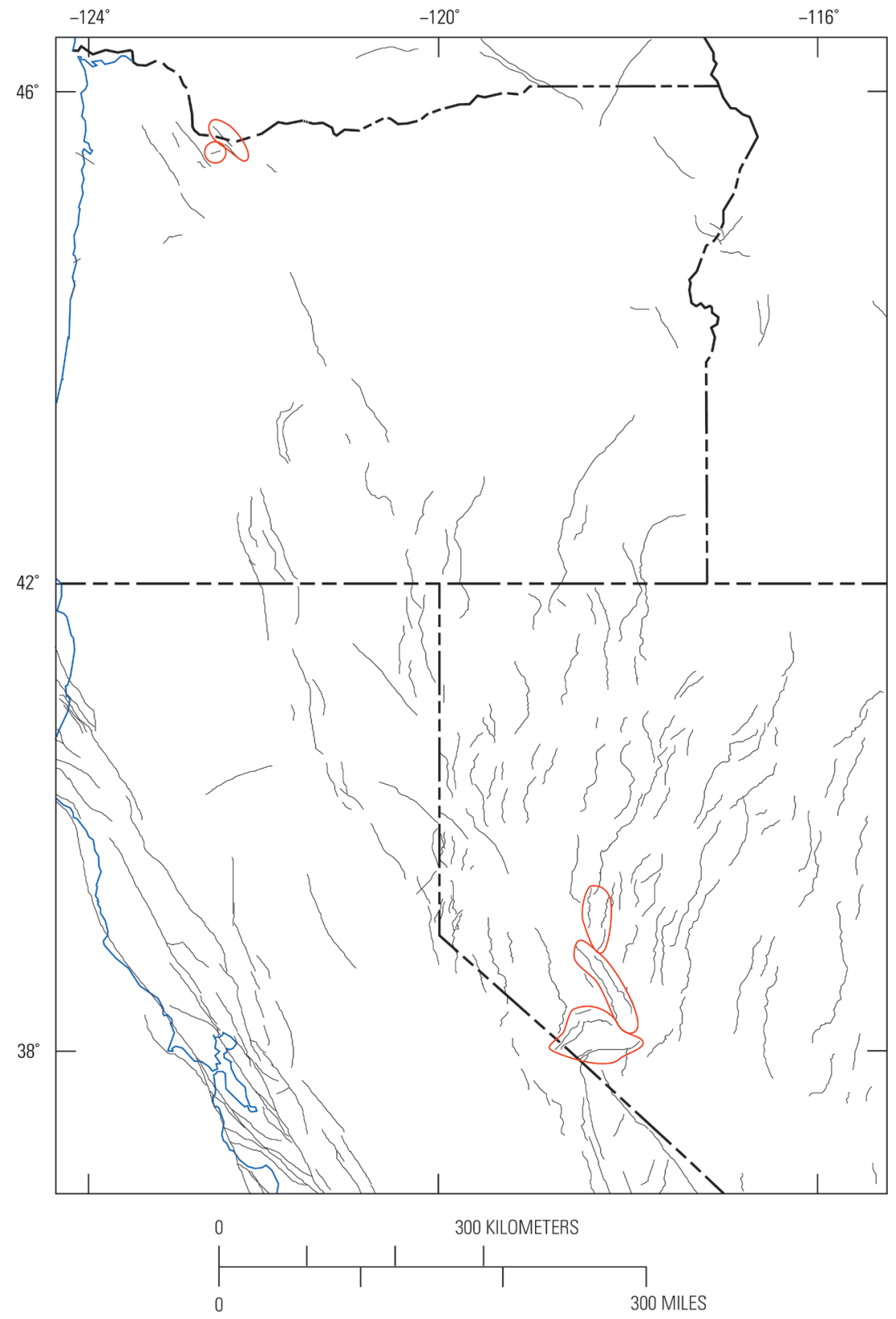

Figure 4. Map showing the location of the zones (surrounded by red lines) imposed on the Bird model (appendix C) to smooth the effects of high slip rates on individual fault sources (see table 2). The rates in the two southern Nevada zones are modeled with 50 percent of slip rate determined in the Bird model. 
Table 2. Comparison of modified 2008 fault-sources and Bird model (appendix C) slip rates for the 10 faults identified by red symbols in figure 2 and outlined in red in figure 4 . Asterisks show models that were not decreased by 50 percent in the hazard models.

[mm/yr, millimeter per year; km, kilometer]

\begin{tabular}{llccccc}
\hline \multicolumn{1}{c}{ Name } & State & $\begin{array}{c}\text { Modified 2008 } \\
\text { fault-source } \\
\text { model slip } \\
\text { rate (mm/yr) }\end{array}$ & $\begin{array}{c}\text { Bird model } \\
\text { (appendix C) } \\
\text { mean slip rate } \\
\text { (mm/yr) }\end{array}$ & $\begin{array}{c}\text { Sense of } \\
\text { slip }\end{array}$ & $\begin{array}{c}\text { Length } \\
\text { (km) }\end{array}$ & $\begin{array}{c}\text { Dip } \\
\text { (degrees) }\end{array}$ \\
\hline Benton Spring fault & Nev. & 0.26 & 1.76 & normal & 85 & 90 \\
Bettles Well-Petrified Springs fault & Nev. & 0.1 & 11.6 & normal & 71 & 90 \\
Buffalo Valley fault & Nev. & 0.13 & 0.483 & strike-slip & 41 & 50 \\
Coaldale fault 1 & Nev. & 0.1 & 4.33 & normal & 66 & 90 \\
Coaldale fault 2 & Nev. & 0.1 & 4.33 & normal & 17 & 90 \\
Fairview fault & Nev. & 0.13 & 0.0981 & strike-slip & 34 & 50 \\
Faults in Excelsior Mountains & Nev. & 0.1 & 1.85 & normal & 27 & 90 \\
Hot Springs fault & Nev. & 0.13 & 0.25 & strike-slip & 24 & 50 \\
Huntoon Valley fault & Nev. & 0.1 & 3.747 & normal & 38 & 90 \\
Rattlesnake fault & Nev. & 0.1 & 2.398 & normal & 15 & 90 \\
Sand Springs fault & Nev. & 0.13 & 0.25 & strike-slip & 42 & 50 \\
Spanish Springs Peak fault & Nev. & 0.1 & 4.33 & normal & 5 & 90 \\
Unnamed faults & Nev. & 0.1 & 1.232 & normal & 40 & 90 \\
Grant Butte fault & Oreg. & 0.14 & 0.247 & strike-slip & 9 & 50 \\
Lacamas Lake fault & Oreg. & 0.03 & 1.68 & normal & 24 & 90 \\
\hline
\end{tabular}

The Zeng and Shen combined-inversion model (appendix D) provides slip rates that compare well to those of the expert analysis of geologic slip-rate model. However, some have criticized that this model is so similar to the purely geologic model that it is not adding much additional information to the seismic hazard model. Nevertheless, we find that there are important differences between the geologic rates and Zeng and Shen model predicted rates. Differences between the expert analysis of geologic slip-rate data and the combined-inversion rates may be important in defining alternative views of earthquake hazard. For example, the southern Wasatch combined-inversion rates are significantly higher than the rates implied by prior expert analysis of geologic slip-rate data; however, recent reanalysis suggests higher geologic slip rates (Lund, 2013). These differences may point out locations where the slip rates vary in time and where faults are currently more active than the long-term average given by the geologic data (Chang and others, 2006) or where the geologic data are affected by bias or unmodeled complexity. Alternatively, the differences may indicate that the geologic slip rates derived from expert analysis as a whole are not kinematically compatible. It seems prudent to account for increased hazard along the southern Wasatch where geodetic data indicate high slip rates during the past 25 years.

Figure 5 shows a comparison of the on-fault cumulative geologic slip rates and fault-based combined-inversion slip rates of Bird, and Zeng and Shen along east-west oriented profiles located at $0.1^{\circ}$ intervals from $35^{\circ}$ to $45^{\circ}$ latitude for east (extension, fig. $5 A$ ) and north (strike-slip, fig. $5 B$ ) motion with the Pacific Plate held fixed. Hanging-wall displacements were separated into two components 
(north and east) and summed along transects to show variability from north to south across the study area; total slip is shown in millimeters per year. The transects show variation of total slip up to $5 \mathrm{~mm} / \mathrm{yr}$ extension (fig. $5 \mathrm{~A}$ ) and less than $4 \mathrm{~mm} / \mathrm{yr}$ strike-slip component (fig. $5 B$ ), which is more than a factor of 20 lower than the UCERF 3 model for California (WGCEP, 2013). For the extensional rates (east), the three models track each other very well in the north, but the Bird (appendix C) model deviates from the other two near the southern end of the central Nevada seismic zone (latitudes between $38^{\circ}$ and $40.5^{\circ}$ ). This area encompasses the faults that have reduced slip rates in the Bird model. For the strike-slip rates (north), the three models again track each other in the north but deviate from each other near the southern central Nevada seismic zone.
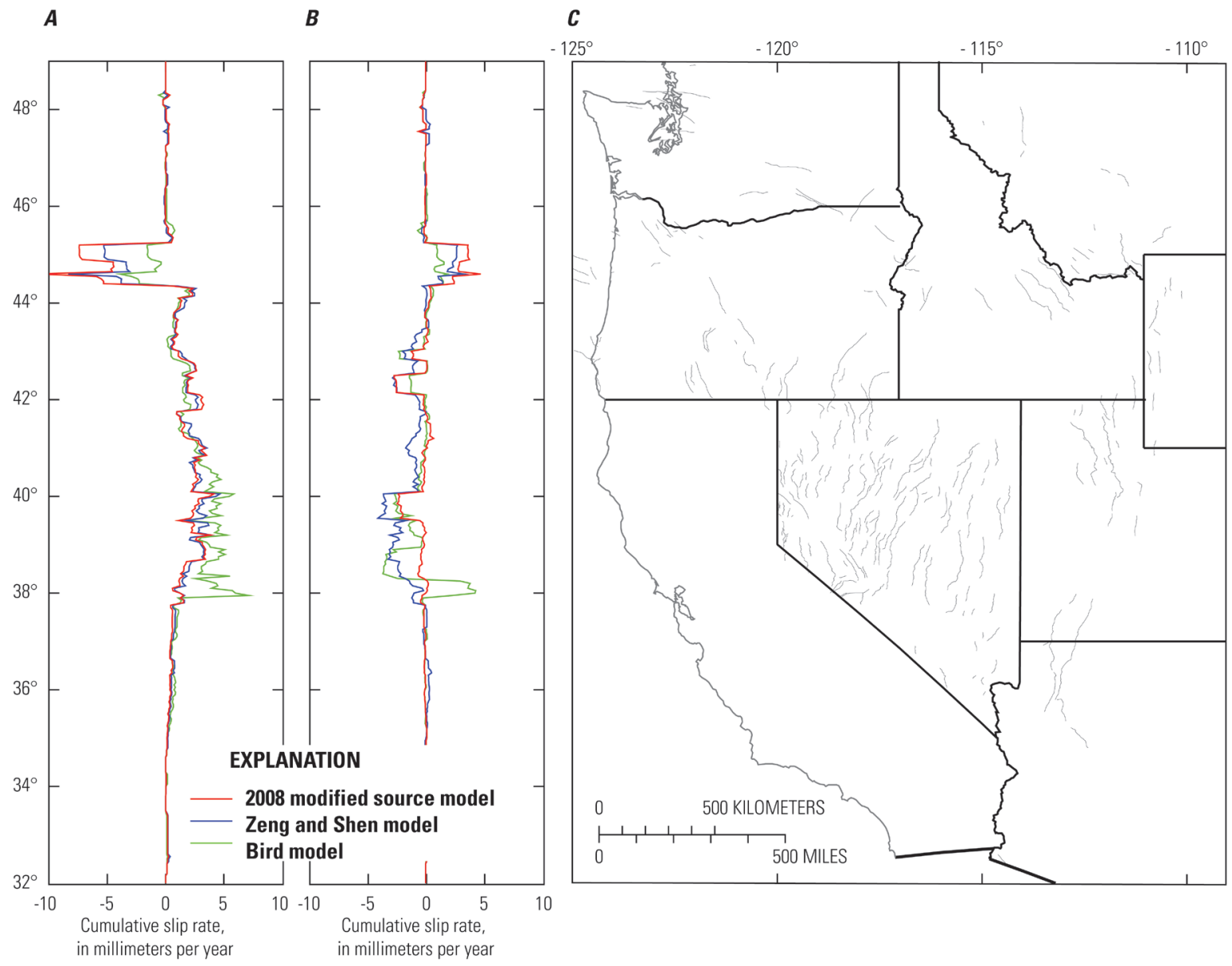

Figure 5. The cumulative on-fault total slip summed along east-west oriented profiles for the geologic, Bird (appendix $C$ ), and Zeng and Shen (appendix D) slip rates at $0.1^{\circ}$ intervals from $35^{\circ}$ to $45^{\circ}$ latitude for $A$, east (extension) and $B$, north (strike-slip) motion.

The combined-inversion models have not been included in past versions of the maps, so we introduce them into the 2014 NSHMP maps with a low weight (0.2) in the Intermountain West and Pacific Northwest, although a higher weight (0.7) is applied in California where the data are more spatially and temporally abundant (see $h t t p / / w w w . s c e c . o r g / u c e r f)$. The two fault-based models are weighted equally because we do not favor any particular model. The remaining weight $(0.8)$ is given to the NSHMP geologic-based fault-source model. Project members, the steering committee, and 
workshop participants recommended low weights for the combined-inversion models. The final weighted model results in a hazard map that is similar to previous hazard maps (which is an advantage when constructing building codes that require some level of stability) but allows for additional earthquakes in places where higher strain rates have been observed over the past two decades. It should also be pointed out that although the geologic-based slip rates derived from expert analysis receives most of the weight, it also considers the geodetic data implicitly in that the cumulative slip rates across the region are modeled to be consistent with the regional geodetic rates. In addition, we maintain the geodetic-based shear zones outside of California to account for additional earthquakes in areas of observed high strain rates, as applied in the 2008 NSHMP maps. These zones correspond with high offfault velocities. We assume that higher weights will be applied to the combined-inversion models as they mature, and we can better interpret the results and understand the differences between the geologic and geodetic models in the future. The inclusion of these models in this version of the maps demonstrates our recognition that there are advantages to using both the geodetic- and combinedinversion slip rates. Both datasets have benefits and limitations in constraining the hazard maps. We expect that with further research the block combined-inversion models will also be applied directly in future versions of the map.

\section{Methodology for Constructing Combined-Inversion Off-Fault Seismicity-Rate Models}

For the update of the 2014 NSHMP maps, we examined the off-fault strain rates estimated from the four combined-inversion models in order to determine whether permanent (non-elastic) off-fault strain rates could be used as an alternative branch for calculating background seismicity in the study area. We convert permanent off-fault strain rates to seismicity rate by first converting to moment rate through Kostrov's (1974) formula (see Parsons and others, 2013, for more detail) and then solving for seismicity rates by equating the combined-inversion and seismic-moment rates and assuming a Gutenberg-Richter distribution for earthquake frequency. Details of the study are presented in appendix E. Materials and figures in appendix E were presented to the NSHMP Steering Committee on May 6-7, 2013. Although the steering committee recognized the importance and potential benefit of the model off-fault strain rates, they recommended against the use of these results in the seismic-hazard calculations because of concerns about transient artifacts in the GPS data, the wide range of calculated moment rates associated with the four combined-inversion models, and the absence of multiple models to provide confidence for the inversion results. Workshop participants, steering committee members, and project staff regard the off-fault component of the geodetic models as an important constraint for rates of background seismicity in future updates of the NSHMP maps.

Because the seismicity rates from the combined-inversion for off-fault permanent strain rate will not be incorporated into the source models for the 2014 NSHMP maps, we plan to retain the use of areal shear zone sources in western Nevada. Since 1996 (Frankel and others, 1996), the seismic-source model for the NSHMP maps has included areal shear zone sources in eastern California and western Nevada. Because few potential fault sources are represented in this region, but high relative strain rates are indicated by GPS measurements, there is concern that the hazard in eastern California and western Nevada is artificially depressed in the NSHMP maps. In particular, the Walker Lane is known to exhibit a large discrepancy between geodetic and geologic strain rates (Thatcher and others, 1999; Hammond and others, 2011). The NSHMP shear zones were developed to account for potential earthquake sources that are not represented elsewhere in the NSHMP source model. The 2014 NSHMP maps will retain shear-zone sources in western Nevada to account for these unmodeled sources (we do not consider the California shear zones that were modeled separately (WGCEP, 2013). It is interesting to note that the 
shear zones are located in areas of high off-fault strain (appendix E). Future updates of the model may introduce off-fault strain rates from geodetic inversions and reduce the weighting on these shear zones.

\section{Seismic-Hazard Results}

Maps showing the differences (figs. 6 and 7) and ratios (figs. 8 and 9) in seismic hazard between the four combined-inversion models and the modified 2008 fault sources at 2-percent probability of exceedance in 50 years on a firm rock-site condition for 1-hertz $(\mathrm{Hz})$ and $5-\mathrm{Hz}$ spectral acceleration with 5 percent damping. The $1-\mathrm{Hz}$ and $5-\mathrm{Hz}$ maps show similar patterns with the $5-\mathrm{Hz}$ models having larger differences and ratios than the 1-Hz models. The four combined-inversion models for the WUS generally show higher hazard in large portions of western and central Nevada, the southern Wasatch fault in Utah, and along the Rio Grande rift in Colorado and New Mexico. They also indicate higher hazard along the contiguous borders of Washington, Oregon, and Idaho and show lower hazard across southern and central Idaho, western Wyoming, and along the southern Oregon coast. 


\section{A. McCaffrey model}

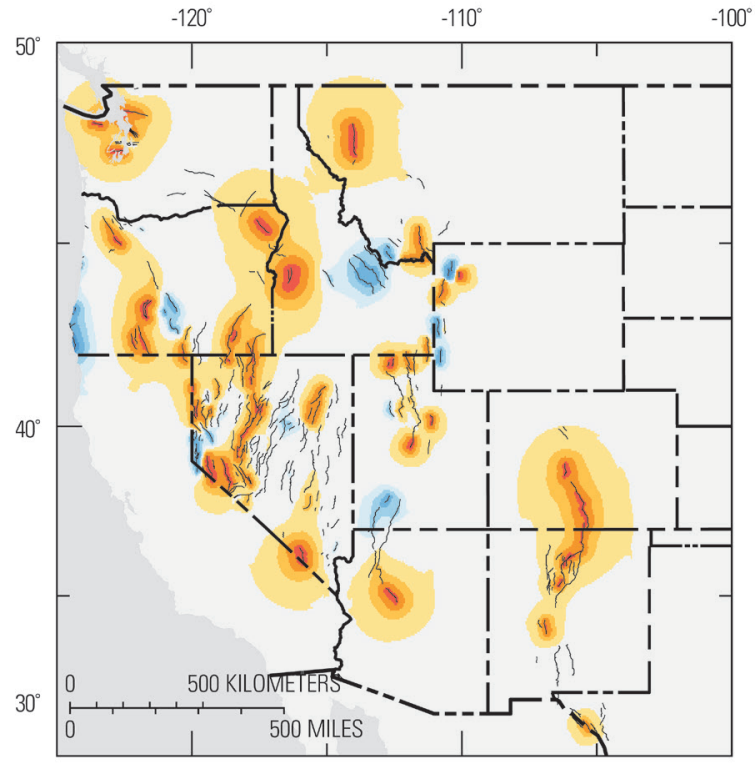

C. Bird model

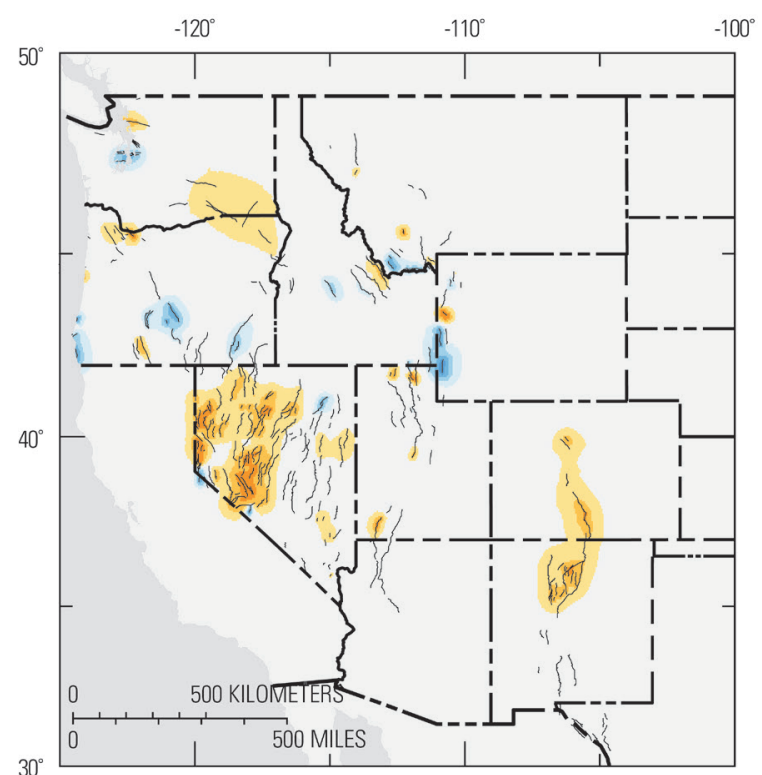

B. Hammond and Bormann model

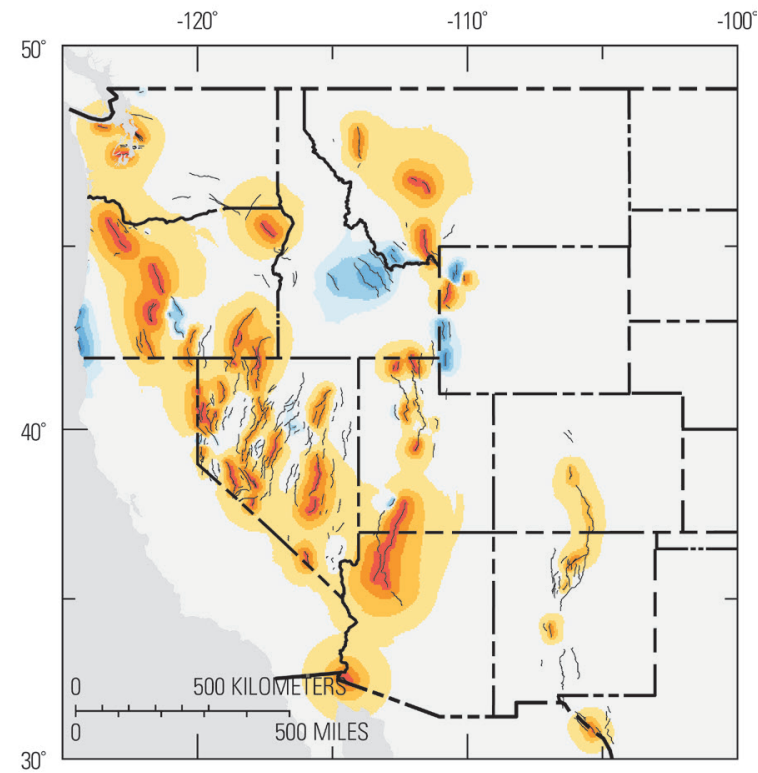

D. Zeng and Shen model

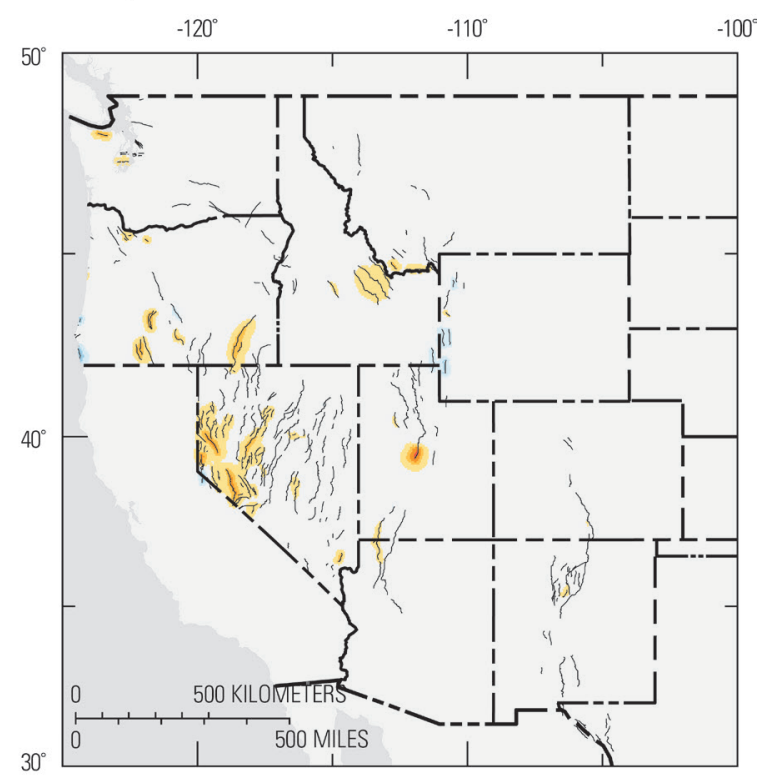

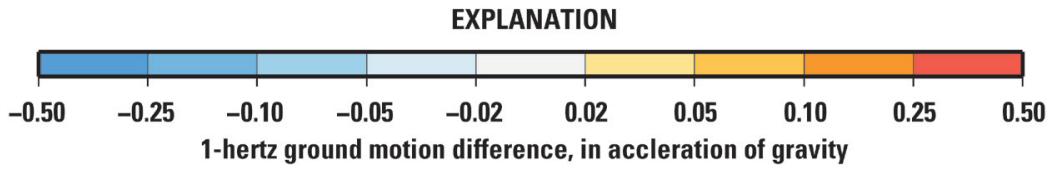

Figure 6. Difference maps of 1 -hertz spectral acceleration for 2 percent probability of exceedance in 50 years on firm rock-site condition for the geodetic-based block models of $A$, McCaffrey (appendix $A$ ) and $B$, Hammond and Bormann (appendix B) and the fault-based models by C, Bird (appendix C) and D, Zeng and Shen (appendix D). 


\section{A. McCaffrey model}

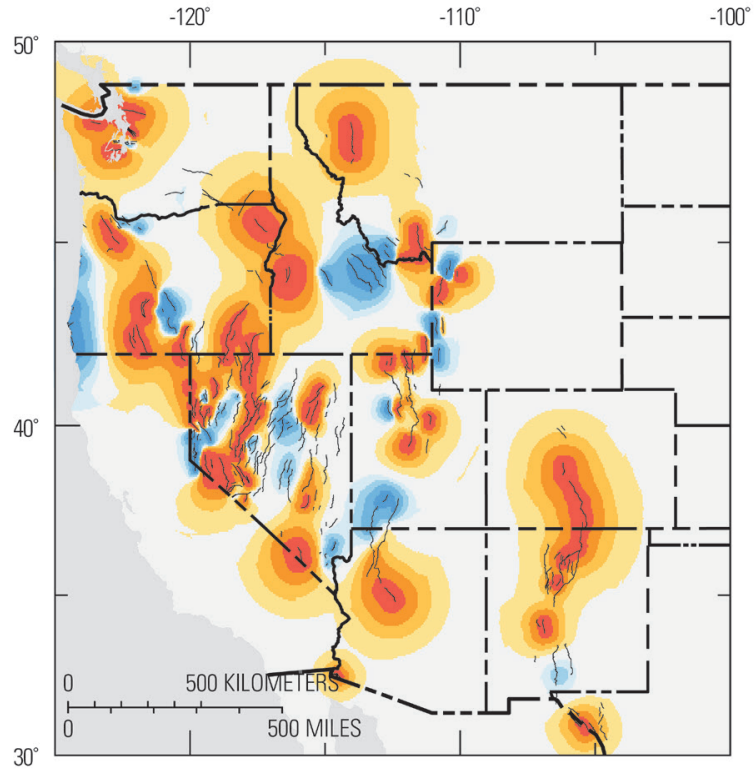

C. Bird model

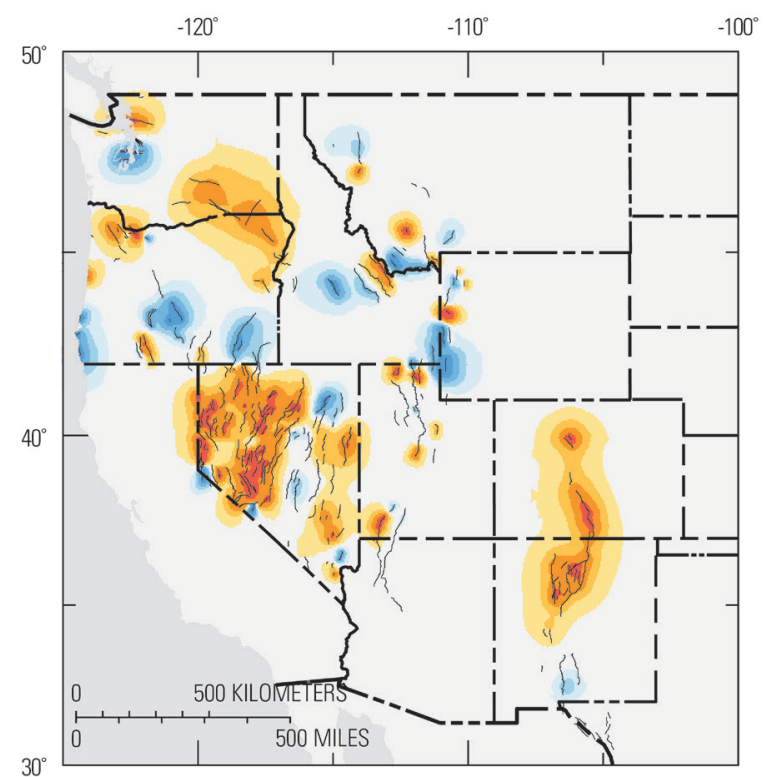

B. Hammond and Bormann model

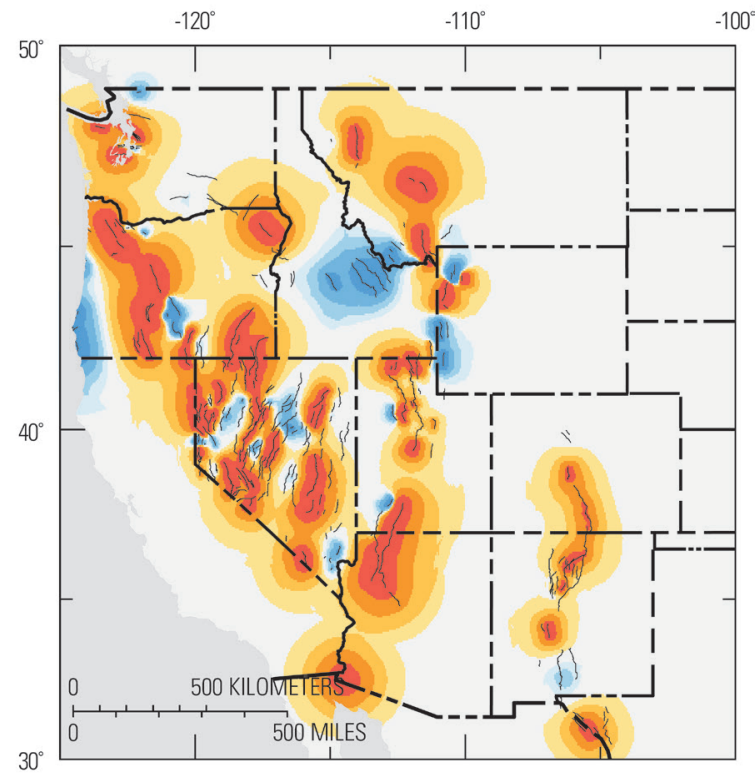

D. Zeng and Shen model

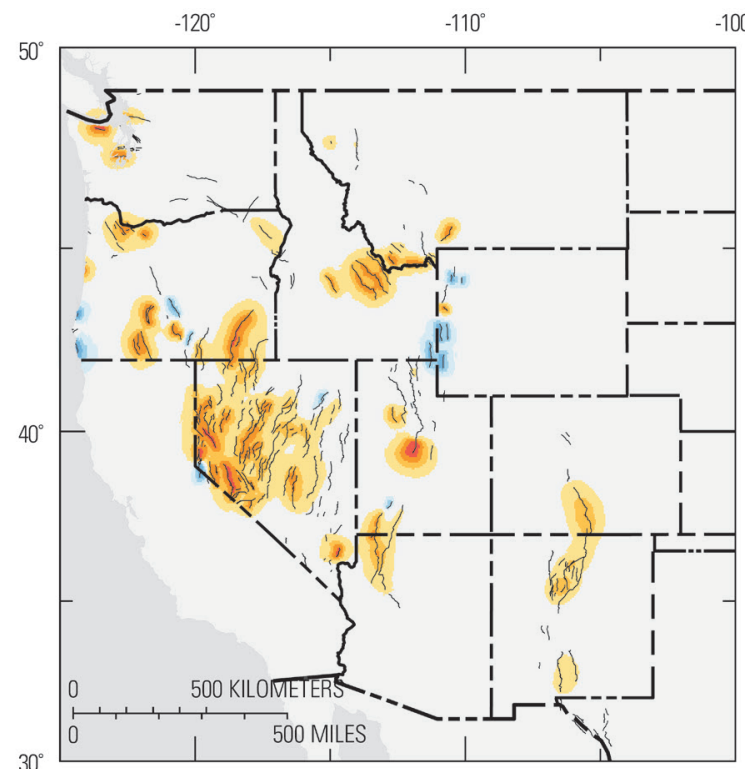

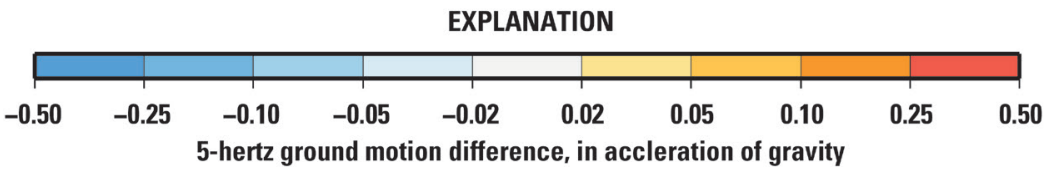

Figure 7. Difference maps of 5 -hertz spectral acceleration for 2 percent probability of exceedance in 50 years on firm rock-site condition for the geodetic-based block models of $A$, McCaffrey (appendix $A$ ) and $B$, Hammond and Bormann (appendix B) and the fault-based models by C, Bird (appendix C) and D, Zeng and Shen (appendix D). 


\section{A. McCaffrey model}

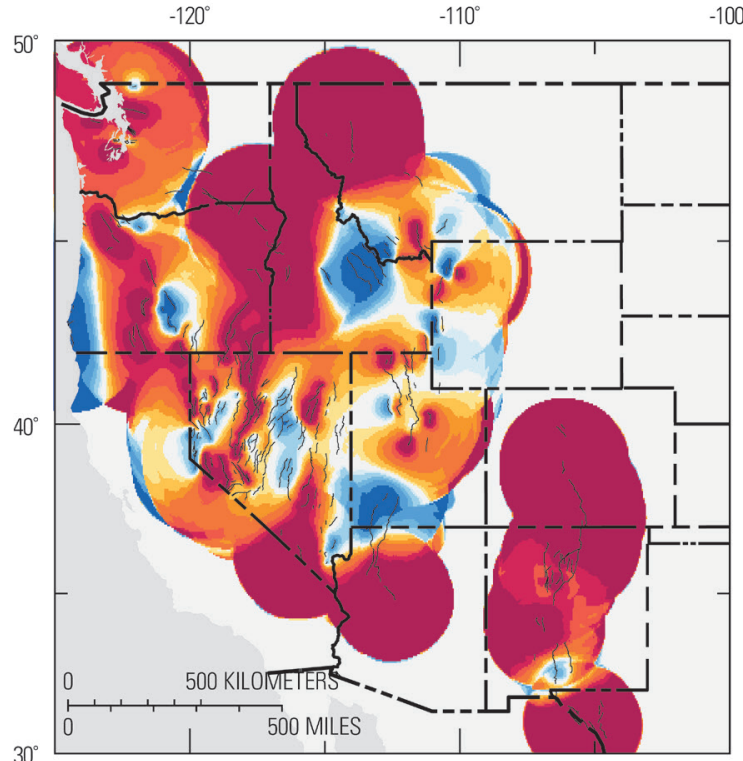

C. Bird model

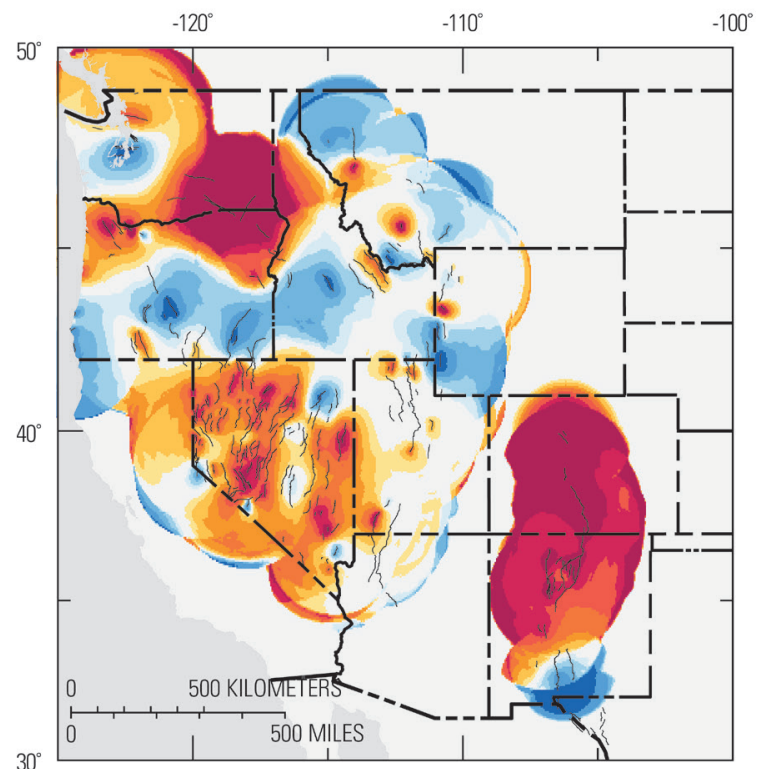

B. Hammond and Bormann model

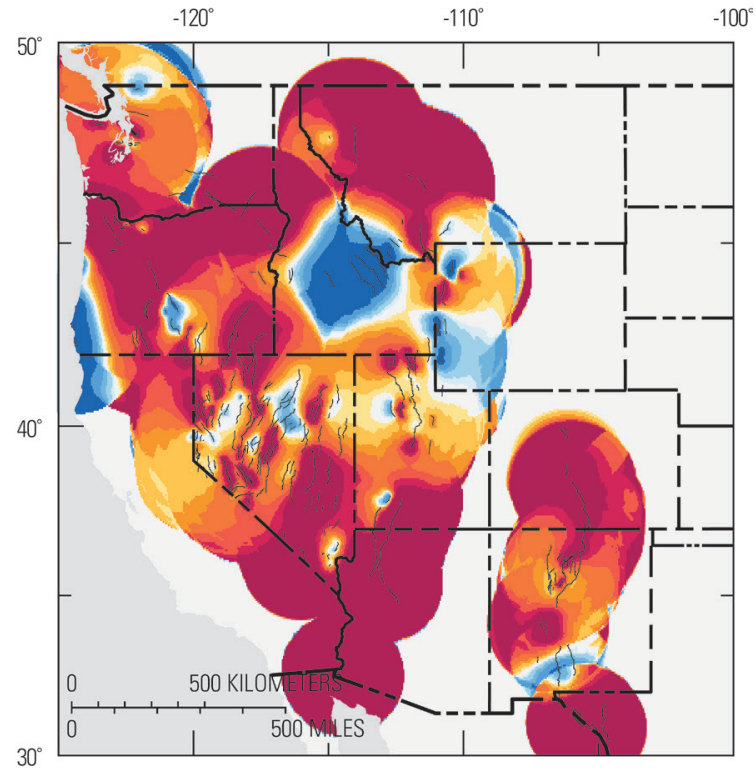

D. Zeng and Shen model

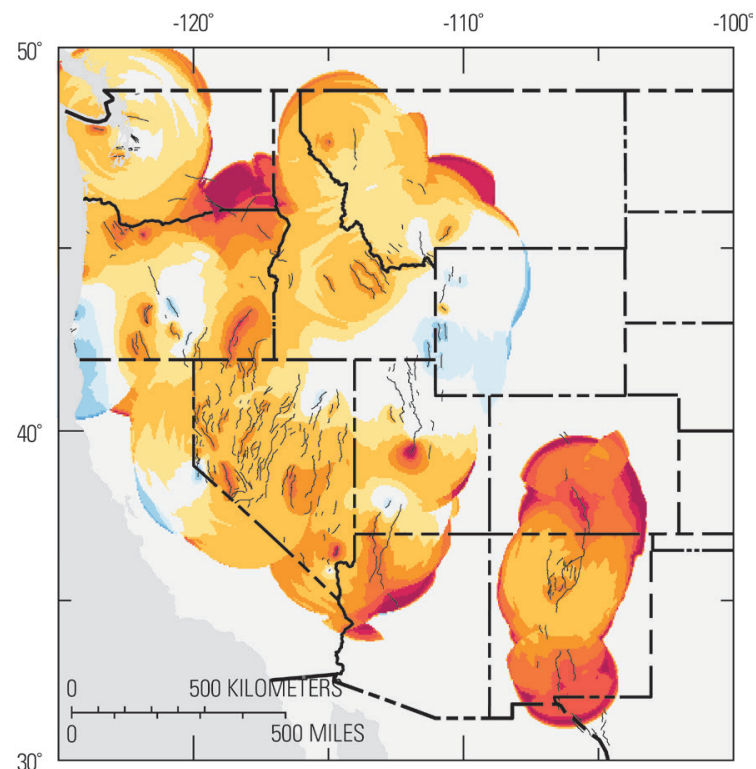

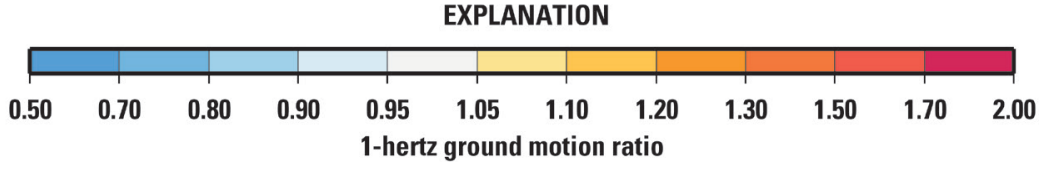

Figure 8. Ratio maps of 1-hertz spectral acceleration for 2 percent probability of exceedance in 50 years on firm rock-site condition for the geodetic-based block models of $A$, McCaffrey (appendix $A$ ) and $B$, Hammond and Bormann (appendix B) and the fault-based models by C, Bird (appendix C) and D, Zeng and Shen (appendix D). 


\section{A. McCaffrey model}

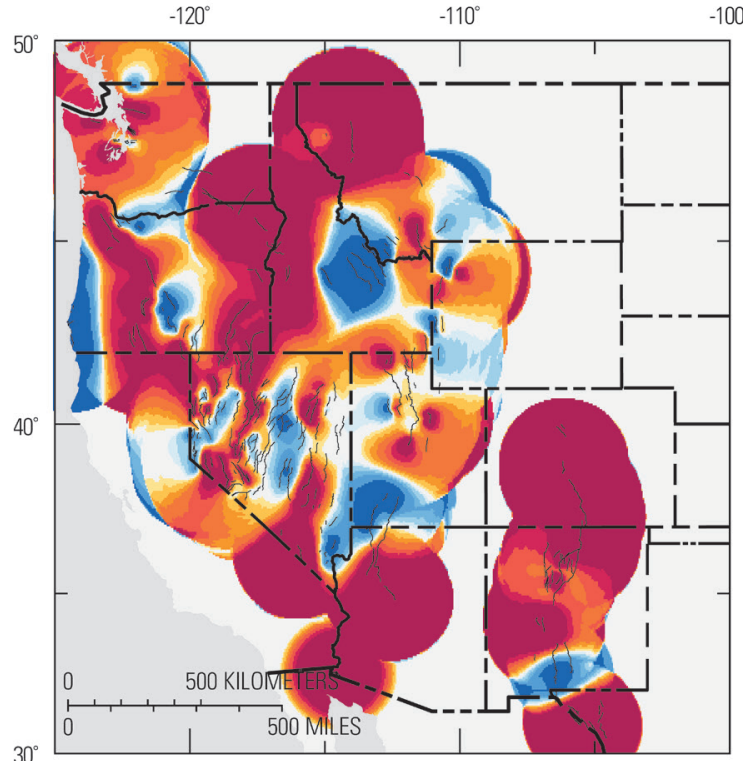

C. Bird model

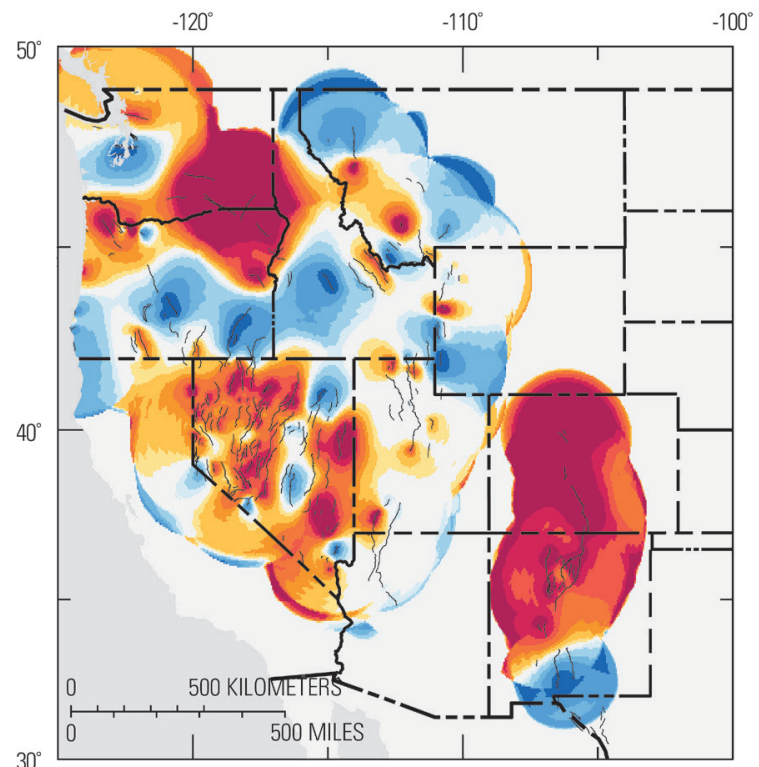

B. Hammond and Bormann model

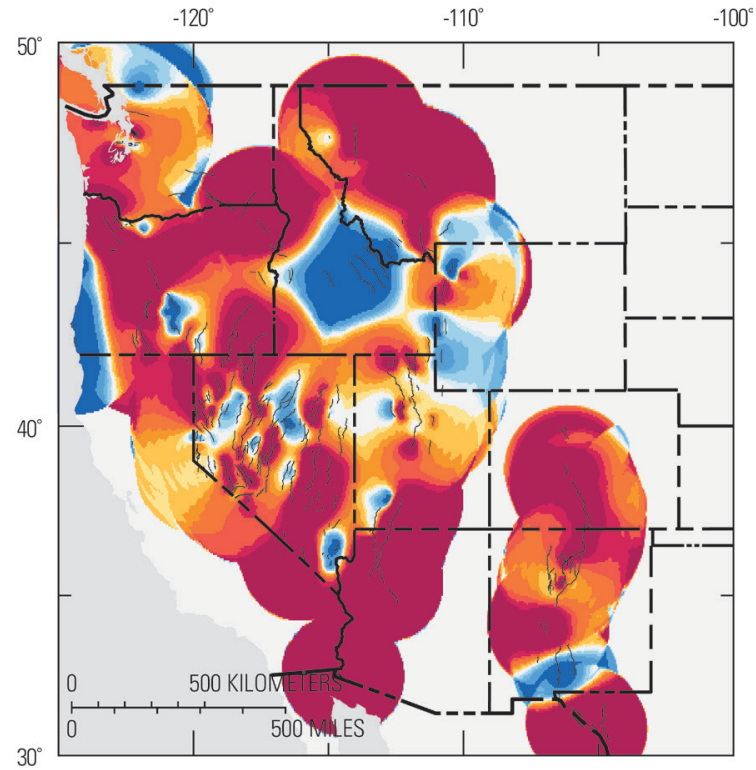

D. Zeng and Shen model

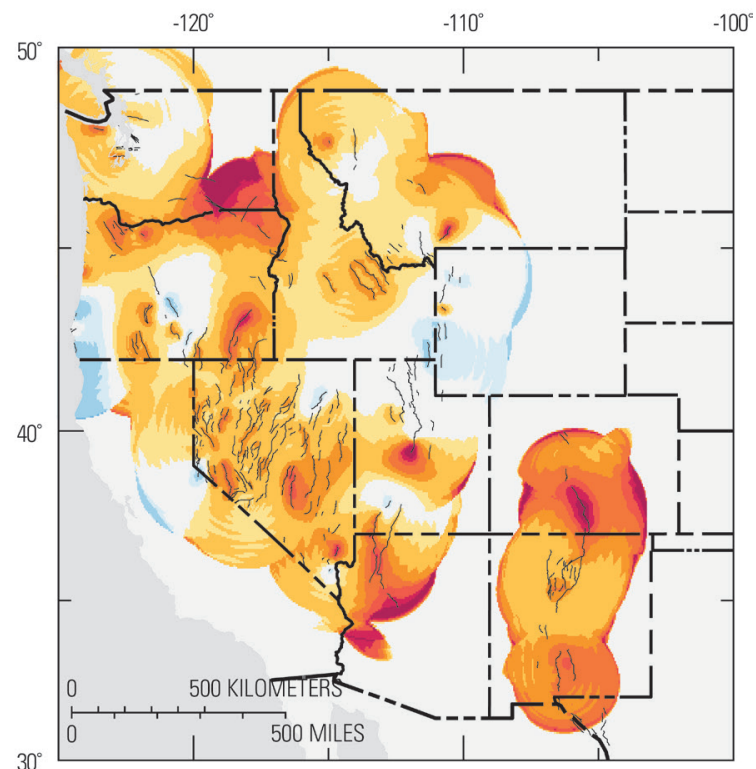

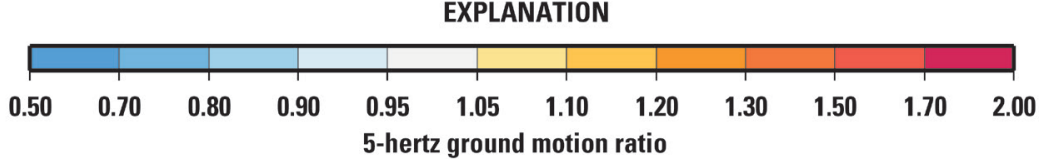

Figure 9. Ratio maps of 5-hertz spectral acceleration for 2 percent probability of exceedance in 50 years on firm rock-site condition for the geodetic-based block models of $A$, McCaffrey (appendix $A$ ) and $B$, Hammond and Bormann (appendix B) and the fault-based models by C, Bird (appendix C) and D, Zeng and Shen (appendix D). 
The block models of McCaffrey (appendix A) and of Hammond and Bormann (appendix B) tend to have higher hazard along faults modeled as block boundaries (for example, higher hazard in eastern Montana than the fault-based models) and apparent lower hazard within the blocks (for example, a low region stands out in central Nevada) than the fault-based models of Bird (appendix C) and Zeng and Shen (appendix D) is a consequence of not considering the internal strain rates that are integral components of the block models, and thus this comparison is biased. The fault-based combinedinversion models show more consistency with slip rates derived from expert analysis, and ratios of hazard are quite a bit smaller for many of the faults in these models. The Bird model has been modified in specific zones, as described above, so some of the differences are not as great as they would have been without the modifications.

Figure 10 shows the combination of the modified 2008 fault-source model or geologic model (weight $=0.8$ ), the Bird (weight $=0.1$ ), and the Zeng and Shen (weight $=0.1$ ) combined-inversion models that we apply in the NSHMP maps compared to the slip rates derived from expert analysis. Differences in the weighted combination are only about \pm 0.05 percent gravity $(\mathrm{g})$. 


\section{A. 1-hertz ground motion difference}

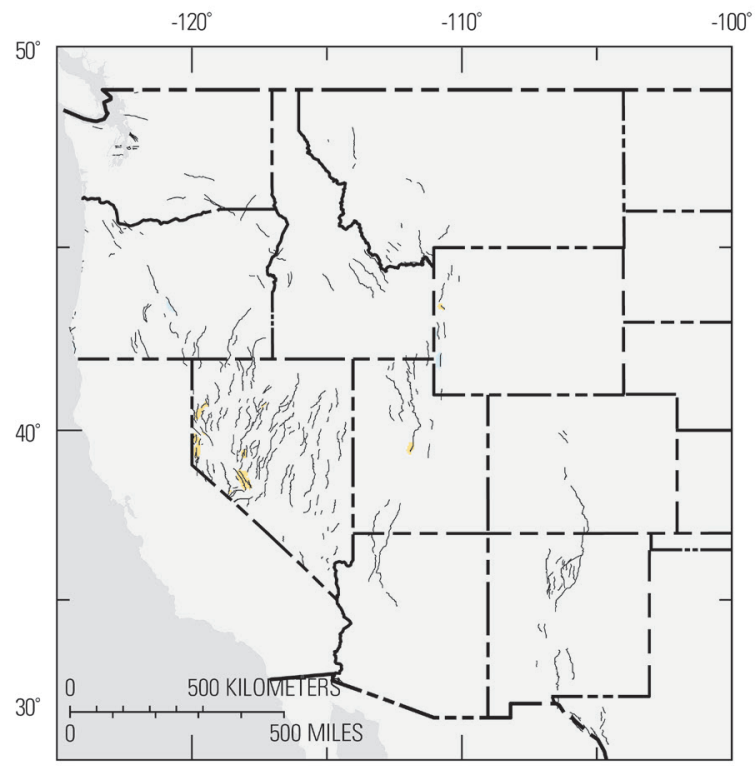

\section{B. 5-hertz ground motion difference}

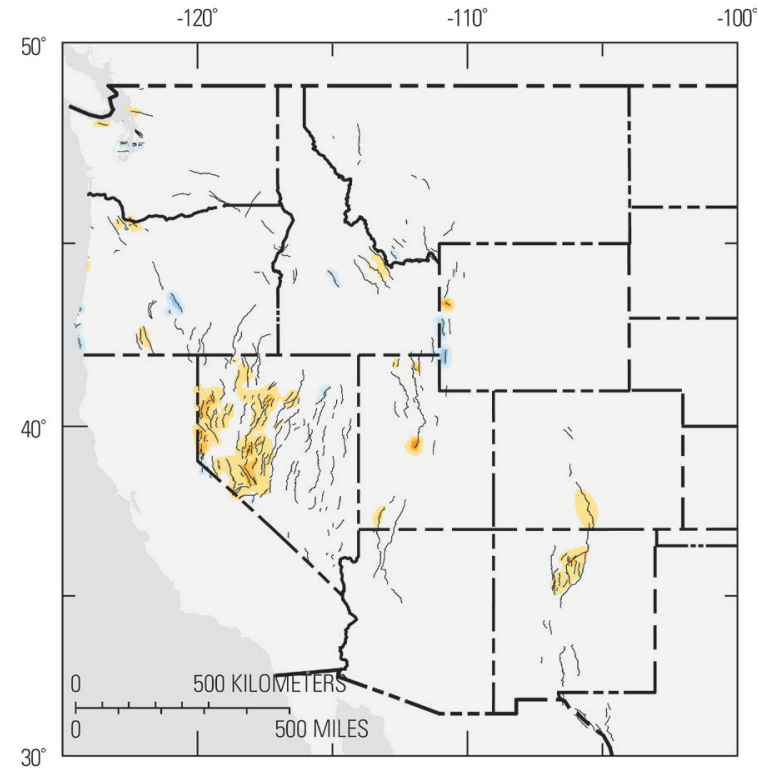

EXPLANATION

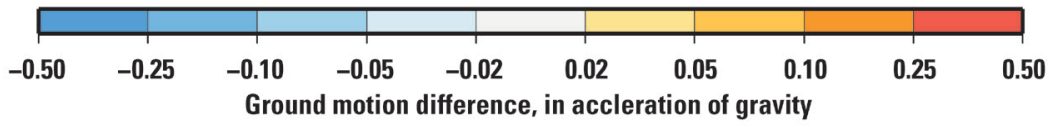

C. 1-hertz ground motion ratio

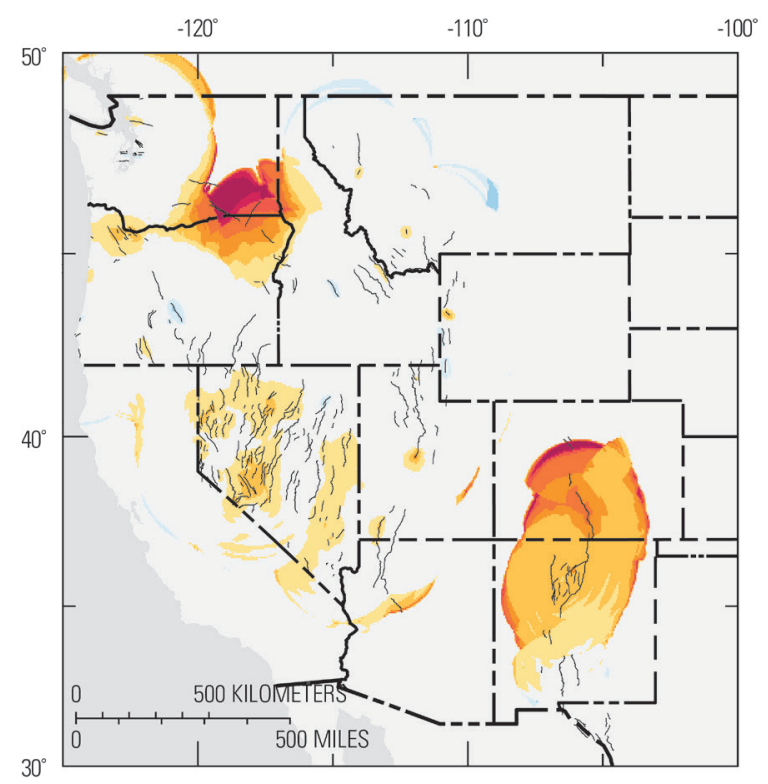

D. 5-hertz ground motion ratio

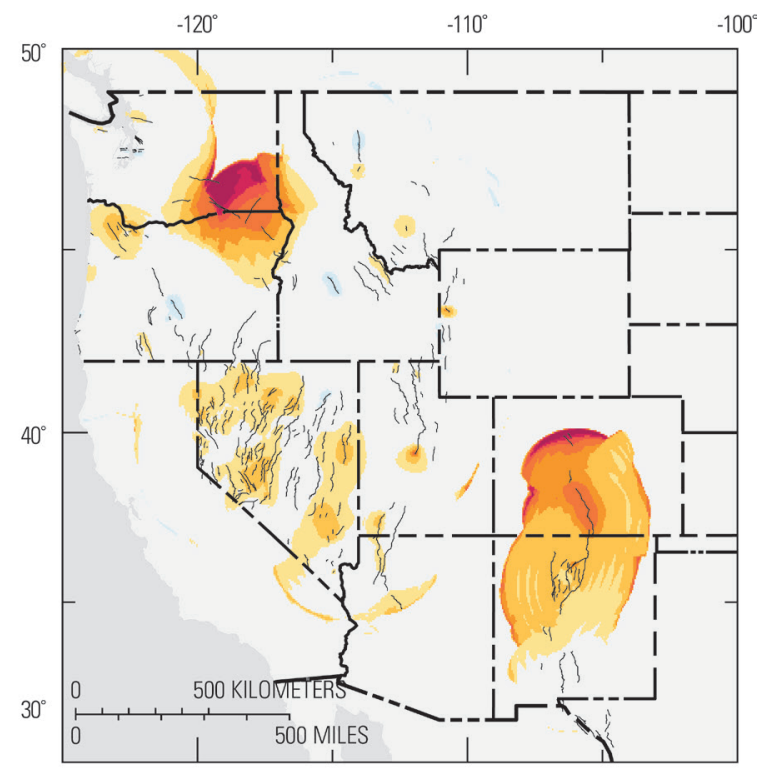

EXPLANATION

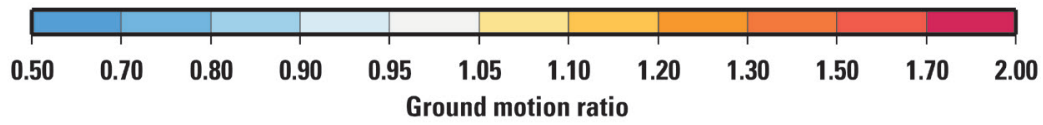

Figure 10. Difference and ratio maps of combined geologic and geodetic models compared to the geologic model alone for 5-hertz and 1-hertz spectral acceleration at 2 percent probability of exceedance 
in 50 years. The models are assigned the following weights: geologic model (weight $=0.8$ ), Bird combinedinversion model (0.1), and Zeng and Shen combined-inversion model (0.1).

\section{Conclusions}

Hazard models that are based on combined inversions of geologic and geodetic data can be substantially different from hazard models based on expert analysis of geologic slip-rate data that have been applied in previous seismic hazard maps. Some of these differences persist across the four different models and may indicate important alternatives to the geologic-based slip-rate model. Some high slip rates in the combined-inversion models may be artifacts of transient or aseismic strain that will not result in future large earthquakes. However, overall the combined-inversion models incorporate to varying degrees a new independent dataset that broadens the range of modeling approaches that can be used to assess earthquake rates. For the 2014 NSHMP maps, we have introduced combined-inversion models for the first time directly into the slip-rate calculations. The models are given low weights at this stage because we expect they will continue to mature and may change significantly as we collect additional data and develop new methods and models. However, the combined-inversion models should be improved in the next few years, and we expect that these models will continue to grow in importance for seismic-hazard assessment across the United States.

\section{References Cited}

Bauer, P.W., and Kelson, K.I., 2004, Rift extension and fault slip rates in the southern San Luis Basin, New Mexico, in Brister, B.S., Bauer, P.W., Read, A.S., and Lueth, V.W., eds., New Mexico Geological Society Guidebook, 55th Field Conference, Geology of the Taos region: Socorro, New Mexico, New Mexico Bureau of Geology and Mineral Resources, p. 172-180.

Bell, J.W., 1995, Quaternary geologic map of the Mina quadrangle, Nevada: Nevada Bureau of Mines and Geology Field Studies Map 10, scale 1:24,000.

Bell, J.W., Caskey, S.J., Ramelli, A.R., and Guerrieri, Luca, 2004, Pattern and rates of faulting in the central Nevada seismic belt and paleoseismic evidence for prior belt-like behavior: Bulletin of the Seismological Society of America, v. 94, no. 4, p. 1229-1254.

Bormann, J.M., Surpless, B.E., Caffee, M.W., and Wesnousky, S.G., 2012, Holocene earthquakes and late Pleistocene slip-rate estimates on the Wassuk Range fault zone, Nevada: Bulletin of the Seismological Society of America, v. 102, no. 4, p. 1884-1891.

Caskey, S.J., Bell, J.W., Wesnousky, S.G., and Ramelli, A.R., 2004, Historic surface faulting and paleoseismicity in the area of the 1954 Rainbow Mountain-Stillwater earthquake sequence, central Nevada: Bulletin of the Seismological Society of America, v. 94, no. 4, p. 1255-1275.

Chang, W.-L., Smith, R.B., Meertens, C.M., Harris, R.A., 2006, Contemporary deformation of the Wasatch fault, Utah, from GPS measurements with implications for interseismic fault behavior and earthquake hazard - Observations and kinematic analysis: Journal of Geophysical Research, v. 111, no. B11405, doi:10.1029/2006JB004326.

Chuang, R.Y., and Johnson, K.M., 2011, Reconciling geologic and geodetic model fault slip-rate discrepancies in southern California - Consideration of nonsteady mantle flow and lower crustal fault creep: Geology, v. 39, no. 7, p. 627-630.

Derouin, S.A., Piety, L.A., and Feng, Su, 2010, Evaluation of the Gore Range frontal fault and revised probabilistic seismic hazard analysis for Green Mountain Dam, Colorado: Bureau of Reclamation Seismotectonic Report 2010-01, 89 p. 
Dragovich, J.D., Anderson, M.L., Walsh, T.J., Johnson, B.L., and Adams, T.L., 2007, Geologic map of the Fall City 7.5-minute quadrangle, King County, Washington: Washington Division of Geology and Earth Resources Geologic Map GM-67, scale 1:24,000, 16-page text.

Ferguson, C.A., Gootee, B.F., Pearthree, P.A., and Cook, J.P., 2012, Geologic map of the Paulden 7 1/2' quadrangle, Yavapai County, Arizona: Arizona Geological Survey Digital Geologic Map 91, ver. 1.0, scale 1:24,000.

Frankel, A.D., Petersen, M.D., Mueller, C.S., Haller, K.M., Wheeler, R.L., Leyendecker, E.V., Wesson, R.L., Harmsen, S.C., Cramer, C.H., Perkins, D.M., and Rukstales, K.S., 2002, Documentation for the 2002 update of the national seismic hazard maps: U.S. Geological Survey Open-File Report 02-420, http://pubs.usgs.gov/of/2002/ofr-02-420/.

Frankel, Arthur, Mueller, Charles, Barnhard, Theodore, Perkins, David, Leyendecker, E.V., Dickman, Nancy, Hanson, Stanley, and Hopper, Margaret, 1996, National seismic-hazard mapsDocumentation June 1996: U.S. Geological Survey Open-File Report 96-532, 110 p.

Gootee, B.F., Ferguson, C.A., Spencer, J.E., and Cook, J.P., 2010, Geologic map of the Chino Valley North 7 1/2' quadrangle, Yavapai County, Arizona, v. 1.0: Arizona Geological Survey Geologic Map DGM-80, scale 1:24,000, with 38 p text.

Haller, K.M., and Wheeler, R.L., 2008a, Parameter for faults in the Intermountain West, in Peterson, M.D., and others, Documentation for the 2008 update of the national seismic hazard maps: U.S. Geological Survey Open-File Report 2008-1128, p. G-1-G-18.

Haller, K.M., and Wheeler, R.L., 2008b, Parameter for faults in the Pacific Northwest, in Peterson, M.D., and others, Documentation for the 2008 update of the national seismic hazard maps: U.S. Geological Survey Open-File Report 2008-1128, p. H-1-H-6.

Hammond, W.C., Kreemer, Corné, and Blewitt, Geoffrey, 2009, Geodetic constraints on contemporary deformation in the Northern Walker Lane-3. Central Nevada seismic belt postseismic relaxation, in Late Cenozoic structure and evolution of the Great Basin-Sierra Nevada transition: Geological Society of America Special Paper 447, p. 33-54, doi: 10.1130/2009.2447(03).

Hammond, W.C., Blewitt, Geoffrey, and Kreemer, Corné, 2011, Block modeling of crustal deformation of the northern Walker Lane and Basin and Range from GPS velocities: Journal of Geophysical Research, v. 116, B04402, doi:10.1029/2010JB007817.

Hampel, Andrea, Hetzel, Ralf, Densmore, A.L., 2007, Postglacial slip-rate increase on the Teton normal fault, northern Basin and Range Province, caused by melting of the Yellowstone ice cap and deglaciation of the Teton Range?: Geology, v. 35, p. 1107-1110.

Hayes, G.F., 1985, Late Quaternary deformation and seismic risk in the southern Sierra Nevada Great Basin boundary zone near the Sweetwater Mountains, California and Nevada: Reno, University of Nevada, M.S. thesis, 135 p.

Hearn, E.H., Pollitz, F.F., Thatcher, W.R., Onishi, C.T., 2013, How do "ghost transients" from past earthquakes affect GPS slip rate estimates on southern California faults?: Geochemistry, Geophysics, Geosystems, v. 14, p. 828-838.

Hoeft, J.S., and Frankel, K.L., 2010, Temporal variations in extension rate along the Lone Mountain fault and strain partitioning in the eastern California shear zone-Walker Lane: Geosphere, v. 6, p. 917-936.

Johnson, E.M., 2010, Lacustrine evidence of seismic events on the Sawtooth fault in Redfish Lake drainage, Sawtooth Mountains, central Idaho: Pocatello, Idaho State University, M.S. thesis, 125 p.

Kirkham, R.M., 2004, Quaternary faulting in the Williams Fork valley graben, north-central Colorado, and comparison with late Quaternary deformation near Spinney Mountain, central Colorado: 
Technical report to U.S. Geological Survey, Reston, Va., under Contract 02HQGR0102, 46 p., http://earthquake.usgs.gov/research/external/reports/02HQGR0102.pdf.

Koehler, R.D., and Wesnousky, S.G., 2011, Late Pleistocene regional extension rate derived from earthquake geology of late Quaternary faults across the Great Basin, Nevada, between $38.5^{\circ} \mathrm{N}$ and $40^{\circ} \mathrm{N}$ latitude: Geological Society of America Bulletin, v. 123, no. 3-4, p. 631-650.

Kostrov, V.V., 1974, Seismic moment and energy of earthquakes: Izvestiya, Russian Academy of Sciences, Physics of the Solid Earth, v. 1, p. 23-44.

Lund, W.R., ed., 2006, Basin and Range Province Earthquake Working Group seismic-hazard recommendations to the U.S. Geological Survey National Seismic Hazard Mapping Program: Utah Geological Survey Open-File Report 477, 23 p., http://geology.utah.gov/ghp/workgroups/brpewg.htm.

Lund, W.R., comp., 2013, Working group on Utah earthquake probabilities preliminary fault characterization parameters for faults common to the working group study area and the U.S. national seismic hazard maps - Data provided to the U.S. Geological Survey for use in the 2014 update of the national seismic hazard maps in Utah: Utah Geological Survey Open-File Report 611, 7 p.

Lund, W.R., Knudsen, T.R., and Vice, G.S., 2008, Paleoseismic reconnaissance of the Sevier fault, Kane and Garfield Counties, Utah: Utah Geological Survey Special Study 122, 31 p.

O'Connell, D.R.H., Wood, C.K., Ostenaa, D.A., Block, L.V., and LaForge, R.C., 2003, Ground motion evaluation for Jackson Lake Dam, Minidoka project, Wyoming: U.S. Bureau of Reclamation Seismotectonic Report 2003-2, http://www.usbr.gov/pn/programs/srao_misc/jackson/seismic_summary.pdf

Parsons, Tom, Johnson, K.M., Bird, Peter, Bormann, Jayne, Dawson, T.E., Field, E.H., Hammond, W.C., Herring, T.A., McCaffrey, Rob, Shen, Z.-K., Thatcher, W.R., Weldon, R.J., II, and Zeng, Yuehua, 2013, Appendix C-Deformation models for UCERF3: U.S. Geological Survey Open-File Report 2013-1165, $66 \mathrm{p}$.

Pearthree, P.A., and Ferguson, C.A., 2012, Geologic map of the Wineglass Ranch $712^{\prime}$ quadrangle, Yavapai County, Arizona: Arizona Geological Survey Digital Geologic Map 90, ver. 1.0, scale $1: 24,000$.

Personius, S.F., Crone, A.J., Machette, M.N., Mahan, S.A., Kyung, J.B., Cisneros, H., and Lidke, D.J., 2007, Late Quaternary paleoseismology of the southern Steens fault zone, northern Nevada: Bulletin of the Seismological Society of America, v. 97, p. 1662-1678.

Petersen, M.D., Bryant, W.A., Cramer, C.H., Cao, Tianqing, Reichle, M.S., Frankel, A.D., Lienkaemper, J.J., McCrory, P.A., and Schwartz, D.P., 1996, Probabilistic seismic hazard assessment for the State of California: California Division of Mines and Geology Open-File Report 96-08 and U.S. Geological Survey Open-File Report 96-706, 33 p.

Petersen M.D., Frankel, A.D., Harmsen, S.C., Mueller, C.S., Haller, K.M., Wheeler, R.L., Wesson, R.L., Zeng, Yuehua, Boyd, O.S., Perkins D.M., Luco, Nico, Field, E.H., Wills, C.J., and Rukstales, K.S., 2008, Documentation for the 2008 update of the United States national seismic hazard maps: U.S. Geological Survey Open-File Report 2008-1128, 60 p., 11 appendixes, http://pubs.usgs.gov/of/2008/1128/.

Petersen, M.D., Moschetti, M.P., Powers, P.M., Mueller, C.S., Haller, K.M., Frankel, A.D., Zeng, Yuehua, Rezaeian, Sanaz, Harmsen, S.C., Boyd, O.L., Field, Ned, Chen, Rui, Rukstales, K.S., Luco, Nico, Wheeler, R.L., Williams, R.A., and Olsen, A.H., in press, Documentation for the 2014 update of the United States national seismic hazard maps: U.S. Geological Survey Open-File Report.

Petrik, F.E., 2008, Scarp analysis of the Centennial normal fault, Beaverhead County, Montana and Fremont County, Idaho: Bozeman, Montana State University, M.S. thesis, 287 p. 
Thackray, G.D., Rodgers, D.W., Johnson, E.M., and Shapley, M.D., 2009, Preliminary evaluation of a newly discovered Holocene scarp on the Sawtooth fault, central Idaho [abs.]: Geological Society of America Abstracts with Programs, v. 41, no. 7, p. 55.

Thatcher, Wayne, Foulger, G.R., Julia, B.R., Svarc, Jerry, Quilty, E., and Bawden, G.W., 1999, Presentday deformation across the Basin and Range Province, Western United States: Science, v. 283, p. 1714-1718.

U.S. Bureau of Reclamation, 2009, Ground water elevations-Seepage and groundwater investigations Yuma area: U.S. Bureau of Reclamation map, 1 sheet, http://www.usbr.gov/lc/yuma/programs/YAWMS/Groundwater/YA122008-72dpi.pdf.

Wesnousky, S.G., 2005, Active faulting in the Walker Lane: Tectonics, v. 24, TC3009.

Wesnousky, S.G., and Caffee, Marc, 2011, Range-bounding normal fault of Smith Valley, NevadaLimits on age of last surface-rupture earthquake and late Pleistocene rate of displacement: Bulletin of the Seismological Society of America, v. 101, no. 3, p. 1431-1437.

White, B.J.P., Smith, R.B., Husen, Stephan, Farrell, J.M., and Wong, Ivan, 2009, Seismicity and earthquake hazard analysis of the Teton-Yellowstone region, Wyoming: Journal of Volcanology and Geothermal Research, v. 188, p. 277-29.

Working Group on California Earthquake Probabilities (WGCEP), 2013, Uniform California earthquake rupture forecast, version 3 (UCERF3) - Time-independent model: U.S. Geological Survey Open-File Report 2013-1165, variously paginated. 
Appendixes 


\title{
Appendix A-NSHMP Block Model of Western United States Active Tectonics
}

\author{
By R. McCaffrey, ${ }^{1}$ P. Bird, ${ }^{2}$ J. Bormann, ${ }^{3}$ K.M. Haller, ${ }^{4}$ W.C. Hammond, ${ }^{3}$ W. Thatcher, ${ }^{5}$ R.E. Wells, ${ }^{5}$ Y. Zeng ${ }^{4}$
}

${ }^{1}$ Dept. of Geology, Portland State University, Portland, Oreg.

${ }^{2}$ Dept. of Earth and Space Sciences, University of California, Los Angeles, Calif.

${ }^{3}$ Nevada Geodetic Laboratory, University of Nevada Reno, Nev.

${ }^{4}$ USGS Golden, Colo.

${ }^{5}$ USGS Menlo Park, Calif.

\section{Abstract}

We developed a block model of active faults in the Western United States (WUS) in support of the 2014 National Seismic Hazards Mapping Project (NSHMP14). The block model used a modified 2008 fault-source model as block boundaries as much as reasonably possible with the aim of estimating slip rates on those faults. Global positioning system (GPS)-derived horizontal velocity data were compiled from seven regional solutions and rotated into a common North American reference frame. The GPS velocities were edited to remove outliers, and a correction was made to account for elastic strain rates caused by locking on the Cascadia subduction zone. The GPS velocity field was used by researchers to assess, and if necessary, modify fault slip rates in the modified 2008 fault-source model. Block models resulted in generally faster fault slip rates than assigned in the modified 2008 fault-source model.

Introduction

Block models of crustal deformation allow analysis and simultaneous interpretation of multiple types of data that relate to motions of the crust and slip rates on faults. The models are based on plate tectonic formulations; that is, crustal blocks, like tectonic plates, rotate about Euler poles. In addition, the block models can account for elastic strain rates that occur near faults due to friction on them and distributed strain rates that result from slip on multiple, closely spaced faults. Elastic-strain-rate corrections are needed to interpret decade-scale global positioning system (GPS) velocity data in terms of longer term fault motions. This appendix reports on the development of the Western United States (WUS) block model WUS5 used to interpret GPS velocity data in the context of fault slip rates assigned in the modified 2008 NSHMP source model.

\section{Block Model WUS5}

We developed a block model, called WUS5 that includes 70 blocks in the WUS (fig. A-1). To maintain continuity with UCERF3 (Uniform California Earthquake Rupture Forecast, version 3), this model also includes the blocks in California used in the UCERF3 average block model (ABM), but the number of fault segments was decreased for simplicity. In WUS5, the block boundaries outside California were greatly modified from those used in UCERF3. 


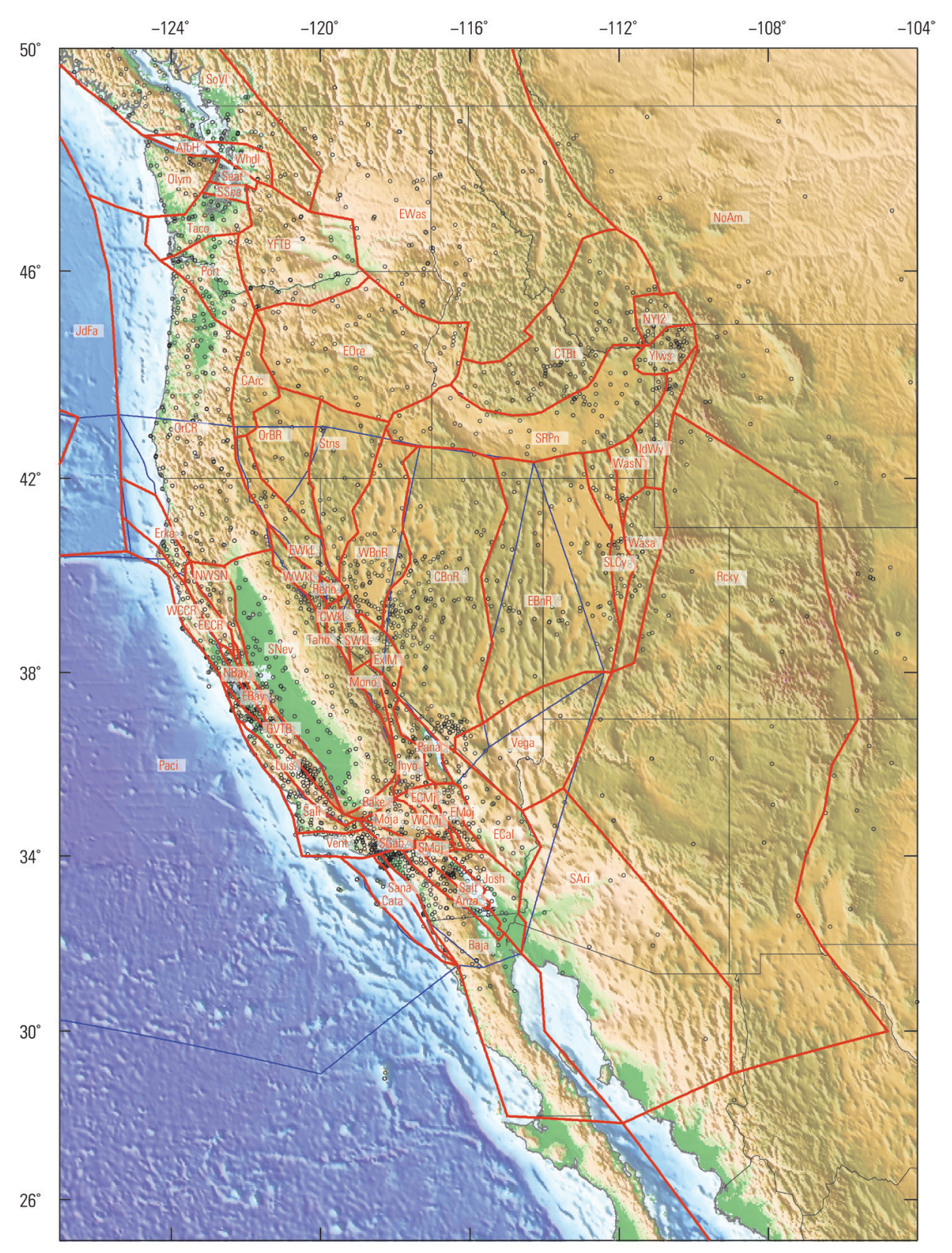

Figure A-1. Map of Western United States (WUS) showing block boundaries for WUS5 (red) and California's UCERF3 ABM (Uniform California Earthquake Rupture Forecast, version 3, average block model) (blue). Black dots show locations of global positioning system velocities used. Four-letter codes are block names.

The initial block model was adapted from those of McCaffrey (2005) and Meade and Hager (2005) for California, McCaffrey and others (2007) for the Pacific Northwest, Payne and others (2008, 2012) for the Wasatch and Snake River Plain region, Hammond and others (2011) for the Walker Lane area, and Kreemer and others (2010) for the southern Great Basin. The initial model was modified to connect the separate regions and to follow more closely the set of NSHMP14 target faults (fig. A-2). The block boundaries include most NSHMP14 faults with slip rates of greater than $1 \mathrm{~mm} / \mathrm{yr}$. Other modifications were to break up the original long, thin blocks, within which motions are difficult to resolve, into smaller entities. Block boundaries were used to separate regions of differing strain rates 
even though we did not always believe the boundaries themselves are areas of significant slip; in these cases some models included estimates of the off-fault strain rates, which are not included in the modified 2008 NSHMP source model.

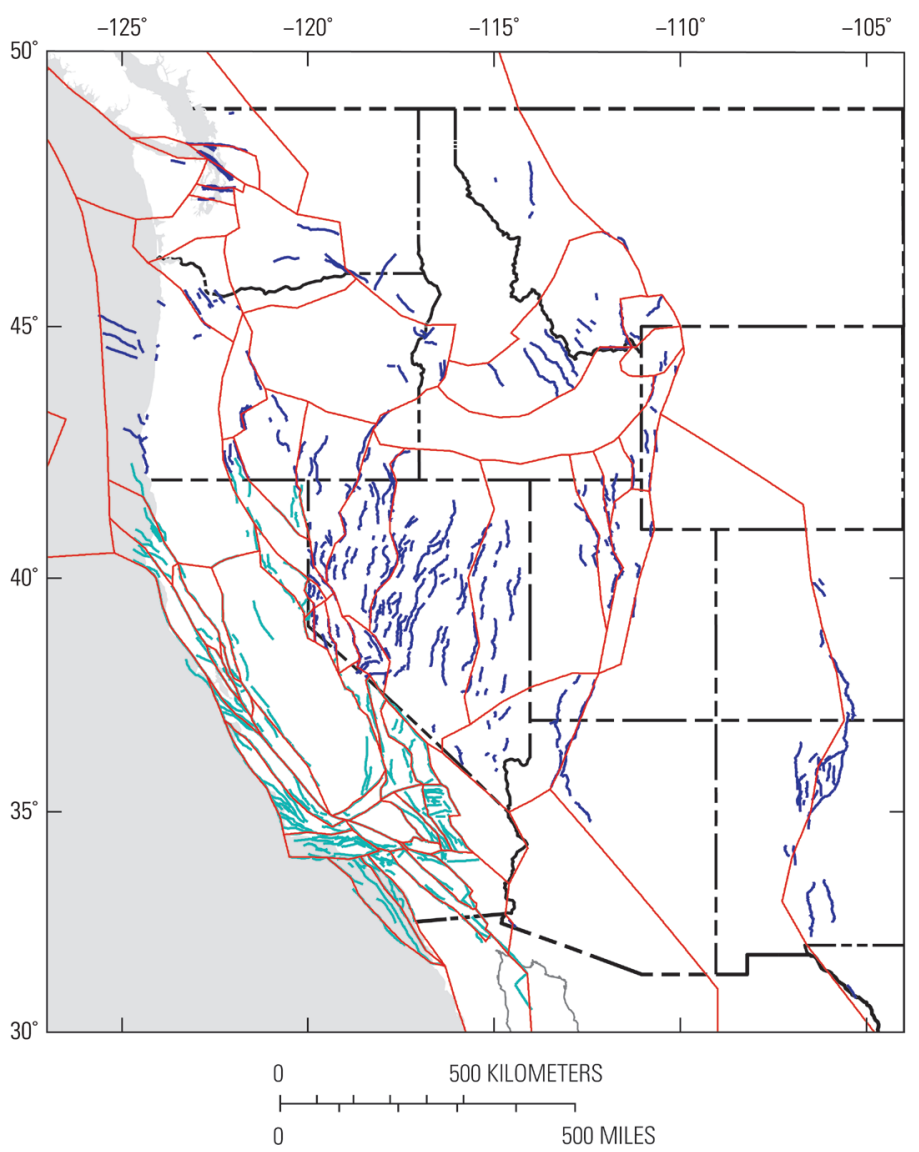

Figure A-2. Block-model boundaries (red lines) and National Seismic Hazards Mapping Project fault sources. Turquoise lines represent UCERF3 (Uniform California Earthquake Rupture Forecast, version 3) faults; blue lines represent faults in study area.

In many regions, GPS data cannot distinguish between slip on multiple, closely spaced individual faults and more uniformly distributed strain rates. For example, as Payne and others (2012) show, the CTBt block (fig. A-2), north of the Snake River Plain, could be subdivided along known faults (Lemhi, Beaverhead, Lost River, and so forth), but in doing so, the fit to the GPS data does not change. Hence the GPS velocities do not provide additional information on the slip rates of these faults. There are many similar examples throughout the WUS, most notably the Basin and Range of Nevada where we assigned block boundaries based on perceived spatial changes in strain rates but without expectation to constrain slip rates on them.

\section{GPS Data}

GPS velocities were compiled from seven velocity fields, listed in table A-1 and shown in figure A-3A. Some of the velocity fields encompassed the entire boundary, whereas others were more regional in scale. 
Table A-1. Velocity fields used and rotation into North American reference frame.

[GPS (global positioning system) is the number of velocities in the solution. Longitude, latitude, and omega give the Euler pole used to rotate the velocity field into the North American reference frame. PBO (Plate Boundary Observatory), PANGA (Pacific Northwest Geodetic Array), and SOPAC (Scripts Orbit and Permanent Array Center) access date in Reference column]

\begin{tabular}{lrcccl}
\hline \multicolumn{1}{c}{ Field } & GPS & Longitude & Latitude & Omega & \multicolumn{1}{c}{ Reference } \\
\hline PNW & 696 & 282.1 & 24.9 & 0.022 & McCaffrey and others (2013) \\
CMM4 & 551 & 285.3 & 35.3 & 0.020 & Shen and others (2011) \\
PBO & 942 & 331.0 & -40.0 & 0.014 & PBO 2011.08.01 \\
UNR & 219 & 273.9 & -2.9 & 0.184 & Hammond and others (2011) \\
PANGA & 308 & 299.6 & 43.0 & 0.023 & PANGA 2012.03.05 \\
SOPAC & 1252 & 273.5 & -4.9 & 0.185 & SOPAC 2012.07.06 \\
SHEN & 1997 & 69.1 & -18.4 & 0.011 & Z-K Shen, unpublished \\
\hline
\end{tabular}

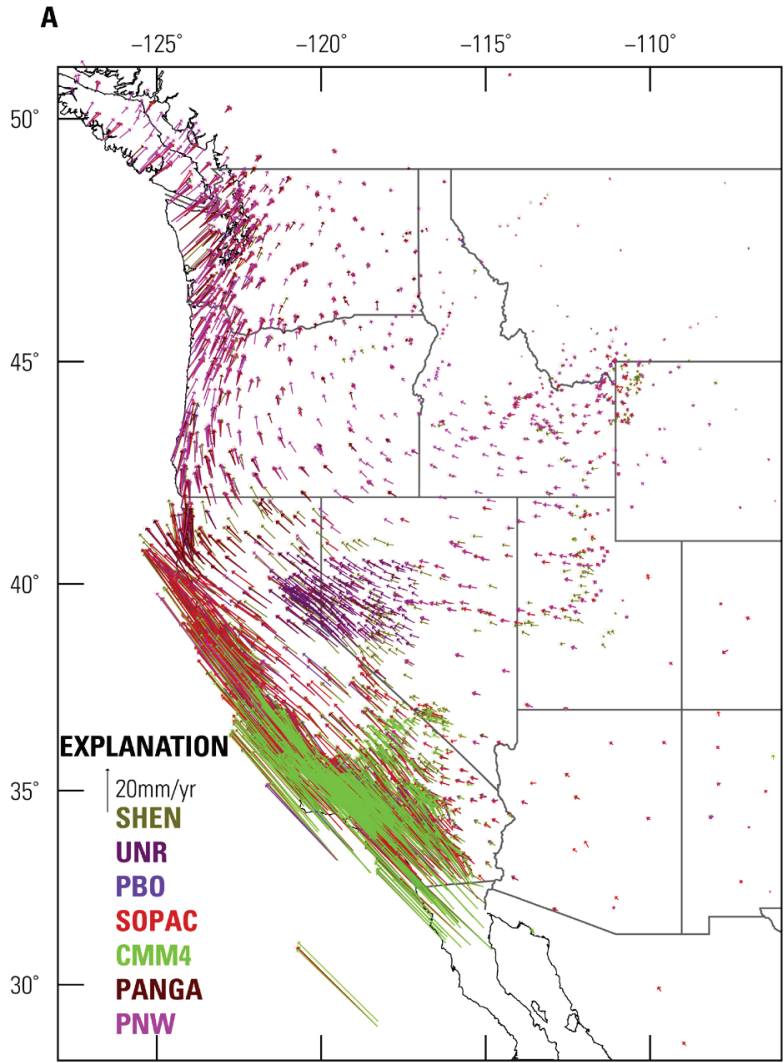

0
B

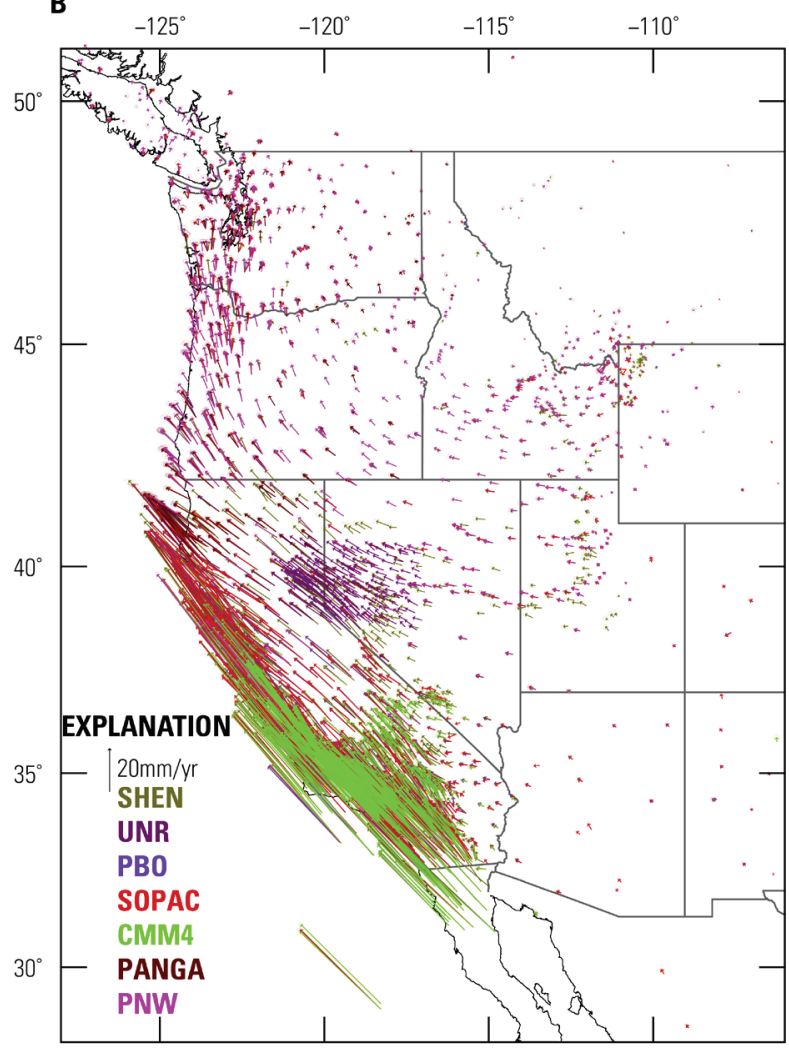

500 KILOMETERS

Figure A-3. Maps of global positioning system (GPS) velocity field data for the Western United States. A, Original velocity fields rotated into North American reference frame. $B$, Corrected velocity fields with effects of Cascadia subduction-zone locking removed. Vector colors correspond to source in table A-1. 
In addition to the GPS velocities, for which we used only the horizontal components in the block modeling, vertical velocities derived from leveling surveys (Burgette and others, 2009) were used to help constrain the locking on the Cascadia subduction fault (see McCaffrey and others, 2013, for details). The vertical rates were not distributed with the corrected horizontal velocities or used in subsequent modeling.

\section{Reference Frame}

Using the block model WUS5 and the inversion program tdefnode (McCaffrey, 2002, 2009), the velocity fields were rotated into a common reference frame defined by the North American (NoAm) block. This is accomplished by rotating each velocity field to minimize the velocities of the GPS sites on the reference (NoAm) block. For velocity fields that have no or few sites on NoAm, the reference frame rotations result from aligning it with the other velocity fields. To get the rotation of a velocity field $(\mathrm{V})$ relative to NoAm $(\mathrm{N})$, we solve:

$$
{ }_{\mathrm{V}} \Omega_{\mathrm{N}}={ }_{\mathrm{V}} \Omega_{\mathrm{B}}+{ }_{\mathrm{B}} \Omega_{\mathrm{N}}
$$

where B represents a block. Because ${ }_{B} \Omega_{N}$ is the same for all velocity fields, ${ }_{\mathrm{V}} \Omega_{\mathrm{B}}$ is estimated by minimizing the velocity residuals for velocity field $V$ in the block $B$. And because ${ }_{V} \Omega_{N}$ is the same for all blocks, it is estimated by minimizing velocity residuals in all the blocks. In the inversion, only $\Omega_{\mathrm{N}}$ and ${ }_{\mathrm{B}} \Omega_{\mathrm{N}}$ are estimated. Using this approach, the velocity fields do not require common sites, and not all need sites on the reference block. Each velocity field, however, must cover multiple blocks.

Most of the velocity fields used were already close to being in the North American reference frame and needed only small adjustments, on the order of $1 \mathrm{~mm} / \mathrm{yr}$ or less, to align with the average field. Two fields (University of Nevada, Reno, UNR and Scripts Orbit and Permanent Array Center, SOPAC; table A-1 and fig. A-3) were initially in a global International Terrestrial Reference Frame (ITRF) and required adjustments of closer to $15 \mathrm{~mm} / \mathrm{yr}$ (the adjustments are by rotations so will vary across the network).

\section{Data Editing}

After initial runs of the block model, during which the velocity fields were rotated into a common reference frame, the velocities were edited by visual inspection and by examining the statistics and misfits. For mature velocity fields, in the absence of co-seismic signals, the velocities vary spatially in a very smooth manner. Hence, if a single velocity was very different from nearby velocities in either azimuth or magnitude or both, we removed it from the dataset. In other cases, the deviation of a velocity was not visually obvious but was statistically different from nearby velocities, and it was removed.

We also excluded velocities with high uncertainties because they add little information in a leastsquares inversion. The uncertainty cutoffs applied were $0.8 \mathrm{~mm} / \mathrm{yr}$ for PNW and UNR fields (table A-1) and $1.0 \mathrm{~mm} / \mathrm{yr}$ for the others. In addition we applied a "floor" to the uncertainties in the sense that any formal uncertainty of less than $0.3 \mathrm{~mm} / \mathrm{yr}$ was set to $0.3 \mathrm{~mm} / \mathrm{yr}$. This limitation was aimed to avoid sites with very low uncertainties, some less than $0.1 \mathrm{~mm} / \mathrm{yr}$, from dominating the least-squares solution. It also represents some expected level of uncertainty among the reference frames. We removed "equated" sites from some of the solutions; these are nearby sites where data were combined in the GAMIT/GLOBK velocity analysis (http://www-gpsg.mit.edu/ simon/gtgk/) to estimate a single velocity and uncertainty. Sites within about $30 \mathrm{~km}$ of five actively deforming volcanic regions were also removed (Mount Saint Helens, Mono Lake, Rainier, Shasta, and Sisters). 


\section{Cascadia Elastic Strain-Rate Correction}

Locking on the Cascadia subduction zone was estimated by inverting the horizontal GPS and vertical leveling data (fig. A-4). The details of the procedure are outlined in McCaffrey and others (2013), but in this application we used all seven velocity fields. The geometry of the Cascadia plate interface was taken from McCrory and others (2003). The elastic velocities due to fault locking were calculated using dislocations in an elastic half-space following Okada (1985) and using the Savage (1983) backslip approach; the backslip component is $-\varphi \mathbf{V}$ where $\varphi$ is a locking fraction and $\mathbf{V}$ is the relative motion vector across the fault. The vector $\mathbf{V}$ is derived from the blocks' Euler poles and $\varphi$ is estimated in the inversion. For this calculation we parameterized the distribution of the locking fraction $\varphi$ with a defined function describing the change in locking with depth along profiles down the dip of the slab interface. The parameterization follows Wang and others (2003); $\varphi=1.0$ at depths shallower than the top, $z_{u}$, of what they call the effective transition zone (ETZ) and $\varphi=0.0$ at depths below the bottom, $\mathrm{Z}_{1}$, of the ETZ. Within the ETZ

$$
\varphi(\mathrm{z})=\left[\exp \left(-\mathrm{z}^{\prime} / \gamma\right)-\exp (-1 / \gamma)\right] /[1-\exp (-1 / \gamma)]
$$

where $\mathrm{z}^{\prime}=\left(\mathrm{z}-\mathrm{z}_{\mathrm{u}}\right) /\left(\mathrm{z}_{1}-\mathrm{z}_{\mathrm{u}}\right)$ and $\gamma$ is a shape factor. McCaffrey and others (2007) modified Wang's representation to allow for a more general case. Equation (2), in addition to constraining $\varphi$ to decrease with depth, forces the slope $\mathrm{d} \varphi / \mathrm{dz}$ to increase or remain approximately constant with depth (fig. 8 in Wang and others, 2003). To allow the slope to decrease with depth, we use a new parameter, $\gamma^{\prime}$, and make the substitution in (2) of $\gamma=\gamma^{\prime}$ when $\gamma^{\prime} \leq 5$, and $\gamma=\gamma^{\prime}-10$ when $5<\gamma^{\prime} \leq 10$. For values of $\gamma^{\prime}$ between 0 and $5, \varphi(z)$ is given by (2), and for $\gamma^{\prime}$ between 5 and 10, $\varphi(z)$ is (2) reflected about the $\varphi$ and $z$ axes (fig. 7a in McCaffrey and others, 2007). 


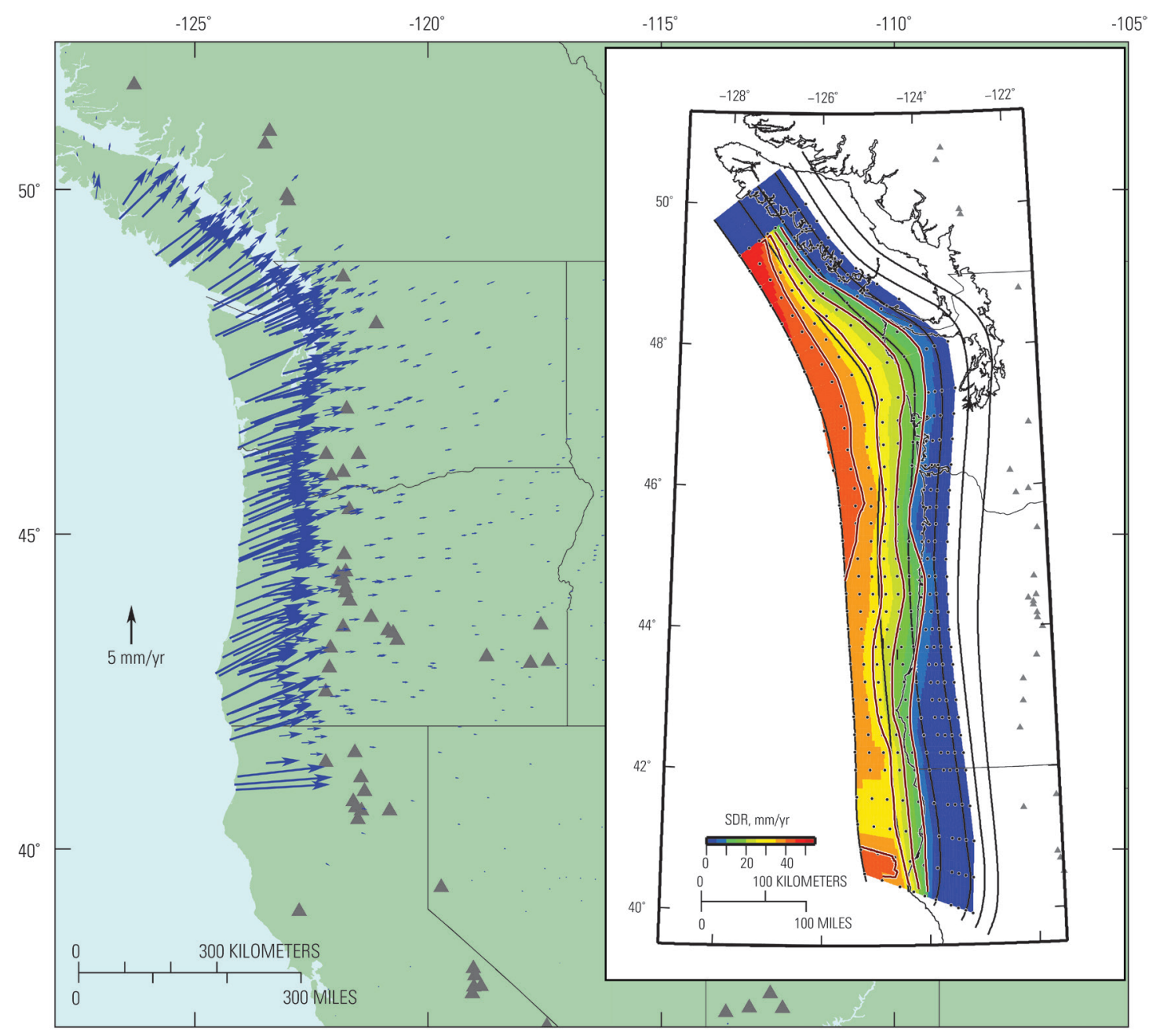

Figure A-4. Corrections to velocity field for locking at the Cascadia subduction zone. Insert shows locking model; SDR is the slip-deficit rate; dots are node positions; black lines are 10-kilometer slab contours and red lines are 10 millimeter per year (mm/yr) SDR contours. Triangles represent volcano locations.

The Cascadia slab interface was divided into 34 profiles starting at the deformation front, running perpendicular to it, and in the down-dip direction. The profiles were then discretized by node positions in longitude, latitude, and depth; the value of $\varphi$ was estimated at each node (depth) following the function (2). In the inversion, the parameters $\gamma^{\prime}, z_{1}$, and $z_{u}$ were estimated for each profile, subject to along-strike smoothing. Smoothing is applied by using a penalty function to damp the Laplacian of the $\varphi$ distribution (McCaffrey and others, 2013). The "best-fit" set of parameters was found by minimizing the sum of the data misfit (reduced chi-square) plus the penalty function.

The model used to estimate Cascadia locking included all the blocks (fig. A-1) while solving for their angular velocities but not internal strain within them. The motion of the Juan de Fuca plate (JdFa) was estimated in the inversion using spreading rates at the Juan de Fuca Ridge (DeMets and others, 2010) and fixing the Pacific-North America pole. The motion of JdFa relative to the fore-arc blocks give the slip vector $\mathbf{V}$ used in the calculation of elastic strain at the Cascadia subduction zone. Once a best-fit set of parameters was determined, they were used to solve the forward problem to estimate a velocity at each GPS site arising from Cascadia locking (fig. A-4). These velocities were then subtracted from the 
observed site velocities and 10 percent of the locking velocities were added to the velocity uncertainties as follows:

$$
\sigma_{\text {new }}=\sqrt{ }\left[\sigma_{\text {old }}^{2}+\left(0.10 * V_{\text {lock }}\right)^{2}\right]
$$

The resulting corrected velocity field is shown in figure $\mathrm{A}-3 \mathrm{~B}$.

\section{Geologic Slip Rates}

In block models, geologic data, that is, estimated or observed slip rates on faults by geologic means, can be used to constrain the motions of blocks in a formal inversion because the fault slip rate is simply the relative motions of the blocks across the boundary. The WUS5 block model does not provide a one-to-one correspondence between the modified 2008 NSHMP source model based on expert analysis of geologic slip-rate data and block boundaries (fig. A-2), largely for the reason noted above. Block models cannot provide unique information on closely spaced faults, and therefore, not every fault is represented in a block model. Even using strain rates within the blocks does not permit a unique sliprate estimate on the interior faults. Models that report slip rates on closely spaced faults are not strictly basing those rates on GPS data.

The source of geologic rates was the 2008 NSHMP source model with a few updates (Haller and Wheeler, 2008a,b; table 1 this volume). For the block models that include only horizontal long-term motions, the fault-parallel slip rates were converted to horizontal (heave) rates assuming the dip angles given in the modified 2008 NSHMP source model. For comparison with the other model results, the model predicted horizontal rates $\mathrm{V}_{\mathrm{h}}$ were converted back to along-dip-slip rates $\mathrm{V}_{\mathrm{ds}}$ using the same dip angles; $\mathrm{V}_{\mathrm{ds}}=\mathrm{V}_{\mathrm{h}} /$ cosine (dip). Unfortunately, most of the fault slip rates were estimated from throw observations with little knowledge of dip angles; thus, the horizontal rates used in the block modeling are poorly constrained. Also available to the modeling were fault slip rates calculated by Bird (appendix C), using the technique described by Bird (2007), and rates taken from the literature and listed in McCaffrey and others (2007).

\section{Block-Model Results with tdefnode}

The WUS5 block model was run using the inversion program tdefnode, which is a modification of defnode (McCaffrey, 2002, 2009). Two runs were done, one of the entire WUS5 model and another that excluded California (WUS5-noCA; table A-2). As noted above, the representation of the UCERF-3 block model in California was coarsened, so the fit to the data was degraded. The reduced chi-square $\chi_{\eta}{ }^{2}$ misfit is large for these models compared with single-velocity field models of the U.S. Pacific Northwest, which typically have $\chi_{\eta}{ }^{2}$ less than $\approx 2$ (McCaffrey and others, 2013). We attribute this to the use of multiple velocity fields that estimate velocities and uncertainties in different ways and to a heterogeneous set of observed fault slip rates.

Table A-2. Model run statistics.

[GPS (global positioning system) and SR (slip rate) give the number of GPS and slip-rate observations, respectively. Nrms is the normalized root mean square of the misfit to the data type. The reduced chi-square is $\left.\chi \eta^{2}\right]$

\begin{tabular}{lcccc}
\hline \multicolumn{1}{c}{ Model } & GPS/Nrms & SR/Nrms & \#Parameters & $\chi \eta^{2}$ \\
\hline WUS5 & $12,385 / 3.1$ & $1,028 / 4.2$ & 564 & 10.4 \\
WUS5-noCA & $6,821 / 2.1$ & $424 / 4.2$ & 353 & 5.2 \\
\hline
\end{tabular}




\section{Slip Rates Derived from Block Model}

The block model was used by two groups to estimate fault slip rates; McCaffrey (hereafter referred to as RM) used tdefnode (McCaffrey 2002, 2009) and Hammond and Bormann (appendix B; hereafter referred to as HB) used the method described in Hammond and others (2011). The block models made estimates for 114 of the 294 faults in the modified 2008 NSHMP source model, including most of those with published slip rates exceeding $1 \mathrm{~mm} / \mathrm{yr}$. The two inversions used the same block geometry and fault dips and generally the same formulation but differed in details of the implementation and the data (appendix B). A major difference was the level of off-fault strain rates allowed within the block. The RM model allowed more strain within blocks than did HB resulting in faster fault slip rates in the HB model (fig. A-5A). Both block inversions resulted in generally faster slip rates than in the modified 2008 NSHMP source model (figs. A-5B and A-5C). This latter result suggests that the GPS velocity fields may be indicating more total moment on faults than is implied by the modified 2008 NSHMP source model. This result is consistent with the Zeng and Shen fault-based inversion (appendix D) that forces a fit to the source model slip rates and estimated much higher off-fault moment rates than models that did not (appendix E) - a full 10 times more than the HB model. Hence, there is information in the geodetic data that is not incorporated into NSHMP14, which should be among the targets of research prior to the next NSHMP.
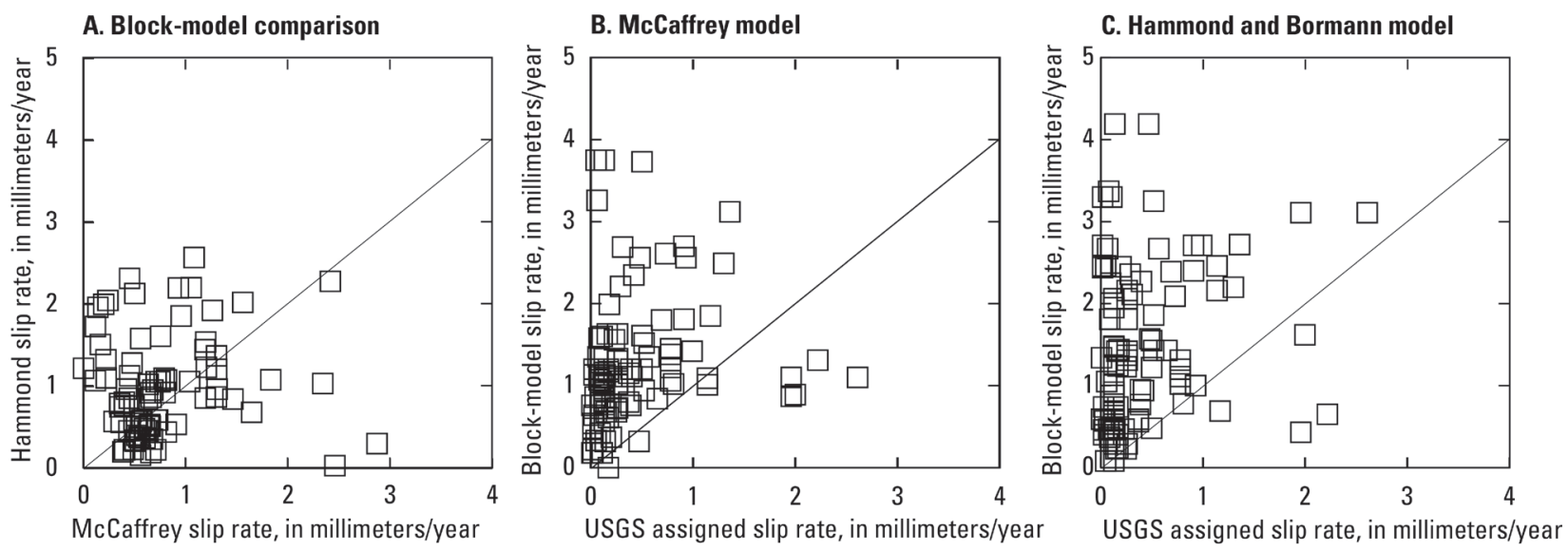

Figure A-5. Comparison of fault slip rates (total rate) for A, McCaffrey (appendix A) and Hammond and Bormann (appendix B) block models and slip rates for the modified 2008 fault source model compared to the $B$, McCaffrey (appendix A) block model, and the C, Hammond and Bormann (appendix B) block model.

\section{Internal Block Strain Rates}

Along with the rotational components of the blocks, uniform strain rates are estimated for them (fig. A-6). The horizontal strain-rate tensor for a spherical Earth is given by Savage and others (2001) the east and north velocities are as follows:

$$
\begin{aligned}
& V_{\lambda}(\lambda, \theta)=e_{\lambda \lambda} R_{e} \sin \theta_{\mathrm{o}}\left(\lambda-\lambda_{\mathrm{o}}\right)+e_{\lambda \theta} R_{e}\left(\theta-\theta_{\mathrm{o}}\right) \\
& V_{\theta}(\lambda, \theta)=e_{\lambda \theta} R_{e} \sin \theta_{\mathrm{o}}\left(\lambda-\lambda_{\mathrm{o}}\right)+e_{\theta \theta} R_{e}\left(\theta-\theta_{\mathrm{o}}\right)
\end{aligned}
$$


where $\lambda$ is longitude, $\theta$ is co-latitude, $R_{e}$ is the radius of the Earth, $e_{\mathrm{ij}}$ is the strain-rate tensor, and $\left(\lambda_{\mathrm{o}}\right.$, $\theta_{\mathrm{o}}$ ) is the centroid of the block. When applied, the three independent components of the symmetric strain-rate tensor, $e_{\lambda \lambda}, e_{\theta \theta}$, and $e_{\lambda \theta}$, are formally estimated in the inversion (McCaffrey, 2005). These terms are intended to represent deformation due to unmodeled faults within the blocks. In the WUS outside California, the internal strain rates are generally low, less than 10 nanostrain/year (1 nanostrain/year $=10^{-9}$ year $\left.^{-1}\right)$. The fastest straining regions are the Yakima fold-thrust belt in Washington and parts of the Basin and Range (fig. A-6).
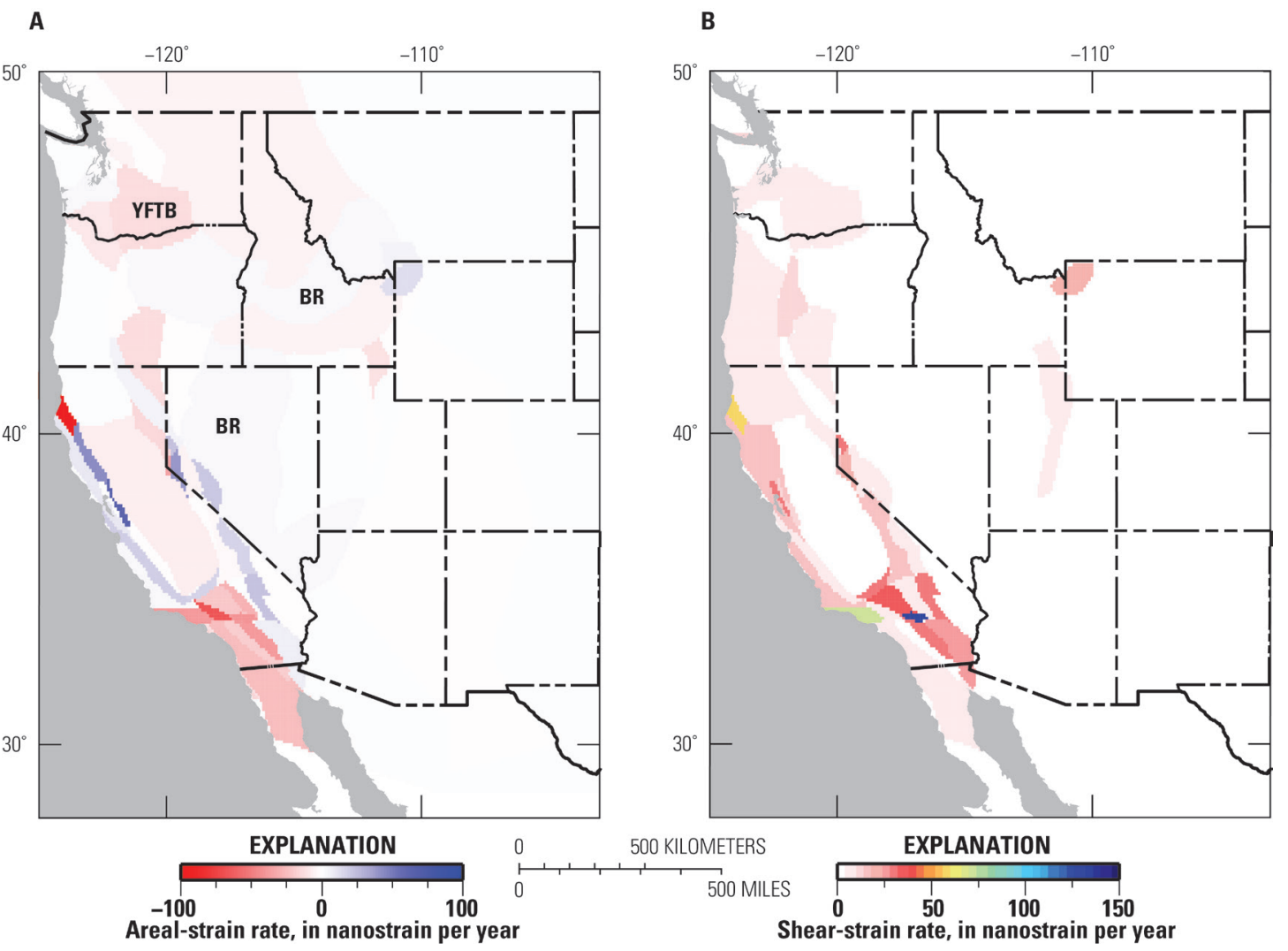

Figure A-6. Maps of $A$, areal strain rate and $B$, shear strain rate within blocks estimated from global positioning system data and the inversion program tdefnode. BR = Basin and Range; YFTB = Yakima fold-thrust belt. Negative strain rates are contraction and positive are extension.

\section{Summary}

A working group developed a block model for the WUS to incorporate GPS data into the assessment of slip rates to be adopted by NSHMP14. The model was run through two separate codes and predicted slip rates for a subset of the 2014 source faults. The block models showed considerable scatter in their agreement on slip rates, but both were consistently faster than the adopted geologic slip rates from expert analysis. The WUS outside California poses a particular difficulty for geodetic methods to contribute to hazards assessment due to the low density of GPS stations and low slip rates on faults. Continued densification of the geodetic networks and longer observation spans, to reduce errors, will enhance the utility of GPS for earthquake hazards assessment. 


\section{References Cited}

Bird, Peter, 2007, Uncertainties in long-term geologic offset rates of faults - General principles illustrated with data from California and other Western States: Geosphere, v. 3, p. 577-595, doi: 10.1130/GES00127.1.

Burgette, R.J., Weldon, R.J., and Schmidt, D.A., 2009, Interseismic uplift rates for western Oregon and along-strike variation in locking on the Cascadia subduction zone: Journal of Geophysical Research, v. 114, B01408, doi:10.1029/2008JB005679.

DeMets, Charles, Gordon, R.G., and Argus, D.F., 2010, Geologically current plate motions: Geophysical Journal International, doi: 10.1111/j.1365-246X.2009.04491.x

Haller, K.M., and Wheeler, R.L., 2008a, Parameter for faults in the Intermountain West, in Peterson, M.D., Frankel, A.D., Harmsen, S.C., Mueller, C.S., Haller, K.M., Wheeler, R.L., Wesson, R.L., Zeng, Yuehua, Boyd, O.S., Perkins D.M., Luco, Nico, Field, E.H., Wills, C.J., and Rukstales, K.S., Documentation for the 2008 update of the national seismic hazard maps: U.S. Geological Survey Open-File Report 2008-1128, p. G-1-G-18.

Haller, K.M., and Wheeler, R.L., 2008b, Parameter for faults in the Pacific Northwest, in Peterson, M.D., Frankel, A.D., Harmsen, S.C., Mueller, C.S., Haller, K.M., Wheeler, R.L., Wesson, R.L., Zeng, Yuehua, Boyd, O.S., Perkins D.M., Luco, Nico, Field, E.H., Wills, C.J., and Rukstales, K.S., Documentation for the 2008 update of the national seismic hazard maps: U.S. Geological Survey Open-File Report 2008-1128, p. H-1-H-6.

Hammond, W.C., Blewitt, Geoffrey, and Kreemer, Corné, 2011, Block modeling of crustal deformation of the northern Walker Lane and Basin and Range from GPS velocities: Journal of Geophysical Research, v. 116, B04402, doi:10.1029/2010JB007817.

Kreemer, Corné, Blewitt, Geoffrey, and Hammond, W.C., 2010, Evidence for an active shear zone in southern Nevada linking the Wasatch fault to the eastern California shear zone: Geology, v. 38, p. 475-478, doi: 10.1130/G30477.1.

McCaffrey, Robert, 2002, Crustal block rotations and plate coupling, in Stein, Seth, and Freymueller, Jeffrey, eds., Plate boundary zones: AGU Geodynamics Series 30, p. 101-122.

McCaffrey, Robert, 2005, Block kinematics of the Pacific-North America plate boundary in the southwestern US from inversion of GPS, seismological, and geologic data: Journal of Geophysical Research, v. 110, B07401, doi:10.1029/2004JB003307.

McCaffrey, Robert, 2009, Time-dependent inversion of three-component continuous GPS for steady and transient sources in northern Cascadia: Geophysical Research Letters, v. 36, L07304, doi:10.1029/2008GL036784.

McCaffrey, Robert, Qamar, A.I., King, R.W., Wells, Ray, Khazaradze, Giorgi, Williams, C.A., Stevens, C.W., Vollick, J.J., and Zwick, P.C., 2007, Fault locking, block rotation and crustal deformation in the Pacific Northwest: Geophysical Journal International, v. 169, p. 1315-1340, doi:10.1111/j.1365246X.2007.03371.x.

McCaffrey, Robert, King, R.W., Payne, S.J., and Lancaster, Matthew, 2013, Active tectonics of northwestern US inferred from GPS-derived surface velocities: Journal of Geophysical Research, v. 118, doi:10.1029/2012JB009473.

McCrory, P.A., Blair, J.L., Oppenheimer, D.H., and Walter, S.R., 2003, Depth to the Juan de Fuca slab beneath the Cascadia subduction margin-A 3-D model for sorting earthquakes: U.S. Geological Survey Digital Data Series 91, 1 CD-ROM.

Meade, B.J., and Hager, B.H., 2005, Block models of crustal motion in southern California constrained by GPS measurements: Journal of Geophysical Research, v. 110, doi:10.1029/2004JB003209. 
Okada, Yoshimitsu, 1985, Surface deformation due to shear and tensile faults in a half-space: Bulletin of the Seismological Society of America, v. 75, p. 1135-1154.

Payne, S.J., McCaffrey, Robert, and King, R.W., 2008, Strain rates and contemporary deformation in the Snake River Plain and surrounding Basin and Range from GPS and seismicity: Geology, v. 36, p. 647-650.

Payne, S.J., McCaffrey, Robert, King, R.W., and Kattenhorn, S.A., 2012, A new interpretation of deformation rates in the Snake River Plain and adjacent Basin and Range regions based on GPS measurements: Geophysical Journal International, v. 189, p. 101-122, doi: 10.1111/j.1365246X.2012.05370.x.

Savage, J.C., 1983, A dislocation model of strain accumulation and release at a subduction zone: Journal of Geophysical Research, v. 88, p. 4984-4996.

Savage, J.C., Gan, Weijun, and Svarc, J.L., 2001, Strain accumulation and rotation in the eastern California shear zone: Journal of Geophysical Research, v. 106, p. 21,995-22,007.

Shen, Z-K., King, R.W., Agnew, D.C., Wang, M., Herring, T.A., Dong, D., and Fang, P., 2011, A unified analysis of crustal motion in southern California, 1970-2004-The SCEC crustal motion map: Journal of Geophysical Research, v. 116, doi: 10.2019/2011JB008549.

Wang, K., Wells, R., Mazzotti, S., Hyndman, R.D., and Sagiya, T., 2003, A revised dislocation model of interseismic deformation of the Cascadia subduction zone: Journal of Geophysical Research, v. 108, 2026, doi:10.1029/2001JB001227. 


\title{
Appendix B-A Block Model of Western United States Tectonic Deformation for the 2014 National Seismic Hazard Maps from GPS and Geologic Data
}

\author{
By William C. Hammond ${ }^{1}$ and Jayne Bormann ${ }^{2}$ \\ ${ }^{1}$ Nevada Geodetic Laboratory, Nevada Bureau of Mines and Geology and Nevada Seismological Laboratory, \\ Reno, Nev. \\ 2University of Nevada, Reno, Nev.
}

\begin{abstract}
We have constructed a kinematic model of Western United States (WUS) tectonic deformation using the same block geometry and GPS velocity data used in appendix A. The methodology is conceptually similar to that used in the McCaffrey model (appendix A), using GPS velocities and geologic slip rates as constraints on a block model of crustal deformation patterns. Differences in methods include using a different software and model regularization to solve for the rotations of individual blocks and fault slip rates and employing a viscoelastic seismic-cycle model to account for postseismic relaxation of earthquakes in Nevada. Although the resulting model is similar in its deformation patterns to the McCaffrey block model, individual slip-rate estimates differ in many cases. In our modeling we allow for constant tensor strain rates inside large blocks, but our regularization results in a model with more deformation assigned to block-bounding slip rates and less to the interior of large blocks compared to the other models. Throughout the interior of the WUS, the slip rates in our model are on average greater than the geologic slip rates.
\end{abstract}

Introduction

We have developed a kinematic model of crustal deformation of the Western United States (WUS) in order to constrain the geographic distribution of hazard from earthquakes. The purpose of this modeling is to apply the rich and growing dataset of global positioning system (GPS) velocities from several research groups and facilities to obtain a model of deformation that is kinematically consistent and treats all observations uniformly. The model is designed to estimate slip rates on active faults that bound individual blocks of the crust and distribute the remaining deformation within the block interiors. In the model, the blocks move horizontally via rotations described by Euler poles (McKenzie and Parker, 1967) at rates with a sense of rotation that are constrained by a compilation of GPS measurements of horizontal velocity with respect to North America.

Our model is a companion to the model presented by McCaffrey (appendix A). We use the same block geometry, including assumed values for fault-locking depth and fault dips. We also use the same velocity data including correction for interseismic locking on the Cascadia subduction zone. The problem is solved with methodology and software developed at the Nevada Geodetic Laboratory that has been used extensively to estimate crustal motions from GPS observations (Hammond and Thatcher, 2007; Hammond and others, 2011). Though many of the model features are similar to the McCaffrey block model, differences in methodology lead to slightly different results. The degree of similarity between our model and the McCaffrey model shows the degree of repeatability of the results and evaluates the stability of the analysis with respect to modeling technique.

We use the geologic estimates of fault slip rates provided by the U.S. Geological Survey (Haller and Wheeler, 2008a,b) as additional data to constrain our model. However, the weighting placed on the 
geologic slip rate observations is less than that placed on the GPS data, so that deformation is driven primarily by geodetic observations and secondarily by geologic observations. The weight placed on geologic observations is less than in some of the other deformation models (for example, Bird, appendix $\mathrm{C}$, and Zeng and Shen, appendix D). Compared to those models, our model is more likely to reflect contemporary deformation from decadal time-scale measurements and may not be the same as those estimated from longer periods of geologic time.

We allowed strain to occur inside most of the larger blocks, allowing uniform three-component horizontal tensor strain rate representing distributed permanent deformation. However these parameters were damped toward zero, so their contribution to the overall model velocity field was kept to near the minimum necessary to explain the data. Thus, our model explains the data with a deformation field that places more emphasis on the slip on the discrete fault systems at block boundaries; that is, it is "blockier" than the other models. The other deformation models used parameterizations that allowed a greater proportion of the overall deformation budget to occur inside blocks and hence have a greater amount of continuum deformation in addition to slip on block-bounding faults.

\section{Data}

We used the same combination of GPS velocity fields as McCaffrey (appendix A) and the same correction for the effects of the Cascadia subduction zone interseismic locking. This correction has a large effect $(>10 \mathrm{~mm} / \mathrm{yr})$ on the velocities near the Oregon and Washington coasts, replacing eastward interseismic motion with more oceanward long-term motion (McCaffrey and others, 2013). The magnitude of the correction decreases rapidly eastward where the rates are less affected by interseismic locking on the subduction zone plate interface.

We exclude velocity data that do not represent the long-term deformation-field-associated loading of earthquake faults. In particular, we omitted data near active volcanic systems (Long Valley, Lassen Peak, and Mount Shasta in California, Mount Saint Helens in Washington). We also removed velocity outliers that were more than $4 \mathrm{~mm} / \mathrm{yr}$ different than the interpolated expectation based on other velocities within a $25-\mathrm{km}$ radius. Finally, we averaged duplicate velocities from individual GPS stations present in the combined velocity file that were essentially multiple velocity estimates from the same data. The outlier detection removed less than 2 percent of the velocities.

The upper mantle and lower crust in the WUS have viscoelastic material properties and experience transient deformation following large historic earthquakes (see for example, Pollitz and others, 2000). For this analysis we applied a correction to account for viscoelastic relaxation following large historic earthquakes in Nevada and eastern California. Because of lower tectonic strain rates in the Great Basin, the transient early-cycle deformation from these earthquakes stands out more readily from the background than elsewhere in the Pacific-North America plate boundary (Hammond and Thatcher, 2004; Hammond and others, 2012) leading to the potential for proportionally larger bias of slip rates in Nevada. This correction was developed from models of the 1872 Owens Valley, 1915 Pleasant Valley, 1932 Cedar Mountain, 1954 Rainbow Mountain/Stillwater sequence, 1954 Fairview Peak, and 1954 Dixie Valley earthquakes (Hammond and others, 2009). Applying this model reduces the inferred normal component of the slip rate for the large blocks in Nevada east and west of the Dixie Valley fault (blocks WBnR and CBnR, fig. A-1). Hammond and others (2011, their fig. 5) depict this correction graphically. To apply the correction, we subtract the modeled transient velocities from the GPS velocities to estimate a late cycle rate that is similar to the cycle-averaged rate in the slowly deforming Basin and Range. 


\section{Method}

Block modeling is a method by which geodetic measurements made over a few years of interseismic time can be used to infer the motion of blocks of crust over times applicable to seismic hazard analysis, that is, over the next few seismic cycles. This time period is essentially instantaneous in the context of plate tectonics. The analytical details vary somewhat between the different approaches that have been discussed in previous studies (some examples include Matsu'ura and others, 1986; Bennett and others, 1996; Prawirodirdjo and others, 1997; McClusky and others, 2001; Murray and Segall, 2001; McCaffrey, 2002; Meade and Hager, 2005; Reilinger and others, 2006; McCaffrey and others, 2007). These are conceptually similar in that they account for block motion and fault locking. Our model accounts for the difference between the long- and short-term velocity field by applying backslip (Savage, 1983), estimating the elastic strain owing to block-boundary fault segments using the formulation of Okada (1985).

The model geometry is shown in detail in appendix A. It includes known major faults in the WUS from Colorado westward to the Pacific plate and extends south and north into Mexico and Canada. We used the prescribed values for fault dips and locking depths.

The model regularization is similar to that used in the northern Walker Lane model of Hammond and others (2011). In that model, the damping of slip rates and vertical-axis spin rates causes poorly constrained blocks to move in a direction similar to neighboring blocks. Compared to that model, however, the WUS model has a greater number of GPS observations, larger blocks, a greater variety of slip rates, and better constraints on the motions of large blocks at the boundaries of the model. Thus for this WUS model, we relax the block vertical-axis spin-rate damping $\left(10^{-7} / \mathrm{yr}\right)$ and the a priori uncertainty on slip rates $(30 \mathrm{~mm} / \mathrm{yr})$, but otherwise keep all material properties the same. This regularized approach makes the model tolerant to small gaps in data coverage because blocks will follow the averaged behavior of neighboring blocks in the absence of data. In the WUS model, all blocks had at least one GPS station, and only two blocks had fewer than five GPS stations.

In addition to block rotation and fault locking, we allowed a subset of the blocks to experience constant horizontal-tensor strain rate if demanded by the data. We allowed strain in all large blocks (blocks with areas greater than 20,000 $\mathrm{km}^{2}$ ) except for the JdFa, Paci, Josh, WCCR, and EWkL blocks (fig A-1). The Paci and JdFa blocks had rotations poles fixed to values in the literature (Kreemer and others, 2000; McCaffrey and others, 2007) because they had insufficient GPS velocities on those blocks to constrain block motion.

We applied geologic data provided by the USGS (updated from Haller and Wheeler, 2008a,b) as additional constraints on the blocks motions. For each fault segment in the model, we selected the nearest geologic slip rate and used the slip rate as a constraint if it was within $5 \mathrm{~km}$ of the model segment. Slip rates in the model were set to the geologic slip rates, distributed to the appropriate components (dip-slip or strike-slip) using the rake information supplied in the USGS file. We regularized the importance of the geologic slip-rate constraint by setting the a priori uncertainty in the model slip rate. After testing several choices, we selected a value that placed a weaker (but greater than zero) emphasis on geologic slip rates. This had the effect of constraining the model mostly by GPS data but stabilizing the model where GPS data were weak.

Additional tests of the modeling were performed to determine if the solution was stable with respect to specific factors. In one test we used an independent GPS velocity field, generated by the Nevada Geodetic Laboratory, to see if homogenous processing using only continuous and semicontinuous stations would improve the model. We found that a model generated using this velocity field had fewer outliers, but it fit the data only slightly better than the velocities used for this model. This suggested that the limitations to fitting the GPS data are likely attributable to the relative simplicity 
of the block geometries where a small number of large blocks and constant strain rates are used to explain a large and complex plate boundary deformation zone.

\section{Results and Discussion}

The results of our modeling are shown in figure B-1. Most blocks spin around vertical axes at rates between $2^{\circ}$ clockwise and $1^{\circ}$ counterclockwise per million years, with lower rates in the Intermountain West and Basin and Range and higher rates with a variable sign inside the San Andreas and Cascadia plate boundary zones. The root mean square (RMS) misfits of the model to the GPS data are near 1.3 and $1.4 \mathrm{~mm} / \mathrm{yr}$ in the east and north components, respectively (fig. B-2). The misfits tend to be higher in regions where (1) slip rates are higher and deformation patterns are more complex (for example, near the creeping sections of the San Andreas Fault in California) and (2) recent large earthquakes are distorting the GPS velocity field with unmodeled transient deformations (for example, around the 1999 Hector Mine and 1992 Landers earthquakes). The normalized chi-squared misfit values for the entire model, including both north and east components of GPS velocity (but excluding velocities that were omitted as outliers as discussed above) is 8.46 . However, considering only data outside of California results in a smaller normalized chi-square of 3.48 (table B-1). The difference in misfits between our and the other models is likely attributable to the difference in number of parameters, modeling style, and method of outlier detection and removal.

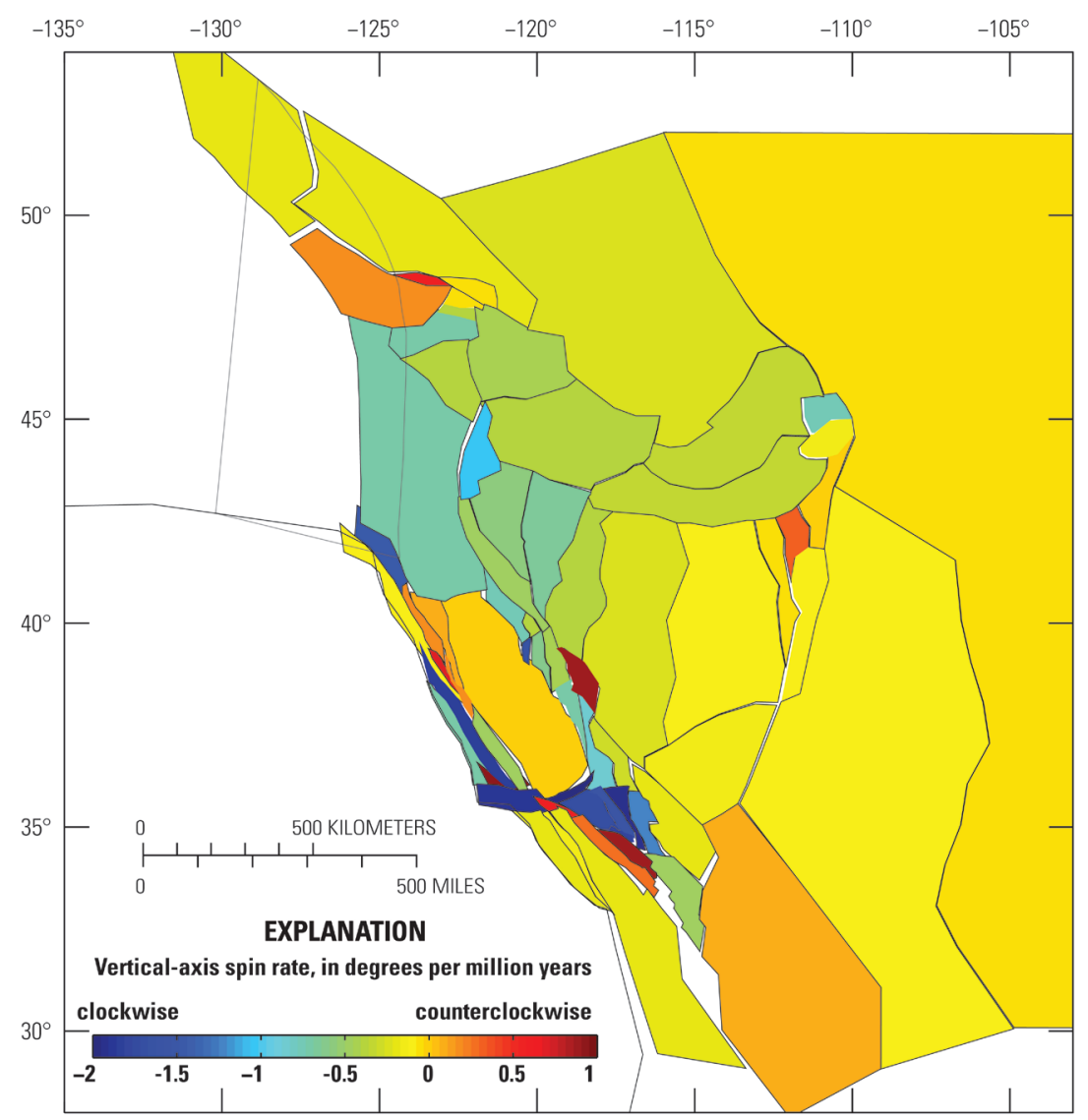

Figure B-1. Rotation of blocks in the model. Color represents vertical-axis spin rate of blocks in the model. The displacement of blocks represents the long-term horizontal block motion greatly exaggerated. The Juan de 
Fuca and Pacific blocks (see fig. A-1 JdFa and Paci, respectively) have been made transparent to better show blocks near the coast. Magenta lines represent the original position of the blocks.

Table B-1. Misfit of model to data.

[RMS, root mean square]

\begin{tabular}{lcc}
\hline Misfit to GPS data & $\begin{array}{c}\text { Entire Western } \\
\text { U.S. model }\end{array}$ & Outside California \\
\hline Number of GPS observations (sites times 2) & 5,790 & 3,134 \\
RMS of residual velocities (mm/yr) & 1.32 & 0.90 \\
Normalized chi-square (unitless, 1.0 ideal) & 8.46 & 3.48 \\
Number of model parameters & & 267 \\
Reduced chi-square (unitless, 1.0 ideal) & 8.87 & 3.81 \\
\hline
\end{tabular}
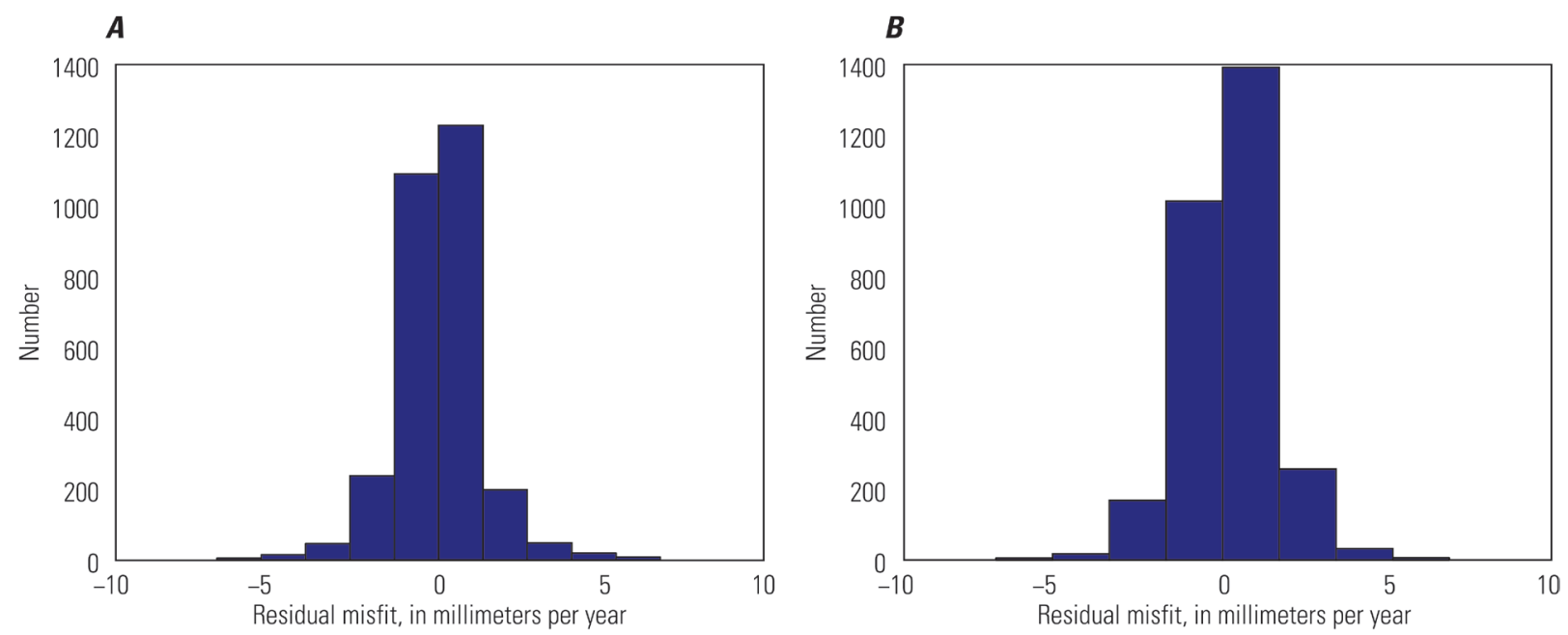

Figure B-2. Plots of residual misfit between global positioning system velocities and predictions from block model $A$, east residuals and $B$, north residuals.

As discussed in appendix A, our model is more "blocky" in the sense that the deformation partitioned to the interior of blocks is less than in the McCaffrey block model (appendix A), and less than in the continuum models of Zeng and Shen (appendix D) and Bird (appendix C). In this respect, our model is an end member that places more slip on faults and concentrates deformation at the known active faults. Future versions of this modeling could be improved by increasing the number of blocks and (or) by allowing more deformation to be partitioned into block interiors. However, when allowing more deformation inside blocks, the hazard will need to be accounted for as distributed source zones that abide by the budget of seismogenic moment across the WUS. 
In both block models, the geodetic slip rates are on average greater than the geologic rates (fig. A-5). That comparison is made for faults outside California that slip at rates much slower than individual slip rates in the San Andreas Fault system (fig. B-3). Possible reasons for these disagreements include, but may not be limited to, (1) geometric simplicity of the block model so its ability to fit GPS data is limited, (2) strike-slip deformation on slowly moving faults is systematically underrepresented in the database of geologic slip rates because it is more difficult to observe in the geologic record, (3) geologic slip rates are estimated without the constraint of regional kinematic consistency so their uncertainties are underestimated, (4) the time scales to which geodetic ( $10^{1}$ years) and geologic data $\left(10^{2}\right.$ to $10^{5}$ years) are sensitive are different, and slip rates have changed over time (see for example, Friedrich and others, 2003; Bennett, 2007). Thus, the disagreements between geologic and geodetic slip rates may represent a combination of real variation and aleatory and epistemic uncertainties in the geographic distribution of tectonic deformation. 

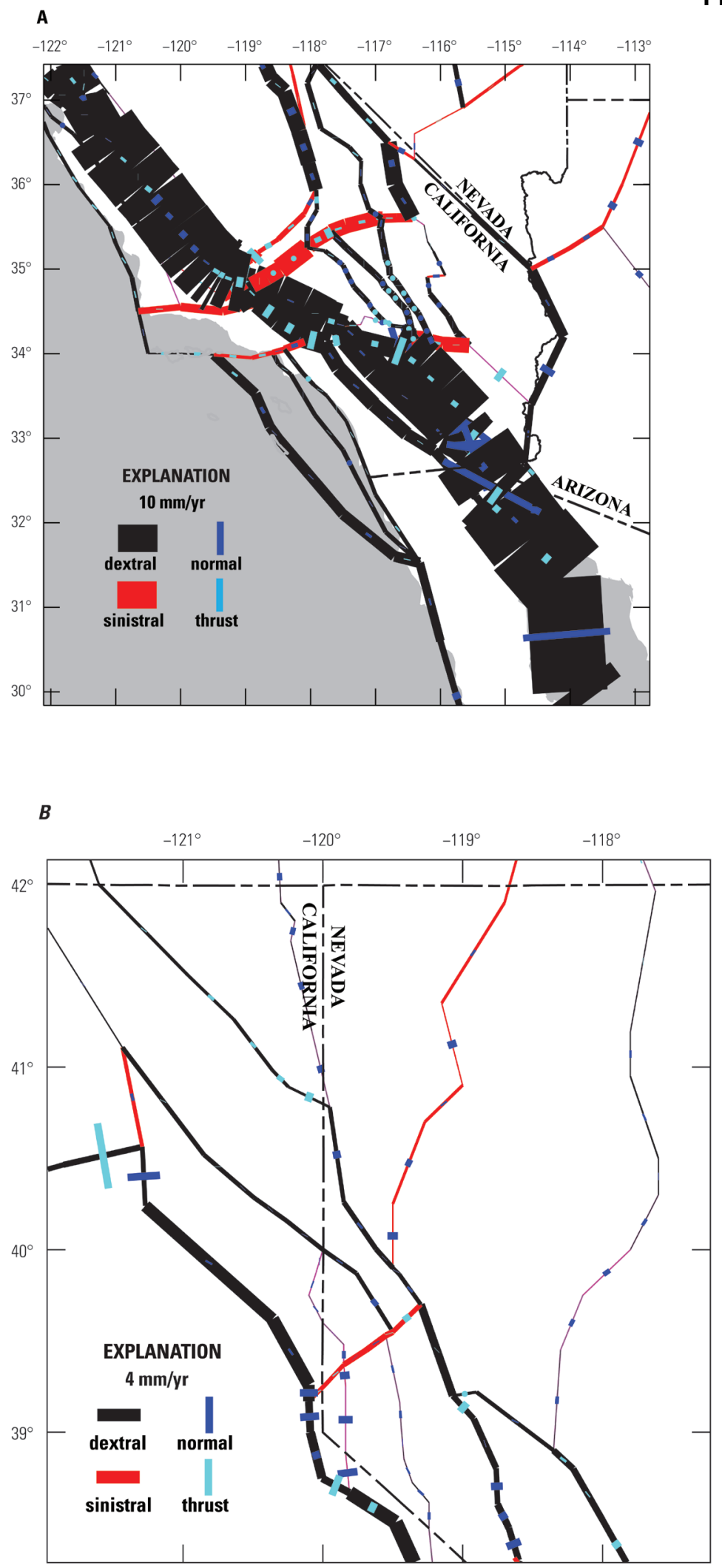

Figure B-3. Close-up of the model in the $A$, southern California and $B$, northern Walker Lane regions. In $A$, slip rates are shown on faults between western Arizona, southern Nevada, and the Pacific plate. In $B$, the slip rates in northeast California and northwest Nevada are much lower, and a different scale is used. Thickness of black and red lines shows dextral and sinistral slip rates, respectively. Length of blue and cyan lines indicates horizontal component of normal and thrust rates, respectively. 


\section{References Cited}

Bennett, R.A., Rodi, William, and Reilinger, R.E., 1996, Global positioning system constraints on fault slip rates in southern California and northern Baja, Mexico: Journal of Geophysical Research, v. 101, no. B10, p. 21,943-21,960.

Bennett, Richard, 2007, Instantaneous slip rates from geology and geodesy: Geophysical Journal International, v. 169, p. 19-28, doi: 10.1111/j.1365-246X.2007.03331.x.

Friedrich, A.M., Wernicke, B.P., Niemi, N.A., Bennett, R.A., and Davis, J.L., 2003, Comparison of geodetic and geologic data from the Wasatch region, Utah, and implications for the spectral character of Earth deformation at periods of 10 to 10 million years: Journal of Geophysical Research, v. 108, no. B4, 2199, doi:10.1029/2001JB000682.

Haller, K.M., and Wheeler, R.L., 2008a, Parameter for faults in the Intermountain West, in Peterson, M.D., Frankel, A.D., Harmsen, S.C., Mueller, C.S., Haller, K.M., Wheeler, R.L., Wesson, R.L., Zeng, Yuehua, Boyd, O.S., Perkins D.M., Luco, Nico, Field, E.H., Wills, C.J., and Rukstales, K.S., Documentation for the 2008 update of the national seismic hazard maps: U.S. Geological Survey Open-File Report 2008-1128, p. G-1-G-18.

Haller, K.M., and Wheeler, R.L., 2008b, Parameter for faults in the Pacific Northwest, in Peterson, M.D., Frankel, A.D., Harmsen, S.C., Mueller, C.S., Haller, K.M., Wheeler, R.L., Wesson, R.L., Zeng, Yuehua, Boyd, O.S., Perkins D.M., Luco, Nico, Field, E.H., Wills, C.J., and Rukstales, K.S., Documentation for the 2008 update of the national seismic hazard maps: U.S. Geological Survey Open-File Report 2008-1128, p. H-1-H-6.

Hammond, W.C., and Thatcher, Wayne, 2004, Contemporary tectonic deformation of the Basin and Range Province, Western United States - 10 years of observation with the global positioning system: Journal of Geophysical Research, v. 109, B08403, doi:10.1029/2003JB002746.

Hammond, W.C., and Thatcher, Wayne, 2007, Crustal deformation across the Sierra Nevada, northern Walker Lane, Basin and Range transition, Western United States measured with GPS, 2000-2004: Journal of Geophysical Research, v. 112, B05411, doi:10.1029/2006JB004625.

Hammond, W.C., Kreemer, Corné, and Blewitt, Geoffrey, 2009, Geodetic constraints on contemporary deformation in the northern Walker Lane-3, Central Nevada seismic belt postseismic relaxation, in Oldow, J.S., and Cashman, P.H., eds., Late Cenozoic structure and evolution of the Great Basin-Sierra Nevada transition: Geological Society of America Special Paper 447, p. 33-54.

Hammond, W.C., Blewitt, Geoffrey, and Kreemer, Corné, 2011, Block modeling of crustal deformation of the northern Walker Lane and Basin and Range from GPS velocities: Journal of Geophysical Research, v. 116, B04402, doi:10.1029/2010JB007817.

Hammond, W.C., Blewitt, Geoffrey, Li, Zhenhong, Plag, H.-P., Kreemer, Corné, 2012, Contemporary uplift of the Sierra Nevada, Western United States, from GPS and InSAR measurements: Geology, v. 40, p. 667-670, doi:10.1130/G32968.1.

Kreemer, Corné, Haines, John, Holt, W.E., Blewitt, Geoffrey, and Lavallée, David, 2000, On the determination of the global strain rate model: Earth Planets Space, v. 52, p. 765-770.

Matsu'ura, Mitsuhiro, Jackson, D.D., and Cheng, Abe, 1986, Dislocation model for aseismic crustal deformation at Hollister, California: Journal of Geophysical Research, v. 91, no. B12, p. 12,66112,674 .

McCaffrey, Robert, 2002, Crustal block rotations and plate coupling, in Stein, S.A., and Freymueller, J.T., eds., Plate boundary zones: AGU Geodynamics Series, v. 30, p. 101-122.

McCaffrey, Robert, Qamar, A.I., King, R.W., Wells, Ray, Khazaradze, Giorgi, Williams, C.A., Stevens, C.W., Vollick, J.J., and Zwick, P.C., 2007, Fault locking, block rotation and crustal deformation in the 
Pacific Northwest: Geophysical Journal International, v. 169, p. 1315-1340, doi:10.1111/j.1365246X.2007.03371.x.

McCaffrey, Robert, King, R.W., Payne, S.J., and Lancaster, Matthew, 2013, Active tectonics of northwestern US inferred from GPS-derived surface velocities: Journal of Geophysical Research, v. 118, doi:10.1029/2012JB009473.

McClusky, S.C., Bjornstad, S.C., Hager, B.H., King, R.W., Meade, B.J., Miller, M.M., Monastero, F.C., and Souter, B.J., 2001, Present day kinematics of the eastern California shear zone from a geodetically constrained block model: Geophysical Research Letters, v. 28, p. 3369-3372.

McKenzie, D.P., and Parker, R.L., 1967, The north Pacific-An example of tectonics on a sphere: Nature, v. 216, p. 1276-1280.

Meade, B.J., and Hager, B.H., 2005, Block models of crustal motion in southern California constrained by GPS measurements: Journal of Geophysical Research, v. 110, B03403, doi:10.1029/2004JB003209.

Murray, M.H., and Segall, Paul, 2001, Modeling broad scale deformation in northern California and Nevada from plate motions and elastic strain accumulation: Geophysical Research Letters, v. 28, p. 4315-4318.

Okada, Yoshimitsu, 1985, Surface deformation due to shear and tensile faults in a half-space: Bulletin of the Seismological Society of America, v. 75, p. 1135-1154.

Pollitz, F.F., Peltzer, Gilles, and Bürgmann, Roland, 2000, Mobility of continental mantle_Evidence from postseismic geodetic observation following the 1992 Landers earthquake: Journal of Geophysical Research, v. 105, p. 8035-8054.

Prawirodirdjo, L., Bocl, Y., McCaffrey, R., Genrich, J., Calais, E., Stevens, C., Puntodewo, S.S.O., Subarya, C., Rais, J., Zwick, P., and Fauzi, R.M., 1997, Geodetic observations of interseismic strain segmentation at the Sumatra subduction zone: Geophysical Research Letters, v. 24, p. 2601-2604. Reilinger, Robert, McClusky' Simon, Vernant' Philippe, Lawrence, Shawn, Ergintav, Semih, Cakmak, Rahsan, Ozener, Haluk, Kadirov, Fakhraddin, Guliev, Ibrahim, Stepanyan, Ruben, Nadariya, Merab, Hahubia, Galaktion, Mahmoud, Salah, Sakr, K., ArRajehi, Abdullah, Paradissis, Demitris, Al-Aydrus, A., Prilepin, Mikhail, Guseva, Tamara, Evren, Emre, Dmitrotsa, Andriy, Filikov, S.V., Gomez, Francisco, Al-Ghazzi, Riad, Karam, Gebran, 2006, GPS constraints on continental deformation in the Africa-Arabia-Eurasia continental collision zone and implications for the dynamics of plate interactions: Journal of Geophysical Research, v. 111, B05411, doi:10.1029/2005JB004051.

Savage, J.C., 1983, A dislocation model of strain accumulation and release at a subduction zone: Journal of Geophysical Research, v. 88, p. 4984-4996. 


\title{
Appendix C-Estimation of Fault Slip Rates in the Conterminous Western United States with Statistical and Kinematic Finite-Element Programs
}

\author{
By Peter Bird, Professor Emeritus ${ }^{1}$ \\ ${ }^{1}$ Department of Earth and Space Sciences, University of California, Los Angeles, Calif. \\ pbird@ess.ucla.edu, http://peterbird.name/
}

\section{Overview}

The estimated fault slip rates obtained from models NSHM-WUS_2013001 and NSHMWUS_2013002 (which are referred to as "the Bird fault-based model" in the accompanying report) were obtained through three sequential processing steps:

1. Statistical modeling of geologic offset-rates with program Slippery.

Direct evidence from dated offset features on each fault and (or) indirect evidence from dated offset features on other faults of the same type in the same tectonic province are combined to obtain the "pure-geologic" probability density function (PDF) for each component of offset-rate on each fault. Additional constraints such as geometric compatibility, plate tectonics, geodesy, and stress directions are not used in this phase of the study.

2. Joint geologic and geophysical inversion for offset rates with program NeoKinema.

The "pure-geologic" offset rates from the previous step (with their uncertainties) are combined and balanced against additional constraints from GPS geodesy, plate tectonics, geometric compatibility (such as, continuum stiffness), and principal stress directions. A kinematic finiteelement solution with program NeoKinema provides trace-averaged mean offset rates for each component of offset on each fault. A simple post-processing step combines these offset-rate components with the model-fault dips to obtain the model predictions for rake and slip-rate of each fault.

3. Manual adjustments to some slip-rates in California.

Following intensive review of model predictions by local geologic experts, some model predictions were adjusted to become (barely) consistent with additional information that had not been used in the previous modeling steps.

Each step is described further in a corresponding section of this appendix and most fully in the previously published papers cited below.

All programs (both source codes and executables), input datasets, output datasets, post-processed reports, and graphical map files associated with this work are available online at http://peterbird.name/oldFTP/NeoKinema/Orogens/WUS_for_UCERF3_and_NSHM2014/; readers are particularly invited to look into the folders named 3_graphics_files along each model branch.

\section{Statistical Modeling of Geologic Offset Rates with Program Slippery}

Bird (2007) presented definitions, assumptions, equations, and a computational algorithm for automated, objective assignment of probability density functions (PDFs) to the scalar, positive offsetrate components of any active fault. These methods were translated into Fortran 90 source code in program Slippery.f90 and compiled into executable Slippery.exe (for the Windows operating system). This program can be used to analyze a single fault but is more powerful when used to jointly (and 
iteratively) analyze all the active faults in a single tectonic province, such as California or the conterminous Western United States (WUS).

Omitting details and equations, the essential steps are as follows: Fault slip rate is separated into strike-slip $(R=$ right-lateral or $L=$ left-lateral $)$ components and dip-slip components. The dip-slip components can be expressed either by relative-vertical (throw) rates ( $N=$ normal or $T=$ thrust faults) or by trace-perpendicular relative-horizontal (trace-perpendicular heave) rates $(D=$ detachment for opening, or $P=$ thrust plate for convergence). The following combinations expressing oblique slip are permitted: $L N, L T, L D, L P, R N, R T, R D$, and $R P$; such combinations are analyzed as two independent processes, although they refer to the same fault. Then, each offset distance and its uncertainty (or inferred uncertainty, if not explicitly stated by the original author) is converted to a PDF for the amount of offset. Different functional forms are used for offset distances that are best estimates, minima, or maxima. Additional uncertainty is added to very small offsets to reflect possible changes in elastic strain around the fault (as a non-integer number of "seismic cycles," if such cycles even exist). Then, the age of the offset feature and its uncertainty (or inferred uncertainty) is converted into a PDF for the age. Different functional forms are used for ages that are best estimates, minima, or maxima. An empirical adjustment is applied to ages from ${ }^{14} \mathrm{C}$ or cosmogenic-nuclide methods, which may contain inheritance. Then, the PDFs for offset distance and age are convolved (using one of two alternate integral equations) to obtain the PDF for one component of offset rate on that one fault, based on a single offset feature.

If a fault has no dated offset features, it is assigned a "prior default" PDF, which is the composite of the rates of all the faults of the same tectonic style in the same province that did have data. For example, a normal fault with no dated offset feature is assigned $N=0.183 \mathrm{~mm} / \mathrm{yr}$, with standard deviation of $0.343 \mathrm{~mm} / \mathrm{yr}$ and 95 percent confidence lower and upper limits of 0 and $1.09 \mathrm{~mm} / \mathrm{yr}$, respectively. A thrust fault with no dated offset feature is assigned $T=0.228 \mathrm{~mm} / \mathrm{yr}$, with standard deviation of $0.691 \mathrm{~mm} / \mathrm{yr}$ and 95 percent confidence lower and upper limits of 0 and $2.41 \mathrm{~mm} / \mathrm{yr}$, respectively.

If the fault has one dated offset feature, then an elementary logic tree expresses the higher probability (ranging from 95 percent down to 50 percent) that the dated offset feature is relevant to neotectonics and correctly interpreted, and a complementary branch expresses the lesser probability (ranging from 5 percent up to 50 percent) that the dated offset feature is irrelevant or misinterpreted-in which case the prior default rate PDF should apply. These percentages were inferred empirically by bootstrap methods in Bird (2007) and depend on the age of the offset feature and the nature of the literature source (primary, secondary, or tertiary). Faults with more than one dated offset feature have more complex logic trees, expressing every possible permutation of relevant and correct and irrelevant and incorrect data.

Note that this method does not require knowledge of the dip of the fault. It is only later, when (or if) the dip-slip component of slip-rate is computed and combined with the strike-slip component in the Pythagorean theorem to obtain the total slip rate, that the dip angle must be chosen. Within program Slippery, dip-slip is represented by a throw rate $(N$ or $T)$ or a heave rate $(D$ or $P)$, whichever is most closely related to the original data from the field.

Another interesting aspect of the Slippery method is that it gives zero consideration to offset rates quoted by authorities. It only uses (and combines) the offset distances (and senses) and ages of offset features found in the literature. Thus, it ignores all "received opinion" and also serves as a check on the calculations of others. Also, I never combine an offset amount from one reference with an age from another reference, unless a published author explicitly states that this is appropriate.

This method was applied by Bird (2007) to two compilations of dated offset features: his table 1 refers to a personal compilation of data from the peer-reviewed literature in the conterminous WUS; his 
table 2 refers to a USGS compilation of Quaternary dated offset features for UCERF2 faults in California. Because of variations in fault names and traces between databases, it is not always possible to relate these old results to the faults in the current UCERF3 and NSHMP models; however, such comparisons are useful wherever possible.

For this project, I computed a new solution for all active faults in the conterminous WUS except those in California, in November 2012. For consistency, this new solution kept the prior default offsetrate PDFs for each fault type ( $L, R, N, T, D, P)$ as previously inferred by Bird (2007) for the conterminous WUS. However, the fault names are those of the modified 2008 NSHMP source model, and the table of offset distances and associated ages is new. Spreadsheet $f \_N S H M-W U S \_N o C A \_2012-$ complete_output.xls [in the file archive whose URL was given at the top of this appendix] gives these results, along with brief tabular summation of the input data and its sources. It is "complete" in two senses: it has at least a nominal entry for every Quaternary-active fault in the conterminous WUS (outside California), and it makes use of all the published accounts of dated offset features known to me at that time.

I used two primary sources of data on offsets and ages:

1. USGS Quaternary fault and fold database ("Qfaults"). I read the "Slip-rate category" section of each "Complete" report and also read the "Dip" and (or) "Age of faulted surficial deposits" sections if necessary to clarify ambiguities. I have referenced what I found as, for example, "USGS Q. Fault \& F. D., 2012: 829a, \#149” in which 2012 refers to the year in which I accessed the database, 829a is the fault or fault-segment number, and \#149 is the data source quoted within that "Complete" report page. I have not taken the time or space to copy names of the authors of Qfaults pages; interpretations of those writers (and data with no further citation, which is presumably their own) is merely attributed to "author(s)."

I should clarify here how I handled certain ambiguities in these reports: (a) Many Qfaults compilers writing about normal or thrust faults quoted "slip rates," even though the available data and context made it fairly clear that these were actually throw rates. I tended to assume that "throw rate" was meant for any $N$ - or $T$-sense data, unless a specific fault-dip angle was mentioned. (b) Certain Qfaults compilers writing about strike-slip faults, and lacking any along-strike offsets, have referred to scarp heights or other potential (although dubious) throw-rate indicators and may even have used them in "slip-rate" calculations. I have been careful not to enter these as offsets of type $R$ or $L$. (c) When no better age was available, I have sometimes accepted "Holocene," or "latest Quaternary," or "late Quaternary," or "middle Quaternary," or "early Quaternary," or "Pliocene," or "Miocene" as quantitative ages appropriate for measured offset features and assigned them the numerical age ranges found in the Qfaults Glossary. I also stretched these designations to include "latest/late/middle/early Pleistocene," even though these are arguably not quite the same. However, I have typically not accepted "Quaternary" without an epoch or other subdivision qualifier, because it is too generic and could be interpreted as simply identifying the rate that the author assigns as the best available estimate. I have occasionally referred to Wikipedia for ages of famous volcanic tuff (and/or tuffaceous sandstone) beds when these are not given in the Qfaults report.

\section{My own long-running summary of dated offset features in western North America.}

This dataset has sadly fallen out-of-date since its last refresh in 2008. However, it sometimes captures data that were published after the comparable Qfaults report page. (Many of these date from 1999.) Also, I sometimes include offsets of dated pre-Quaternary features not mentioned by the Qfaults compilers. (Program Slippery "discounts" such older features with an internal logic tree, which estimates the chance this older offset is relevant to neotectonics.) These data 
have short citations such as, "Stewart, 1998 (scarp height only)" or "Pezzopane and Weldon, 1993, QFFD: 829a, \#149." In the latter example, a note was added to show that this source was also read and referenced by the Qfaults compilers; however, I prefer to use my old notes from the original source and not substitute secondhand versions of the offsets and ages (by citing Qfaults instead).

All offset rates, rate limits, and standard deviations in the dataset are in units of millimeters per year $(\mathrm{mm} / \mathrm{yr})$. All are quoted to three significant digits to avoid unnecessary rounding, even though the original input data often had fewer significant digits.

In the spreadsheet, offset-rate estimates and limits for each dated offset feature can be found. However, the most useful products are the rows with "Reference" of "combined offset rate ( $n$ data)" and with "S" (for Slippery) in the Grade column. I have highlighted these in boldface.

This new analysis of pure-geologic offset rates for active faults (outside California) was provided on November 26, 2012, to the other deformation modelers in the NSHM2014 project and may have been used by some of them as prior constraints or geologic target rates.

\section{Joint Geologic and Geophysical Inversion for Offset Rates with Program NeoKinema}

NeoKinema is a kinematic finite-element (F-E) program; that is, it combines kinematic data from both geologic and geophysical sources to infer what the surface of the Earth is actually doing. (In contrast, most other F-E programs are dynamic F-E programs, which assume the physics and the material properties and the boundary conditions, and use these to predict what the Earth ought to be doing.)

The domain of a NeoKinema F-E grid is the 2-D spherical surface of the Earth. Thus, all nodes are on the surface, and all elements are spherical triangles on the surface. This surficial character of the grid permits a large number of surface nodes $(\approx 10,800)$ and many $(\approx 21,300)$ small F-Es, for good spatial resolution. NeoKinema does not use special fault elements; instead, any number of faults can cut through any triangular element adding to its compliance and its target strain rate. It is recommended that grids be edited manually (with interactive program OrbWin) to create narrow 2-km-wide "corridors" of elongated elements along most fast-slipping faults. However, where there are complex "nests" of slowmoving faults, or where there are no GPS data available (for example, offshore), such customized gridding is optional.

The primary time scale of a NeoKinema velocity solution is "long-term average" corresponding to a number of seismic cycles (if such cycles even exist) or many thousand years. This makes a good match with time-independent, Poissonian, quasi-stationary seismic hazard models like NSHM2014 and the time-independent version of UCERF3. However, most GPS data are collected in short interseismic periods, during which the shallow seismogenic parts of most active faults are temporarily locked. To permit such GPS data to be used as constraints, the program can "correct" any long-term-average velocity field to a short-term interseismic velocity field, or vice versa. This is done by summing the solutions for the expected coseismic displacements of the shallow, temporarily locked fault patches, using established dislocation-in-elastic-halfspace solutions. To allow this correction, the dips of active faults, their lower interseismic locking depths, and their interseismic character (creeping or locked?) must be specified as input data for each fault. The quality of this "correction" is initially very rough in any NeoKinema run, but it improves as the solution is iterated to self-consistency.

Within each iteration (out of 45) in a NeoKinema solution, the horizontal components of the long-term-average velocities of the nodes are computed by maximization of an objective function, which has a weighted-least-squares character. The objective function of NeoKinema is a nondimensional functional of both dimensional model predictions $(p)$ and corresponding dimensional 
data values $(r)$, normalized by dimensional covariance matrix $(\tilde{C})$ or by individual datum standard deviations $(\sigma)$ :

$$
\Pi \equiv-(\vec{p}-\vec{r})^{\mathrm{T}}\left[\tilde{C}_{\mathrm{GPS}}^{-1}\right](\vec{p}-\vec{r})-\frac{1}{L_{0}} \sum_{m=1}^{M} \int_{\text {length }} \frac{\left(p_{m}-r_{m}\right)^{2}}{\sigma_{m}^{2}} \mathrm{~d} \ell-\frac{1}{A_{0}} \sum_{n=1}^{3} \iint_{\text {area }} \frac{\left(p_{n}-r_{n}\right)^{2}}{\sigma_{n}^{2}} \mathrm{~d} a
$$

where the first term is a quadratic form involving the great vector of all geodetic velocity components and its covariance matrix $\tilde{C}_{\mathrm{GPS}}$, the second term concerns $M$ the long-term fault offset-rates $r_{m}$ with their uncertainties $\sigma_{m}$, and the third term concerns the constraints on sizes and orientations of distributed permanent deformation-rate tensors (in 2-D, with three independent components) between the mapped faults. Note that this objective function gives a result that is independent of the sizes of the finite elements into which the length and area integrals are subdivided.

This objective function includes two "tuning" parameters: (1) trace length for unit weight of long-term offset-rate data, $L_{0}$ and (2) area receiving unit weight in continuum stiffness and isotropy constraints, $A_{0}$. (Both are relative to constant unit weight of point-based geodetic data.) Adjustment of these two values controls the relative quality of the fits to geodetic data (best fit with large $L_{0}$ and large $A_{0}$ ), geologic data (best fit with small $L_{0}$ and large $A_{0}$ ), and continuum constraints (including both minimization of strain-rate and orientation of strain-rate; best fit with large $L_{0}$ and small $A_{0}$ ).

The quality of any particular model is described by three dimensionless misfit measures, each of which is a root-mean-square norm $\left(N_{2}\right)$ of a vector of nondimensionalized misfits to data:

$$
N_{2}^{\text {geodetic }} \equiv \sqrt{\frac{1}{2 B} \sum_{b=1}^{B}\left(\vec{p}_{b}-\vec{r}_{b}\right)^{\mathrm{T}}\left[\tilde{C}_{b}^{-1}\right]\left(\vec{p}_{b}-\vec{r}_{b}\right)}
$$

where $B$ is the number of geodetic benchmarks, and this error measure at each benchmark involves only the local $(2 \times 2)$ covariance of its 2 horizontal components $\tilde{C}_{b}$; and

$$
N_{2}^{\text {stress }} \equiv \sqrt{\frac{1}{\sum a_{i}} \sum_{i=1}^{\text {elements }} a_{i}\left(\frac{p_{i}-r_{i}}{\sigma_{i}}\right)^{2}}
$$

where the $a_{i}$ are the areas of the finite elements, and the predictions and data are both transformed versions of the azimuth of the most-compressive principal horizontal-strain rate. One important objective in modeling is to bring these measures below about 2 and as close as possible to 1. (Fits with $N_{2}<1$ could be considered overconstrained; there would be some risk of fitting the high-frequency noise in the data as well as its useful low-frequency signals.)

In previous projects we used a parallel measure of the misfit to long-term geologic offset rates, weighted only by trace-lengths (and inversely by datum variances). However, this measure gave potentially misleading results by suggesting a better fit than had actually been achieved. This is due to the very nonuniform populations of fault-offset rates. Somewhat like earthquake moments in a seismic catalog, they span 4.6 orders of magnitude $(0.001-40 \mathrm{~mm} / \mathrm{yr}$, in this project). Also like earthquakes, the small rates are far more numerous than the large rates, which occur on only a few first-order fault trains (San Andreas, Mendocino, and so forth). Finally, there is a tendency for many datum standard deviations to be the same order of magnitude as the rate (at least for relatively well-constrained rates). A 
weighted-least-squares algorithm like NeoKinema will always fit those data best that have the smallest standard deviations. So, NeoKinema routinely matches with great precision all of those slow offset rates that also have small standard deviations. An inappropriate misfit measure can make this look like a successful fit to all offset rates, when in fact the fit to the rates of first-order faults may be unacceptable. After some experimentation, I programmed a better misfit measure in which, prior to the $N_{2}$ (RMS) norm operation, the dimensionless misfits are each weighted by the seismic potency rate of their associated fault. (Seismic potency rate is the product of seismogenic fault area and slip rate.) For stability of this measure, I use the greater of the model or datum slip-rate to determine this relative weight within the misfit measure. This new misfit measure is called the "potency" misfit:

$$
N_{2}^{\text {potency }} \equiv \sqrt{\frac{1}{\sum \sum \ell_{i m} w_{m} h_{i m}^{\text {sup }}} \sum_{i=1}^{\text {elements }} \sum_{m=1}^{M} \ell_{i m} w_{m} h_{i m}^{\text {sup }}\left(\frac{p_{i m}-r_{m}}{\sigma_{m}}\right)^{2}}
$$

where $\ell_{i m}$ is the trace-length of fault $m$ in element $i, w_{m}$ is the down-dip width of the seismogenic portion of fault $m$, and $h_{i m}^{\text {sup }}$ is the greater of the model heave-rate or datum heave-rate. In practice, I find that criterion $N_{2}^{\text {geologic }}<2$ implies a reasonably good fit to offset rates on first-order faults as well as minor faults.

The most detailed reference on the equations behind NeoKinema is the technical appendix Supplemental Material S1 (sm001.pdf) of Liu and Bird (2008), which is also available from the file set of this project under filename Appendix-Algorithm_of_NeoKinema.pdf. It gives all fundamental equations in matrix form and in spherical coordinates. More qualitative descriptions, with applications to specific active orogens, can be found in Bird and Liu (2007: California), Liu and Bird (2008: Asia), Bird (2009: WUS), Howe and Bird (2010: Europe), and Rucker (2008, 2009: Philippines).

For this project, NeoKinema was upgraded to version 3.0 (as of December 06, 2012) with the addition of important new features. First, dips of faults are no longer limited to preprogrammed values based on tectonic style but can (optionally) be read from the fault-trace input dataset. Second, lower and upper limits can be placed on each offset-rate of each active fault (if desired). Specifically, imposing a lower limit of zero (or higher) on each offset rate will prevent rake-reversals in which the model fault slips in the wrong direction. Additional changes included improvements in memory usage, iteration strategy, and error-capture checks. Full details about NeoKinema version history can be found within comment lines in the source code file, NeoKinema.f90.txt.

The model domain of the current models was bounded on the east by the meridian $103^{\circ} \mathrm{W}$. It was bounded on the west by the continental rise at the outer edge of the California borderland or by the Cascadia trench. (Note that these models do not actually include the Cascadia subduction zone fault.) On the north, the grid extended to $50^{\circ} \mathrm{N}$., or $1^{\circ}$ into Canada. On the south, the grid extended a comparable distance into Mexico.

The eastern part of the north grid boundary (opposite Idaho, Montana, and North Dakota) was fixed to the stable North America plate (NA of Bird, 2003). The west grid boundary, in latitudes south of the Mendocino fracture zone, was fixed to the Pacific plate (PA of Bird, 2003). Relative rotation PANA was taken from the Euler pole of Gonzalez-Garcia and others (2003) (lat $49.890^{\circ}$ S., long $102.989^{\circ} \mathrm{E} ., 0.7660^{\circ} \mathrm{m}$.y.), which Bird (2009) determined to be the best available description of the motion of the easternmost parts of the Pacific plate. Other boundaries were left nominally free (but in practice were constrained by adjacent GPS velocities just inside the model domain).

Input datasets used to produce the current models included the following: 
Fault traces, dips, and predominant rakes inside California were from UCERF3 Fault Model 3.1 (in model NSHM-WUS_2013001) or 3.2 (in model NSHM-WUS_2013002), edited by Timothy Dawson of the California Geological Survey (CGS). However, some vertical or near-vertical dips in these datasets were not used if the corresponding rake indicated dip-slip motion; instead, these dips were allowed to default to NeoKinema's internal expectations of $20^{\circ}$ for thrusts and $55^{\circ}$ for normal faults.

Fault traces, dips, and predominant rakes outside California were from the modified 2008 NSHMP source model (Haller and Wheeler, 2008a,b) updated by Kathy Haller of USGS.

Geologic target offset rates (with standard deviations, lower limits, and upper limits) for faults outside California were from the analysis reported in Statistical Modeling of Geologic Offset Rates with Program Slippery section of this appendix.

Geologic target offset rates (and standard deviations) for faults in California were either based on the UCERF3 table of Quaternary offset features edited by Timothy Dawson of CGS (for faults with at least one offset feature) or were default prior rates and uncertainties from the program-Slippery analysis of the WUS by Bird (2007). Lower and upper limits on offset rates of faults in California were taken from the UCERF3 Geologic Deformation Model of Timothy Dawson and Raymond Weldon in cases where (1) their limits were similar to those of Bird (2007), (2) their limits were broader than those of Bird (2007), or (3) their limits were based on geologic data not considered by Bird (2007). However, in cases where their limits were substantially narrower than the limits of Bird (2007), and no new data had been added, the broader limits of Bird (2007) were applied. Furthermore, any fault that was known to have oblique slip, but which lacked a geologic constraint on one component (strike-slip or dip-slip) was modeled with no upper limit on its slip rate.

Horizontal velocities of GPS benchmarks, with their uncertainty ellipses, were taken from the NSHM2014 compilation by Robert McCaffrey. Specifically, I used his adjusted model wus5_omeS that had been corrected by subtracting velocity components that are due to elastic strain from temporary locking of the Cascadia subduction zone thrust fault and adding some additional uncertainty to account for the error implicit in this correction. (This is necessary for internal consistency because the NeoKinema model domain does not include the Cascadia thrust.) By an iterative process, I removed from this dataset all benchmarks that fell into the same finite element as a fast-slipping $(>1 \mathrm{~mm} / \mathrm{yr})$ fault; this is necessary to prevent model artifacts that would otherwise result from the limited spatial resolution of my F-E grids.

Azimuths of most compressive horizontal principal stresses were obtained from quality-A and quality-B data in the World Stress Map 2008 dataset of Heidbach and others (2008). Most of these are from focal mechanisms of shallow earthquakes, but in certain districts there also are data from wellbore breakouts and (or) hydrofracture experiments and (or) overcoring.

Each NeoKinema calculation was performed on a 32-bit, 3-GHz, Windows XP Pro computer with 1.5 GB of memory, requiring about 3 hours. (Larger or finer grids will require more memory and thus will also require a 64-bit operating system.)

After some systematic experimentation (8 models), the NeoKinema tuning parameters were set to $L_{0}=2 \times 10^{4} \mathrm{~m}$ and $A_{0}=2 \times 10^{8} \mathrm{~m}^{2}$. That is, the geologic rate on each $20-\mathrm{km}$ length of fault has the same weight as the velocity of a single geodetic benchmark, and the continuum-stiffness and stressdirection constraints for each $\left(14.1 \mathrm{~km}^{2}\right)$ patch of ground have the same weight as the velocity of a single geodetic benchmark. These values serve to balance the fit to the different classes of data without overfitting any of them. The RMS continuum deformation rate was set to the value of $\mu=5 \times 10^{-16} / \mathrm{s}$, which was previously determined optimal by Bird (2009). 
The overall performance of the two final preferred models is shown by their residual $N_{2}$ misfits (where lower numbers are better, values near 1 are ideal, and values over 1 indicate some misfit exceeding that expected from aleatory uncertainties in the measurements; table C-1):

Table C-1. Residual $N_{2}$ misfits for final preferred models.

[NSHM, national seismic hazard map; WUS, Western United States]

\begin{tabular}{lcc}
\hline \multicolumn{1}{c}{$N_{2}$ type } & NSHM-WUS_2013001 & NSHM-WUS_2013002 \\
\hline Continuum & 1.356 & 1.383 \\
Stress & 2.564 & 2.448 \\
Offset rate & 0.932 & 0.905 \\
Potency rate & 1.621 & 1.587 \\
Geodetic & 2.295 & 2.292 \\
\hline
\end{tabular}

\section{Manual Adjustments to Some Slip Rates in California}

The UCERF3 review process examined the predictions of these (and other) deformation models for fault slip rates in California at a series of four "fault-by-fault" review sessions in January-February 2013, in Menlo Park and Pasadena, California. The workshops were attended by numerous expert tectonic geologists who were able to provide reactions and input based on both the peer-reviewed published literature and the nonreviewed "gray literature" of USGS NEHRP Final Technical Reports, consulting reports, and unpublished work. In some cases, it became clear that certain fault traces in the UCERF3 Fault Models 3.1 and 3.2 were incomplete or incorrect, or that additional geologic offset-rate constraints existed that had not been collected into Timothy Dawson's UCERF3 database (or into my earlier 2007 compilation). In cases where I decided that their input (if received earlier) would have altered my input datasets and thus my model results, I agreed to make manual adjustments to certain fault slip rates to bring them within the bounds suggested by this new information.

The decision to make manual adjustments, rather than revise and recompute the models, was based on firm and imminent deadlines in the UCERF3 and NSHM2014 processes. Any recomputation would have resulted in small changes to the model slip rates of many surrounding faults (which had already passed review), requiring a lengthy and tedious re-review and perhaps further iterations.

Manual adjustment of any fault slip rate, following a NeoKinema solution, creates incompatibilities in the solution if the long-term (non-elastic) continuum strain rates of neighboring finite-elements are not adjusted to compensate. Usually, this is impossible or impractical to do without a full recomputation. However, by this time we were aware that the UCERF3 leadership had decided to assign zero weight to the logic tree branch "Deformation Model Based" at the "Off-Fault Spatial Seis PDF" node. Therefore, these local inconsistencies had no effect on UCERF3 predictions of seismicity or seismic hazard in California and were allowed to persist in these models.

A complete list of manual adjustments, with rationales and supporting references, may be found in file manual_adjustments_20130223.doc. This list also may be incorporated into the NeoKinema section of appendix C: Deformation Models of the UCERF3 time-independent model report (Parsons and others, 2013). 
No manual adjustments were made to slip rates of any faults in the other conterminous WUS, outside of California.

The final model slip rates of all faults are contained in files

NSHM-WUS_2013001_rake_and_sliprate_per_fault.xls and

NSHM-WUS_2013002_rake_and_sliprate_per_fault.xls, where (as explained previously) model 2013001 used UCERF3 Fault Model 3.1 in California, and model 2013002 used UCERF3 Fault Model 3.2 in California. Except at points very close to the California border, these two models are almost identical in the other conterminous Western States. These same files also contain columns with model predictions of rake and with subdivision of each slip rate into two of its three vector-component rates (Dextral and Opening).

\section{References Cited}

Bird, Peter, 2003, An updated digital model of plate boundaries: Geochemistry, Geophysics, Geosystems, v. 4, no. 3, 1027, doi:10.1029/2001GC000252.

Bird, Peter, 2007, Uncertainties in long-term geologic offset rates of faults-General principles illustrated with data from California and other Western States: Geosphere, v. 3, no. 6, p. 577-595, doi:10.1130/GES00127.1, 9 digital file appendixes.

Bird, Peter, 2009, Long-term fault slip rates, distributed deformation rates, and forecast of seismicity in the Western United States from fitting of community geologic, geodetic, and stress direction datasets: Journal of Geophysical Research, v. 114, B11403, doi: 10.1029/2009JB006317.

Bird, Peter, and Liu, Zhen, 2007, Seismic hazard inferred from tectonics - California, in Hough, S.E., and Olsen, K.B., eds., Regional earthquake likelihood models: Seismological Research Letters, v. 78, p. 37-48.

Gonzalez-Garcia, J.J., Prawirodirdjo, L., Bock, Y., and Agnew, D., 2003, Guadalupe Island, Mexico as a new constraint for Pacific plate motion: Geophysical Research Letters, v. 30, no. 16, 1872, doi: 10.1029/2003GL017732.

Haller, K.M., and Wheeler, R.L., 2008a, Parameter for faults in the Intermountain West, in Peterson, M.D., Frankel, A.D., Harmsen, S.C., Mueller, C.S., Haller, K.M., Wheeler, R.L., Wesson, R.L., Zeng, Yuehua, Boyd, O.S., Perkins D.M., Luco, Nico, Field, E.H., Wills, C.J., and Rukstales, K.S., Documentation for the 2008 update of the national seismic hazard maps: U.S. Geological Survey Open-File Report 2008-1128, p. G-1-G-18.

Haller, K.M., and Wheeler, R.L., 2008b, Parameter for faults in the Pacific Northwest, in Peterson, M.D., Frankel, A.D., Harmsen, S.C., Mueller, C.S., Haller, K.M., Wheeler, R.L., Wesson, R.L., Zeng, Yuehua, Boyd, O.S., Perkins D.M., Luco, Nico, Field, E.H., Wills, C.J., and Rukstales, K.S., Documentation for the 2008 update of the national seismic hazard maps: U.S. Geological Survey Open-File Report 2008-1128, p. H-1-H-6.

Heidbach, O., Tingay, M., Barth, A., Reinecker, J., Kurfeß, D., and Müller, B., 2008, The World stress map database release 2008, http://dc-app3-14.gfz-potsdam.de/pub/stress_maps/stress_maps.html, doi:10.1594/GFZ.WSM.Rel2008.

Howe, T.M., and Bird, Peter, 2010, Exploratory models of long-term crustal flow and resulting seismicity across the Alpine-Aegean orogeny: Tectonics, v. 29, TC4023, doi:10.1029/2009TC002565.

Liu, Zhen, and Bird, Peter, 2008, Kinematic modeling of neotectonics in the Persia-Tibet-Burma orogeny: Geophysical Journal International, v. 172, no. 2, p. 779-797, 3 digital appendixes, doi:10.1111/j.1365-246X.2007.03640.x.

Parsons, Tom, Johnson, K.M., Bird, Peter, Bormann, Jayne, Dawson, T.E., Field, E.H., Hammond, W.C., Herring, T.A., McCaffrey, Rob, Shen, Z.-K., Thatcher, W.R., Weldon, R.J., II, and Zeng, 
Yuehua, 2013, Appendix C-Deformation models for UCERF3: U.S. Geological Survey Open-File Report 2013-1165, 66 p.

Rucker, W.K., 2008, Neotectonic kinematic analysis of Philippines orogeny-Regional strain-rates and a forecast of long-term seismicity [abs]: Eos Transactions AGU, Fall Meeting Supplement, v. 89, no. 53, T53D-1992.

Rucker, W.K., 2009, Neotectonic kinematic analysis of the Philippines orogeny-Regional strain-rates and a forecast of long-term seismicity: Los Angeles, University of California, M.S. thesis, 56 p. 


\section{Appendix D-A Fault-Based Model for Crustal Deformation in the Western United States}

Yuehua Zeng ${ }^{1}$ and Zhengkang Shen ${ }^{2}$

${ }^{1}$ U.S. Geological Survey, Golden, Colo.

${ }^{2}$ University of California, Los Angeles

Introduction

The national seismic hazard maps (NSHMP maps) are constructed principally using three types of data that constrain the rate of activity on faults: instrumental seismicity data, paleoseismic observations on past earthquake occurrence, and geodetic constraints on fault slip rates and strainaccumulation rates (Petersen and others, 2008). Although the first and second datasets constrain the rate, style, and location of past earthquake activity, the third dataset constrains crustal deformation that may potentially lead to future earthquakes.

Geodetic data have been collected over the past several decades, and the consensus from the seismological and geodetic communities are that the NSHMP models should incorporate those data. In previous NSHMP models, slip rates were assigned based on an expert evaluation of available geologic and geodetic data constrained by the total plate-rate budget. This report describes development of the crustal deformation model for the Western United States (WUS) using a kinematic fault model of Zeng and Shen (2014) to determine fault slip rate in the region based on inversions of GPS observation with geological slip-rate constraints. The model consists of six major blocks with distributed faults throughout the WUS. Faults and block boundaries are represented as buried dislocations in a homogeneous elastic half-space. Each fault segment slips at a solved-for slip rate beneath a locking depth, except at a few fault segments where shallow creep is allowed. Slip vector continuity at fault nodes or intersections imposed to regulate slip variability and to simulate block-like motion. The slip distribution is estimated using a least-squares inversion. The locking depth is fixed to the values specified by the modified 2008 NSHMP fault-source model (Haller and Wheeler, 2008a,b).

Two separate models are developed for WUS: a block-like model and a fault-based model. However, in this report, we will focus on our fault-based model to provide slip-rate estimates on WUS faults based on inversion of GPS velocities with geologic slip-rate constraints. In many places, geologic slip rates provide critical constraints on slip-rate solution given the surface GPS data could not resolve slip rates on closely spaced faults. This fault-based model also provides gridded off-fault strain rates to compare with other seismic hazard inputs, that is, regional seismicity, regional strain mechanisms as determined from earthquake focal mechanisms, and earthquake moment budget from other studies.

Method

Zeng and Shen (2014) developed a kinematic fault-network model that simulates geodetic surface-deformation rates from a given distribution of slip rates across all the faults in the region. For a given slip-rate and creep-rate distribution on faults, the ground-velocity vector at any point is obtained by taking a spatial convolution of the static point source Green's function with the slip-rate functions over the faults:

$$
\dot{u}_{n}\left(\boldsymbol{r}_{i}\right)=\sum_{j=1}^{N}\left(\mathrm{U}_{n j}^{1} \Delta \dot{u}_{1}^{j}+\mathrm{U}_{n j}^{2} \Delta \dot{u}_{2}^{j}\right)+\sum_{k=1}^{M}\left(\mathrm{U}_{\text {creep }, n k}^{1} \Delta c_{1}^{k}+\mathrm{U}_{\text {creep, } n k}^{2} \Delta c_{2}^{k}\right)
$$


where $\dot{u}_{n}$ is the predicted surface velocities, and $\mathrm{n}$ is the component of the velocity. Here we only consider the two horizontal components, $\boldsymbol{r}_{i}$ is the location of the $i$-th station, $\Delta \dot{u}_{1}^{j}$ and $\Delta \dot{u}_{2}^{j}$ are the faultparallel and fault-normal slip rate along the $j$-th fault segment, respectively. $\mathrm{U}_{n j}^{1}$ and $\mathrm{U}_{n j}^{2}$ are the Green's function relating those fault slip rates to velocities at the $i$-th station, $\Delta c_{1}^{k}$ and $\Delta c_{2}^{k}$ are the fault-parallel and fault-normal creep rate along the $k$-th fault segment, respectively, and $\mathrm{U}_{\text {creep,nk }}^{1}$ and $\mathrm{U}_{\text {creep,nk }}^{2}$ are the Green's function relating the fault-creep rates at shallow depth to velocities at the $i$-th station. $N$ is the total number of fault segments, and $M$ is the total number of creeping fault segments.

Our kinematic fault model assumes that each fault segment slips at a certain rate beneath a locking depth except at a few fault segments where shallow creep is allowed. We also impose slipvector continuity at fault nodes or intersections to regulate slip variability and to simulate block-like motion. In addition, we minimize slip rates along the fault-normal direction to reduce fault opening or penetration between vertical strike-slip faults. Together with equation (1), they form the basis for solving for the slip distribution using a least-squares inversion. We use Okada's (1992) formulation and code to calculate the surface deformation in an elastic half space.

\section{GPS Data}

The GPS data used for this study were collected from several field networks and reprocessed by several groups. They include PNW (McCaffrey and others, 2013), PANGA 2012.03.05, PBO 2011.08.01, SOPAC 2012.07.06, CMM4 (Shen and others, 2011), UNR (Hammond and others, 2011), and SHEN (Shen and others, 2012). Data were rotated to a common-reference frame defined by the North American block by McCaffrey (appendix A). We have made additional editing after McCaffrey's rotation. This editing was based on visual inspection of the velocities on their consistency with neighbors if they are not near faults. For any velocity vector at a given site that differs significantly from its neighbors in amplitude or azimuthal direction, we remove it from the dataset. We did not use any model to discriminate any data during our edits to avoid these edits being model dependent. There are reported uncertainties in the velocity field that are as small as $0.03 \mathrm{~mm} / \mathrm{yr}$. Our test inversions find that these extremely small uncertainties can overweight these observations, so a lower cutoff of $0.3 \mathrm{~mm} / \mathrm{yr}$ was used to avoid excessively over-weighting during the inversions. We followed Bob Smith's (University of Utah) recommendation and removed campaign GPS observations near Wasatch from the dataset due to potential large biases in the campaign. We also removed data with sigma larger than 2.5 $\mathrm{mm} / \mathrm{yr}$. Figures D- $1 A$ and D- $1 B$ compare the GPS vector before and after these edits. 

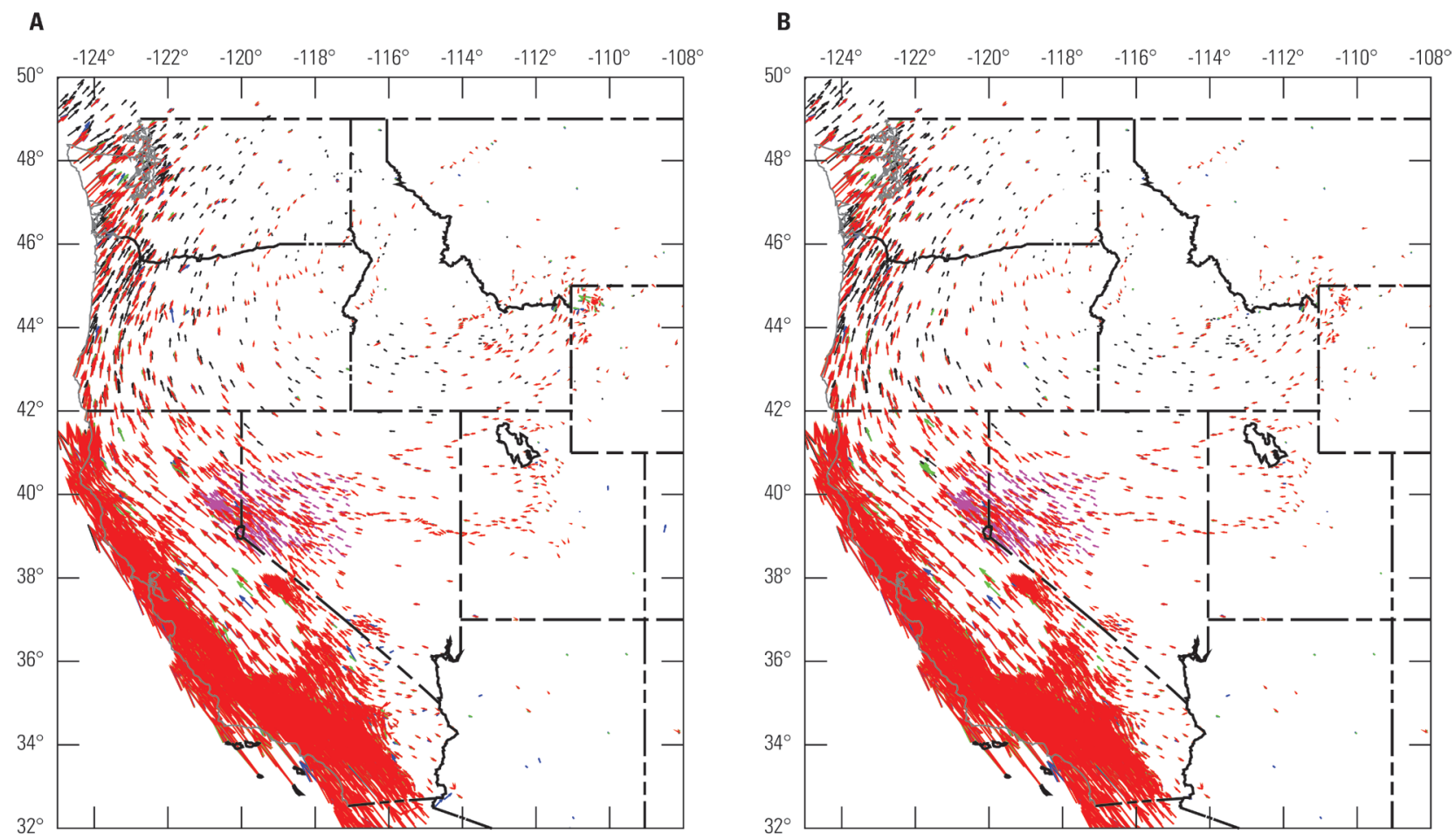

Figure D-1. Maps of global positioning system (GPS) velocity field in the Western United States. A, Original data and $B$, final velocity field after removal of velocity vectors that are inconsistent with neighboring vectors.

\section{Geologic Data}

The source of geologic slip rates for California is the UCERF3 fault model (Dawson and Weldon, 2013). This compilation does not include slip rates that rely on assumptions of characteristic slip, are heavily model dependent (such as using assumptions of horizontal to vertical slip to derive horizontal slip rates from amounts of vertical offset), or slip rates that are in need of revision due to revised dating at a site. Rates that are suspect, because they may be derived from features offset by a limited number of earthquakes that may not represent a long-term average, are also excluded. A single representative slip rate or averaged slip rate is reported for any location. It also includes selected entries from an extensive database of slip rates (including long-term rates) Peter Bird (see appendix B, this report) has compiled based on the same criteria described above. For faults in California, we use either the preferred rates or averages of the minimum and maximum values as our geologic constraints with their corresponding uncertainties (fig. $2 A$ ). 
A

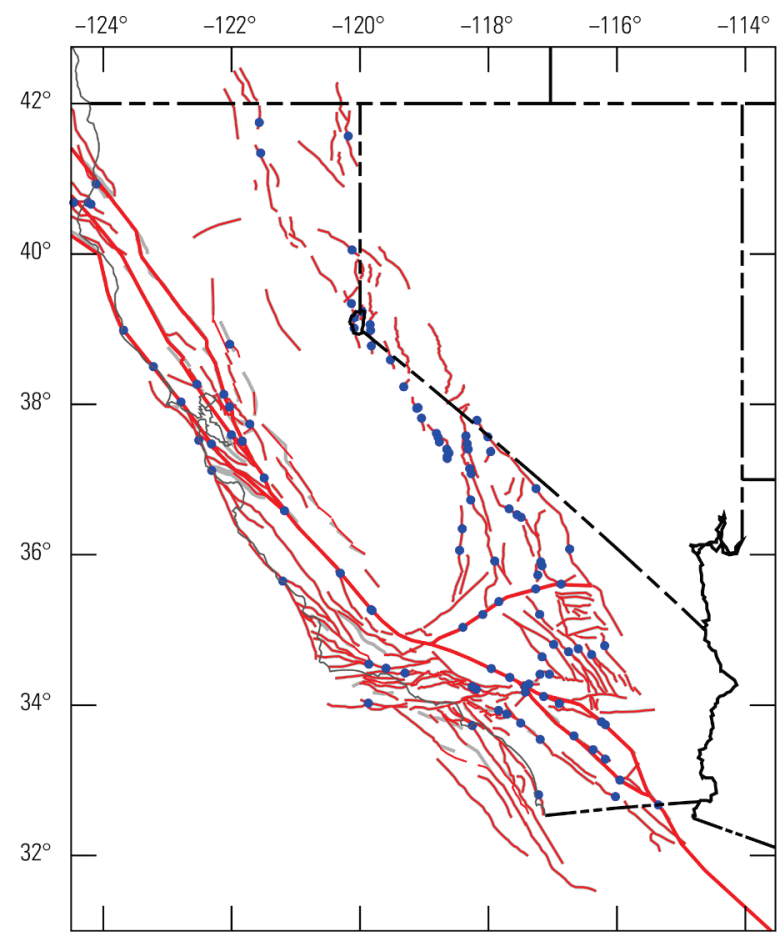

B

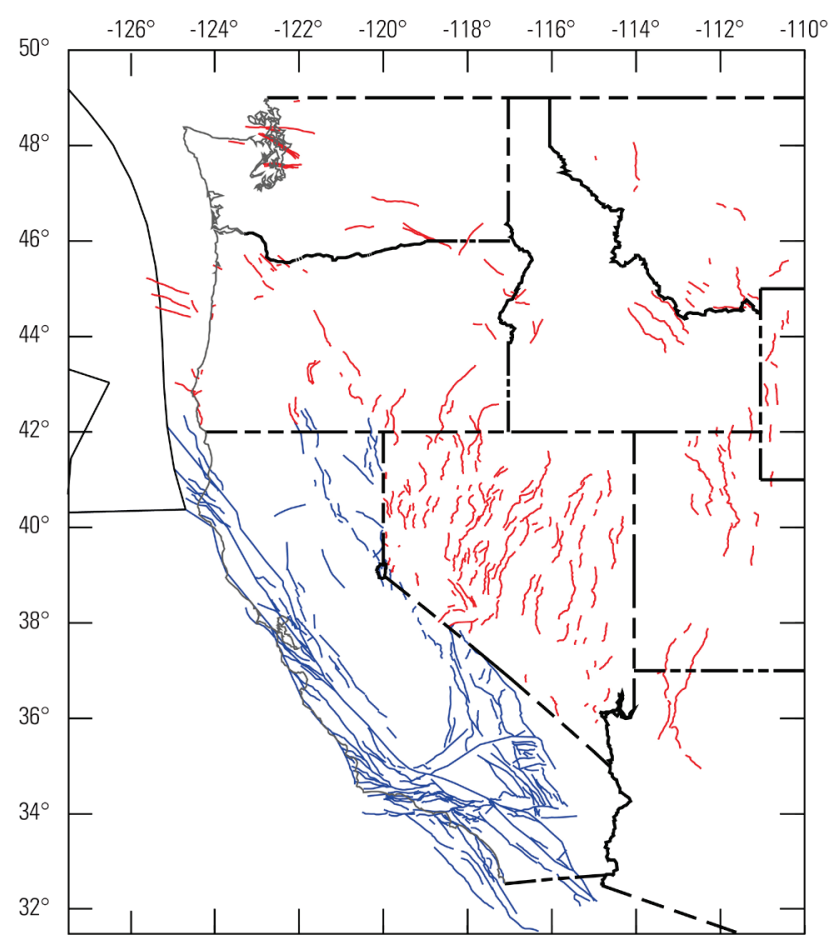

Figure D-2. A, Map of the geologic sites (blue solid circles) used for constraining the model inversion in California. Red lines are the block boundaries and gray lines are UCERF3 (Uniform California Earthquake Rupture Forecast, version 3) fault traces. B, Map of the modified 2008 sources in the Western United States (WUS) (red lines) whose slip rates were used for constraining the model inversion for the rest of WUS.

For the rest of WUS faults, we used slip rates for the 2008 NSHMP source model, with modification, to constrain our model inversion (Haller and Wheeler, 2008a,b). Rakes are used as input constraints for B-type faults in California (see definition in Petersen and others, 1996) and the rest of WUS faults outside California during our least-square inversion. For California, rakes are allowed to vary within \pm 20 degrees of the input values for the reverse/normal and strike-slip faults and \pm 30 degrees for the oblique faults. For faults outside California, rakes are allowed to vary within \pm 40 degrees for all faults.

\section{Fault Model}

Figure D-3 shows our fault-based model for the WUS. Our model divides the region into six major blocks: the Pacific block (blue), North American block (gray), Cascadia block (cyan), San Jacinto block (brown), Hayward-Maacama block (yellow), and Bartlett Springs-Green Valley block (purple). Those blocks are bounded mostly by California A-type faults (see definition in Petersen and others, 1996) with slip-vector continuity at fault nodes or intersections imposed to regulate slip variability and to simulate block-like motion for all the block boundary faults. The Garlock fault is prescribed as a buried fault with its west end cutting through the east wall of the San Andreas Fault. For all other nonblock boundary faults distributed throughout the WUS region, we modeled them as buried dislocation sources (Savage and Burford, 1973). Faults and block boundaries are represented as buried dislocations in a homogeneous elastic half-space except the Cascadia subduction zone. Each fault 
segment slips at a solved-for slip rate beneath a locking depth, except at a few fault segments where shallow creep is allowed (such as along the central California creeping segment, Calaveras fault, Hayward fault, Imperial Valley fault, Brawley seismic zone). We also allow partial locking for the northern Parkfield and southern Santa Cruz Mountain segments of the San Andreas Fault. For the California A-type faults, fault-locking depth is determined based on seismicity depth distribution along faults available in the literature (for example, Hill and others, 1990; Hauksson, 2000). For the rest, faultlocking depth is fixed to the values specified by the UCERF3 and 2008 NSHMP fault-source model.

The Cascadia subduction is modeled using a conventional back-slip model. In this model, we use the same Cascadia subduction-zone geometry as applied in the 2008 and 2002 USGS NSHMP maps. The 2008 NSHMP maps incorporated the thermal models of Flück and others (1997) that define the down-dip transition zone. The bottom of this transition zone (Petersen and others, 2008) is used to define our subduction locking depth, and the surficial expression of the trench is used to define the boundary between the Cascadia and the North American blocks. We divided the entire subduction zone into 17 down-dip slabs. Assuming depth-independent rates, we invert for the in-plane back-slip rates for each slab with a continuity constraint imposed on the back-slip rates between adjacent slabs. This simple depth-independent slip-rate model appears to produce a reasonable fit to the horizontal observations. Further refinement of the model with depth-dependent rates is necessary if vertical geodetic observations are to be incorporated. 


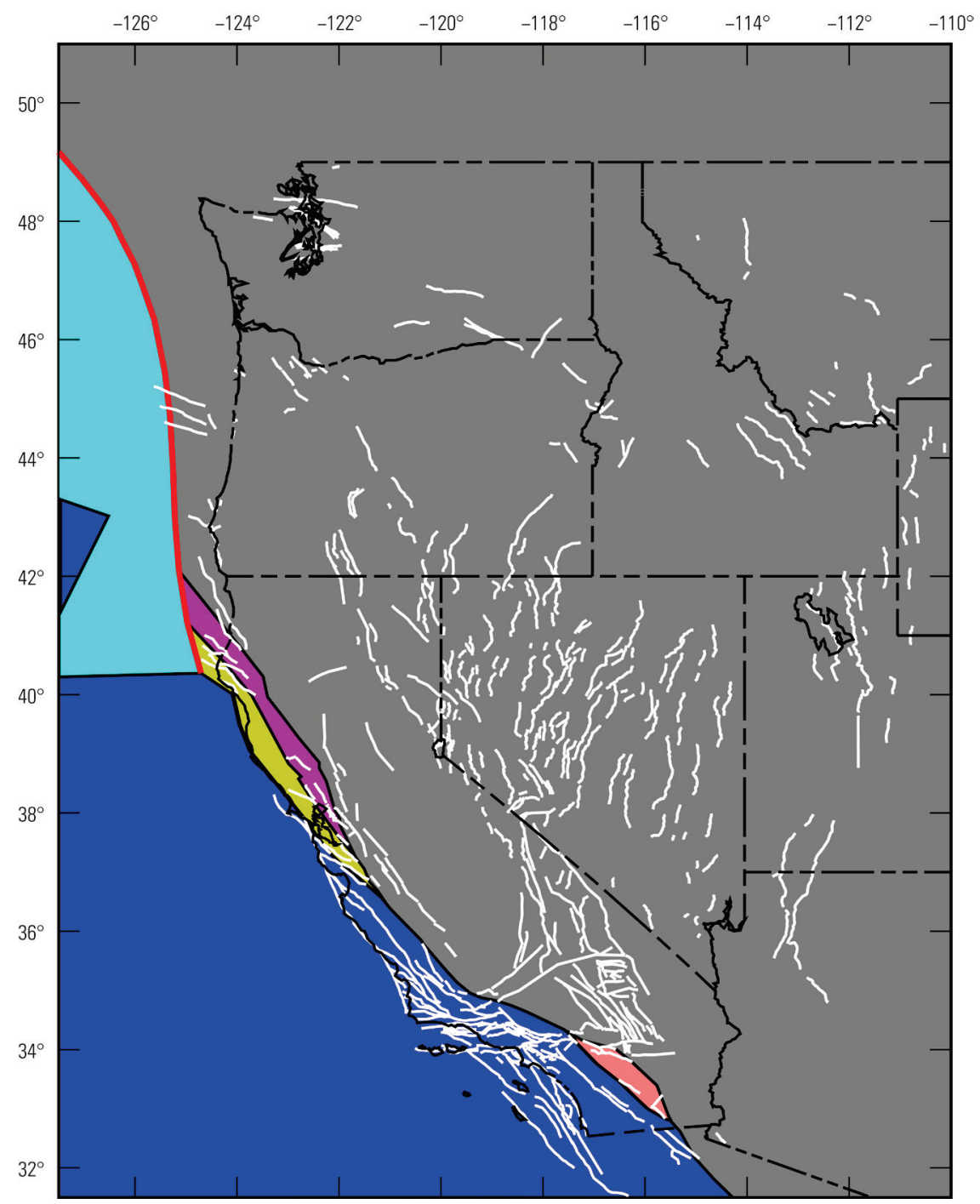

Figure D-3. Map of major blocks: Pacific block (blue), North American block (gray), Cascadia block (cyan), San Jacinto block (pink), Hayward-Maacama block (yellow), and Bartlett Springs-Green Valley block (purple). White lines represent the distributed faults in the Western United States.

\section{Model Results}

We compute inverse solutions for the fault-based deformation model and use the same weighting parameters for the slip-rate vector-continuity constraints across fault node points and for minimizing slip rate along the fault-normal component following Zeng and Shen (2014). In addition to the geologic constraints on slip rates at locations where geologic estimates are available, we also imposed a 50$\mathrm{mm} / \mathrm{yr}$ rate at the southern and northern ends of the San Andreas Fault. Figure D- $4 A$ compares observed GPS velocities (blue) with the predicted GPS velocities based on the fault-based-model calculation. 
A

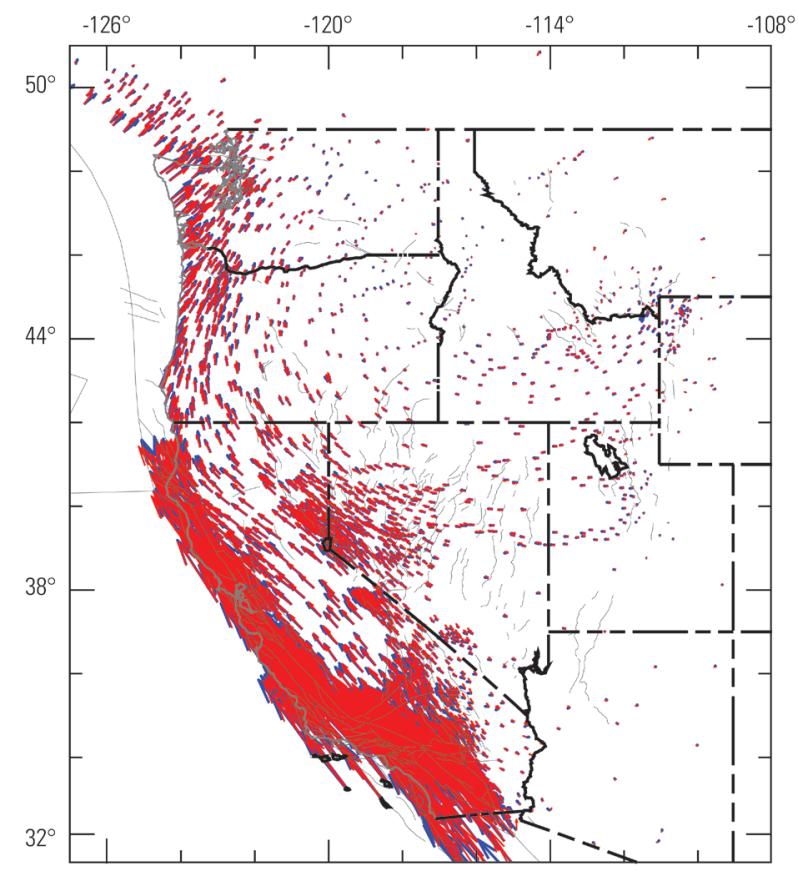

B

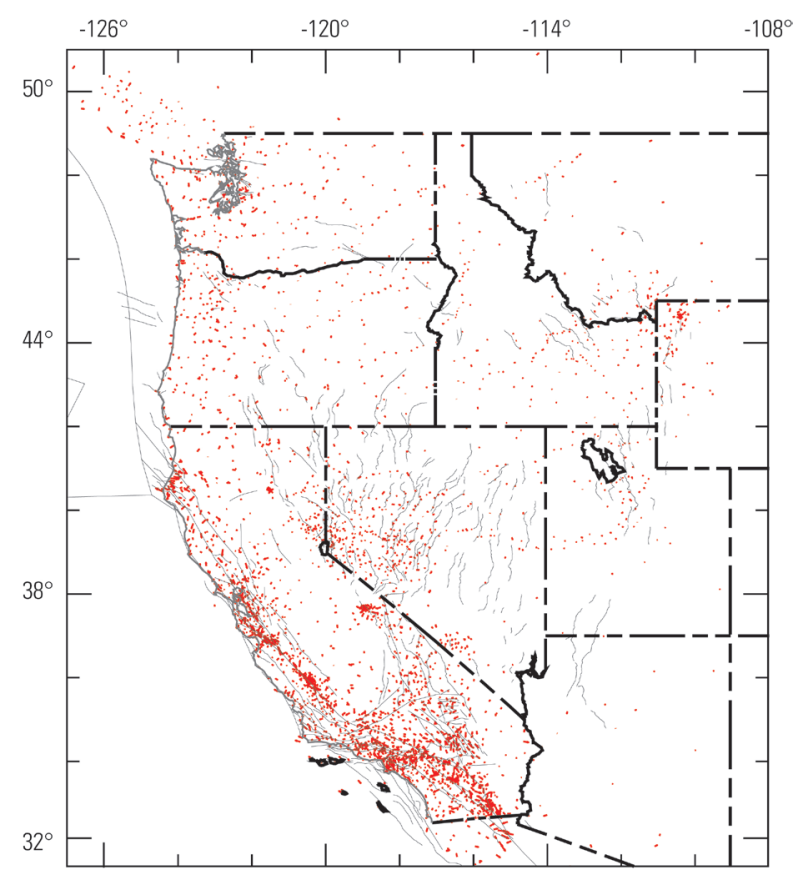

Figure D-4. A, Comparison of the global positioning system (GPS) velocity vectors for the Western United States, referenced to the North American plate, between the observation (blue) and model prediction (red). $B$, Residual velocities for inversion using the fault-based model with geologic constraints. Gray lines are the modeled fault traces. The residual vectors are plotted in the same scale as the GPS velocities in $A$.

Results in figure D-4 demonstrate that our model prediction generally fits the observed GPS velocities. The residuals in figure D- $4 B$ are given by the differences between the observed velocities and model predictions with a chi-square error of 7.01. The relatively large misfits in the Landers/Hector Mines area and in the central Nevada seismic belt are likely a result of the long-term postseismic relaxation of the asthenosphere that is not considered in our current deformation model. Large misfits near the Long Valley Caldera and Yellowstone area are partly caused by the local volcanism, which is not included in our model. Overall, we do not observe any systematic trend in the residuals that might suggest model bias. The model accommodates all of the major features observed in the GPS velocity field.

Figure D-5 plots the comparison of geologic slip rates with the modeled slip rates for California from this study. In general, modeled slip rates agree well with the geologic slip rates for most California faults except the Rogers Creek-Maacama faults, where modeled rates are higher than the geologic rates, and the Mojave fault to San Bernadino segments, where modeled slip rates are lower than the geologic rates. Unlike previous block-model studies (for example, McCaffrey, 2005; Meade and Hager, 2005), modeled slip rates along the Garlock fault closely agree with the geologic rates. This provides an alternative explanation to the viscoelastic relaxation model of Chuang and Johnson (2011) on the Garlock faulting processes. Slip rates along all California B-type faults fit well within the geologic bounds. 

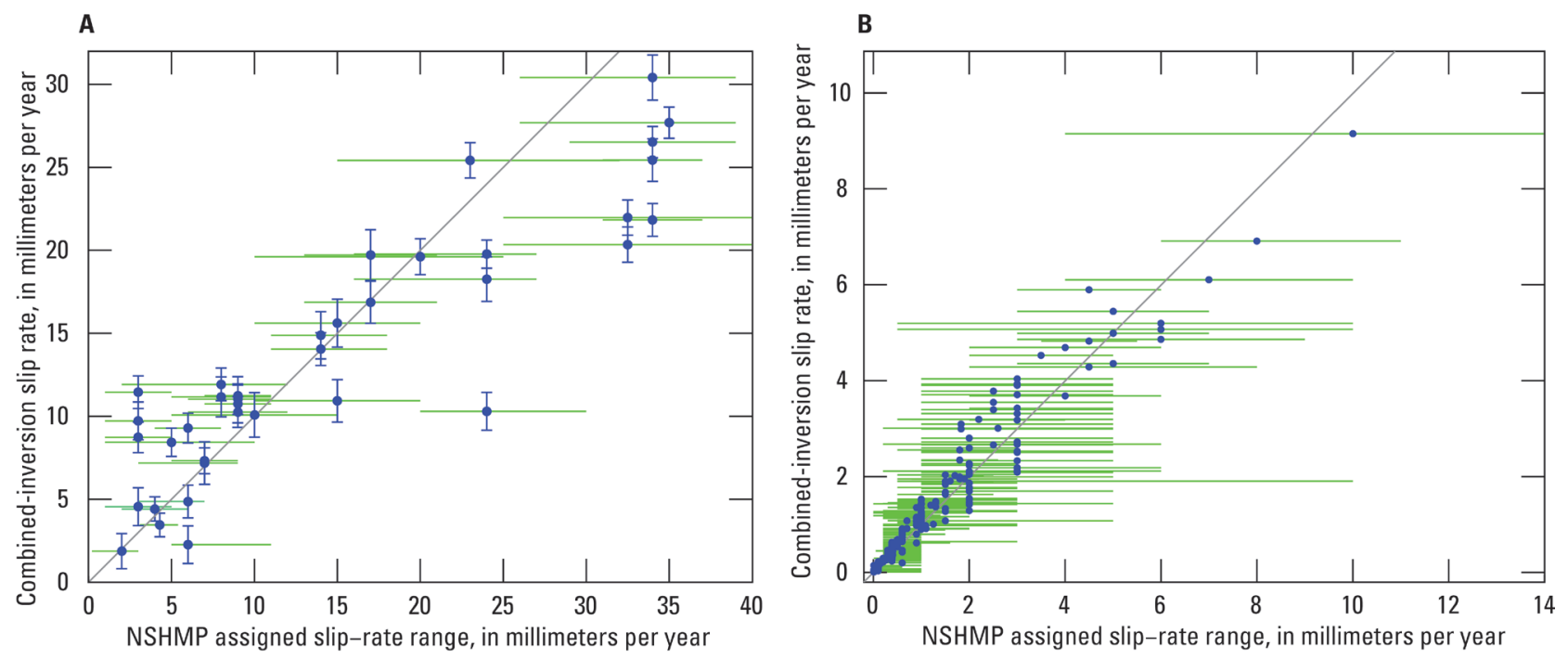

Figure D-5. A, Comparison between model slip-rates (solid blue dots) and geologic bounds on California A-faults. Green and red are geologic upper and lower geologic bounds. Solid line indicates where the two rates are equal. $B$, The same comparison of geodetic rates versus geologic rates (solid blue dots) but for the California B-faults. The geological upper and lower bounds are plotted in green and red crosses, respectively.

Figure D-6 compares geologic slip rates with the modeled slip rates for the rest of the WUS faults. For a few faults on the Pacific Northwest coast, slip rates are systematically lower than the rates from the modified 2008 source model. The modeled rates for the Wasatch fault Levan segment is 1.56 $\mathrm{mm} / \mathrm{yr}$ in comparison with the geologic rate of $0.31 \mathrm{~mm} / \mathrm{yr}$ assigned in the modified 2008 NSHMP source model. Our modeled result is consistent with the GPS observations along the Wasatch front that show constant velocity differences between the footwall and the hanging wall across the Wasatch fault zones. In general, our slip-rate changes are consistent with other geodetic-based models for the WUS (see appendixes $\mathrm{A}-\mathrm{C}$, this report). However, the discrepancies between the modeled slip rates and the geologic slip rates are within \pm one-half of the geologic slip rates for most of the WUS faults. Despite the discrepancy, correlation between the geologic estimates and the GPS solutions are high with a correlation coefficient of 0.9. Statistically, this indicates a strong linear dependence between the GPS estimates and the geologic estimates, suggesting that the geodetic and geologic data are highly compatible for the region. 


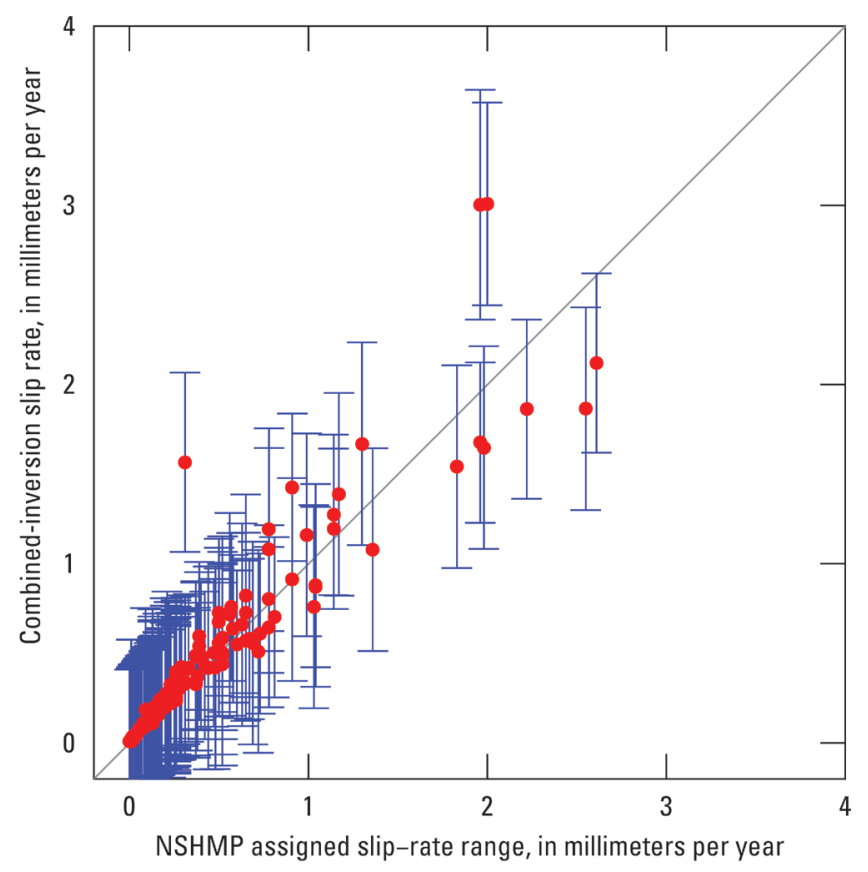

Figure D-6. Comparison between model slip rates and geologic rates for faults in the Western United States, excluding California. Vertical bars represent uncertainty in the combined-inversion slip-rate data.

Our off-fault strain rates consist of two components. The first component is obtained through fitting the residual GPS velocities that are the differences between observed velocities and predictions from the combined inversion. The second component is obtained through modeling of slip rate along the boundaries of blocks.

For the first component, we map the residual GPS velocities onto a uniformly spaced grid that extends across the WUS. The mapping uses a piecewise linear interpolation and smoothing procedure of Shen and others (1996). Our combined inversion of GPS velocities and geologic slip rates resulted in a reduced chi-squared error of 9.8. With this additional residual velocity fitting, the reduced chi-squared error decreases to 7.01. This uniformly spaced velocity field is then translated into a strain-rate field using a simple first-order finite difference scheme. Ideally, this residual off-fault strain rate should be computed simultaneously with the combined inversion, for example, using an iterative inversion scheme. Our study found that the first-order result provides a reasonable approximation to the final simultaneous inverse solution.

For the second component, we model off-fault strain rates by bringing our deeply buried dislocations to the surface along the boundaries of the six major blocks described earlier in this appendix and computing the resulting strain rate on the same uniformly spaced grid. We call this rate our long-term off-fault residual strain rate from the six nonstrict-rigid-behaving blocks. Our final offfault strain rates are the sum of the two strain rates (fig. E-6) with a total off-fault moment rate of $8.6 \times 10^{18}$ Newton-meters per year for the region excluding California.

\section{Conclusions}

We have developed a fault-based deformation model for the WUS. The model consists of several major blocks with numerous faults distributed among those blocks. The boundaries of those blocks align with major faults in California and the Cascadia subduction zone. Faults distributed within 
the blocks have their geometrical structure given by the UCERF3 B-faults, and non-California faults in the WUS are described in the 2008 NSHMP source model. We constrained our fault slip rates for distributed faults within the UCERF3 geologic bounds or \pm one-half of the geologic slip rates for most of the WUS faults. Our fit to the GPS velocities is quite reasonable with a chi-squared error of our inversion at 7.01, which is comparable to any other modeling fits. This demonstrates that the geologic slip rates for the California B-faults and faults in the rest of the WUS are consistent with the observed GPS velocity field. Major discrepancies occur in slip rates along some of the northern California Afaults, from the Mojave to San Bernardino segments of the San Andreas Fault, across central Nevada, and along the southern segment of the Wasatch fault system.

\section{References Cited}

Chuang, R.Y., and Johnson, K.M., 2011, Reconciling geologic and geodetic model fault slip-rate discrepancies in southern California - Consideration of nonsteady mantle flow and lower crustal fault creep: Geology, v. 39, no. 7, p. 627-630.

Dawson, T.E., and Weldon, R.J., 2013, Appendix B-Geologic slip-rate data and geologic deformation model: U.S. Geological Survey Open-File Report 2013-1165, 29 p.

Flück, P., Hyndman, R.D., and Wang, K., 1997, Three dimensional dislocation model for great earthquakes of the Cascadia subduction zone: Journal of Geophysical Research, v. 102, p. 20,53920,550 .

Hauksson, E., 2000, Crustal structure and seismicity distribution adjacent to the Pacific and North America plate boundary in southern California: Journal of Geophysical Research, v. 105, p. 13,87513,903 .

Haller, K.M., and Wheeler, R.L., 2008a, Parameter for faults in the Intermountain West, in Peterson, M.D., Frankel, A.D., Harmsen, S.C., Mueller, C.S., Haller, K.M., Wheeler, R.L., Wesson, R.L., Zeng, Yuehua, Boyd, O.S., Perkins D.M., Luco, Nico, Field, E.H., Wills, C.J., and Rukstales, K.S., Documentation for the 2008 update of the national seismic hazard maps: U.S. Geological Survey Open-File Report 2008-1128, p. G-1-G-18.

Haller, K.M., and Wheeler, R.L., 2008b, Parameter for faults in the Pacific Northwest, in Peterson, M.D., Frankel, A.D., Harmsen, S.C., Mueller, C.S., Haller, K.M., Wheeler, R.L., Wesson, R.L., Zeng, Yuehua, Boyd, O.S., Perkins D.M., Luco, Nico, Field, E.H., Wills, C.J., and Rukstales, K.S., Documentation for the 2008 update of the national seismic hazard maps: U.S. Geological Survey Open-File Report 2008-1128, p. H-1-H-6.

Hammond, W.C., Blewitt, G., and Kreemer, C., 2011, Block modeling of crustal deformation of the northern Walker Lane and Basin and Range from GPS velocities: Journal of Geophysical Research, v. 116, B04402, doi:10.1029/2010JB007817.

Hill, D.P., Eaton, J.P., and Jones, L.M., 1990, Seismicity of the San Andreas Fault system-1980-1986, in Wallace, R.E., ed., The San Andreas Fault system: U.S. Geological Survey Professional Paper 1515 , p. 115-152.

McCaffrey, Robert, 2005, Block kinematics of the Pacific/North America plate boundary in the southwestern United States from inversion of GPS, seismological, and geologic data: Journal of Geophysical Research, v. 110, B07401, doi:10.1029/2004JB003307.

McCaffrey, Robert, King, R.W., Payne, S.J., and Lancaster, M., 2013, Active tectonics of northwestern US inferred from GPS-derived surface velocities: Journal of Geophysical Research, v. 118, doi:10.1029/2012JB009473. 
Meade, B., and Hager, B.H., 2005, Block models of crustal motion in southern California constrained by GPS measurements: Journal of Geophysical Research, v. 110, B03403, doi:10.1029/2004JB003209.

Okada, Y., 1992, Internal deformation due to shear and tensile faults in a half-space: Bulletin of the Seismological Society of America, v. 82, p. 1018-1040.

Petersen, M.D., Bryant, W.A., Cramer, C.H., Cao, T., Reichle, M.S., Frankel, A.D., Lienkaemper, J.J., McCrory, P.A., and Schwartz, D.P., 1996, Probabilistic seismic hazard assessment for the State of California: California Division of Mines and Geology Open-File Report 96-08, U.S. Geological Survey Open-File Report 96-706, unpaginated.

Petersen M.D., Frankel, A.D., Harmsen, S.C., Mueller, C.S., Haller, K.M., Wheeler, R.L., Wesson, R.L., Zeng, Y., Boyd, O.S., Perkins D.M., Luco, N., Field, E.H., Wills, C.J., and Rukstales, K.S., 2008, Documentation for the 2008 update of the United States national seismic hazard maps: U.S. Geological Survey Open-File Report 2008-1128, 60 p., 11 appendixes, http://pubs.usgs.gov/of/2008/1128/.

Savage, J., and Burford, R., 1973, Geodetic determination of relative plate motion in central California: Journal of Geophysical Research, v. 78, p. 832-845.

Shen, Z.-K., Jackson, D.D., and Ge, X.B., 1996, Crustal deformation across and beyond the Los Angeles Basin from geodetic measurements: Journal of Geophysical Research, v. 101, p. 27,95727,980 .

Shen, Z.-K., King, R.W., Agnew, D.C., Wang, M., Herring, T.A., Dong, D., and Fang, P., 2011, A unified analysis of crustal motion in southern California, 1970-2004-The SCEC crustal motion map: Journal of Geophysical Research, v. 116, B11402, doi: 10.2019/2011JB008549.

Shen, Z.-K., Wang, M., and Zeng, Y., 2012, Unified Western US crustal motion map [poster]: 2012 SCEC Annual Meeting, Palm Spring California, Sept. 9-12, 2012.

Zeng, Y., and Shen, Z.-K., 2014, Fault network modeling of crustal deformation in California constrained using GPS and geologic observations: Tectonophysics, v. 612-613, p. 1-17. 


\title{
Appendix E-Consideration of the Use of Off-Fault Strain Rates from Combined Inversions of Geodetic (GPS) and Geologic Data for the National Seismic Hazard Maps
}

\author{
By Morgan P. Moschetti, Mark D. Petersen, and Yuehua Zeng
}

\section{Introduction}

In addition to the on-fault slip rates, the combined inversions of geodetic (GPS) data and geologic slip rates (combined-inversions) also provide off-fault estimates of crustal deformation as horizontal components of the strain-rate tensor on a defined grid for the Western United States (WUS). Although estimates of strain rates are provided for California, the fault network used by the geodetic modelers did not include all known faults within California resulting in artifacts in the off-fault strain rates within California to accommodate these missing features. The process by which off-fault strain rates may be incorporated into the probabilistic seismic hazard maps proceeds with three steps: (1) calculation of seismic moment rates from the off-fault strain rates at all grid points, (2) calculation of seismicity rates (seismic activity) from moment rates for all grid points, and (3) calculation of the probabilistic seismic hazard from the spatially variable seismicity rates using the seismic-source models and methods currently employed for the seismicity-derived component of the USGS national seismic hazard maps (NSHMP maps).

In this appendix, we describe the calculation of seismicity rates from the off-fault strain rates, via moment rates, by presenting the relevant relations and the assumed values. We justify our preliminary selection of strain-rate models, describe the steps taken to constrain the seismicity rates to be consistent with observations, and provide the reasoning for not including seismicity rates from offfault strain rates in the 2014 update for the NSHMP maps.

Four modeling groups participated in the WUS Geodetic workshops, and preliminary comparisons of off-fault seismicity rates were made with all four models and presented to workshop participants. Consistent with terminology used throughout this report, we refer to the models from McCaffrey (appendix A) and Hammond and Bormann (appendix B) as block models, and the models from Bird (appendix C) and from Zeng and Shen (appendix D) as fault-based models. Improper modeling of the Cascadia subduction zone by Zeng and Shen, at the time of the WUS Geodetic workshops, led to biased off-fault strain rates and anomalous moment-rate values. The Cascadia subduction zone back-slip model of Zeng and Shen has since been corrected, and an updated model has been provided to the NSHMP (see the section, Updates to Combined-Inversion Models). Comparison of off-fault strain rates from combined-inversions will therefore be restricted to three models because the aim of this appendix is to summarize the process by which off-fault strain rates from joint geodeticgeologic inversions were considered for implementation in the 2014 update to the NSHMP maps. This appendix will therefore present the combined-inversion models from (1) McCaffrey, (2) Hammond and Bormann, and (3) Bird.

\section{Off-Fault Strain Rates from Combined-Inversions}

Figure E-1 presents the variation in maximum horizontal strain rates from the three geodeticgeologic models. Details about the model parameterizations and combined inversions are provided in the respective appendixes. For the purpose of this appendix, however, the important distinction between the block models and the fault-based models is the way in which the model parameterizations distribute off-fault strain rates. The block models permit variability in off-fault strain rates between blocks but 
require that strain rates within each block are uniform. The fault-based models permit spatially variable off-fault strain rates. Because the calculation of seismic hazard derives from the spatial variability of off-fault strain rate, there are important implications of these two parameterizations for seismic hazard, which we discuss below.
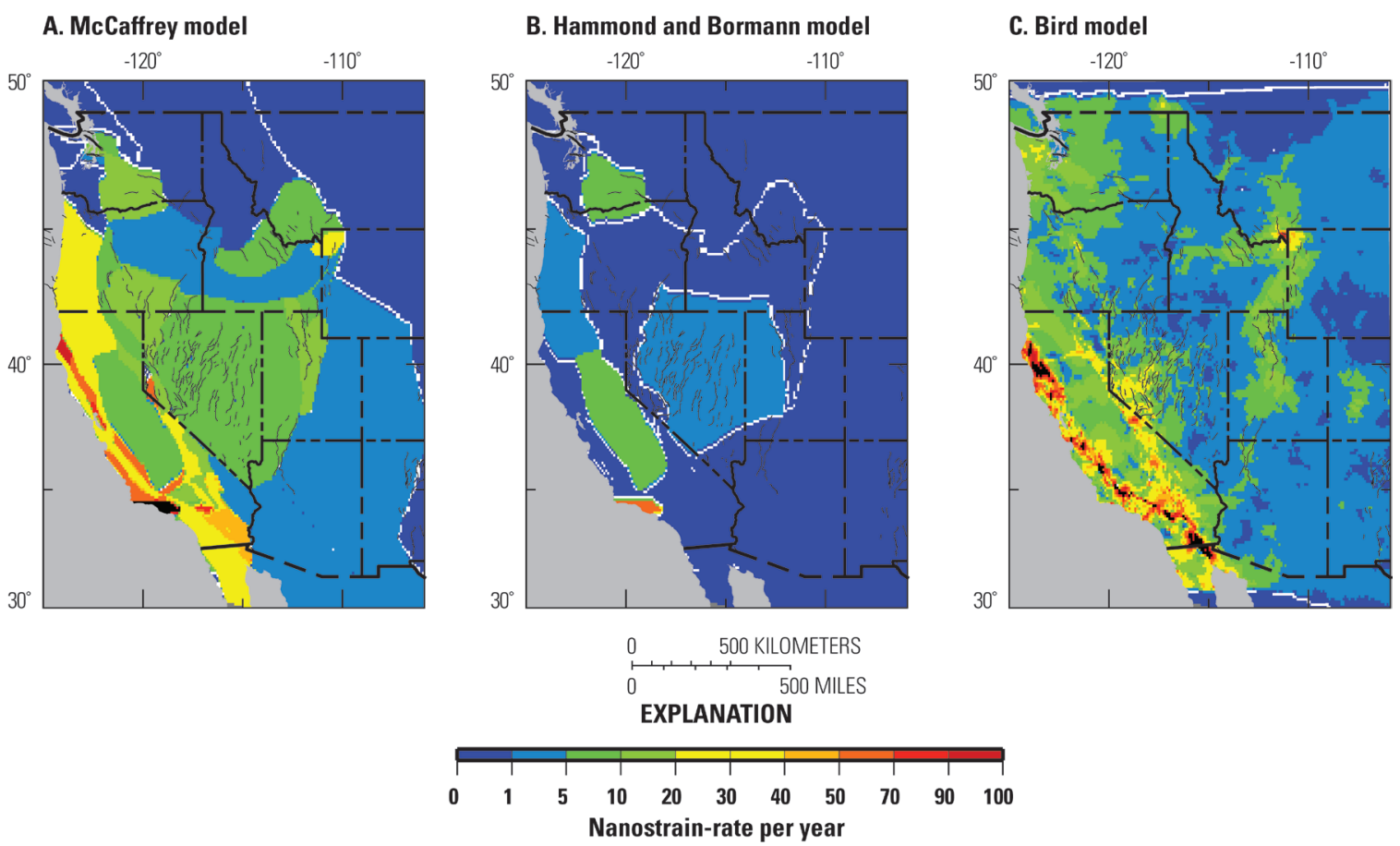

Figure E-1. Comparison of maximum horizontal strain rates from the combined-inversion models of $A$, McCaffrey (appendix A), B, Hammond and Bormann (appendix B), and C, Bird (appendix C). Large differences in spatial distributions of strain rate reflect the model parameterizations and regularizations used by the modelers. Although strain rates within California are provided, they are not considered in the treatment of off-fault strain rates for the Western United States, because the fault system in California is not complete for this study, and the resulting off-fault strain rates show strong tradeoffs because of the absence of many California faults that accommodate deformation.

Estimates of off-fault strain rates from the block models (fig. E-1 $A$ and E-1 $B$ ) largely reflect model regularization in the combined inversions. Strain-rate discontinuities in the combined-inversion block models clearly demarcate most block boundaries. Because the tradeoffs between on-fault slip rates and off-fault strain rates are controlled by inversion regularization and data fit, and because these features differ between the average block models, there are large differences in the off-fault strain rates estimated by the block models. Figure E-2 compares the fraction of strain rates from the three combined-inversion models within strain-rate bins for all elements in the WUS. About 90 percent of grid cells in the Hammond and Bormann model have less than 1 nanostrain per year of off-fault deformation, whereas about 50 percent of grid cells from the McCaffrey model have similarly low strain rates. 


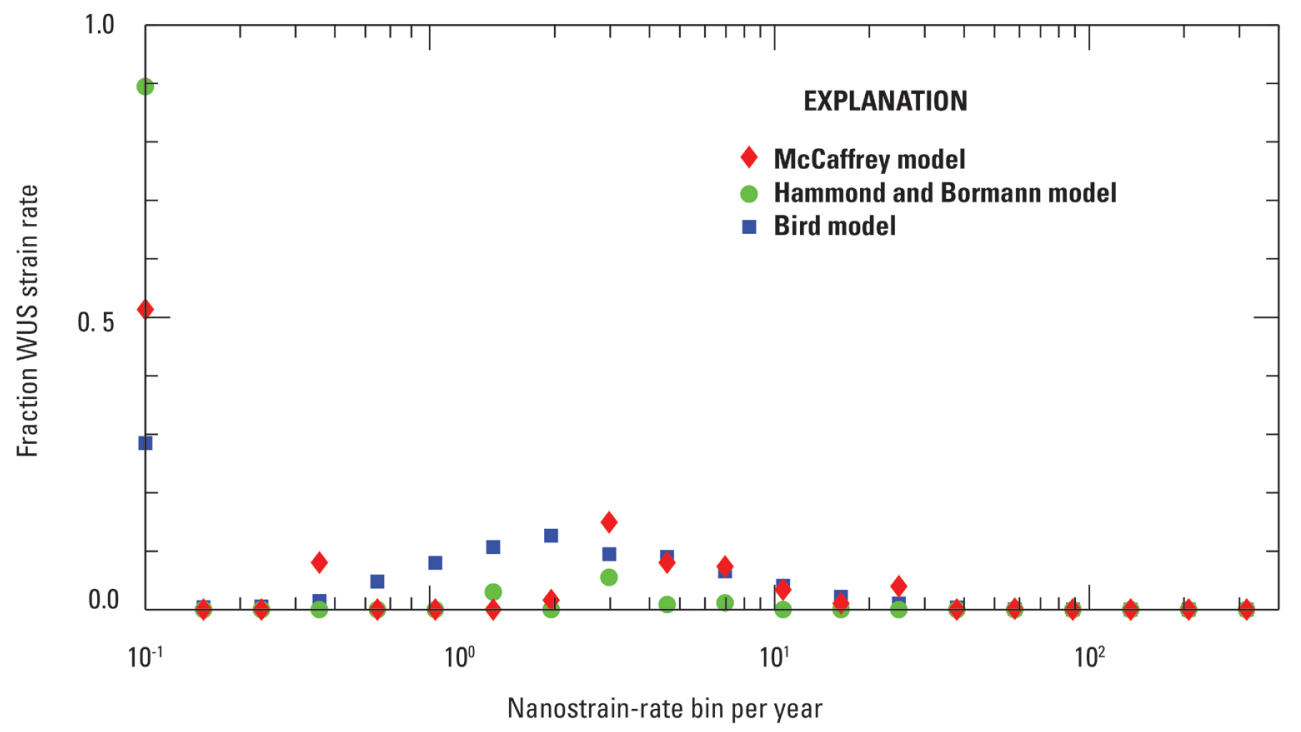

Figure E-2. Fraction of grid cells from the three combined-inversion models with binned strain rates in the study area. Most of the grid cells for the two block models McCaffrey (fig. E-1A; appendix A) and Hammond and Bormann (fig. E-1B; appendix B) have low strain rates, whereas the Bird (fig. E-1C; appendix C) fault-based model shows a much greater distribution of strain rates among grid cells.

The fault-based combined-inversion model of Bird allows for distributed deformation across the region but also shows large differences in the lateral distribution of off-fault strain rate due to model regularization and treatment of faults. About 30 percent of grid cells in the model have strain rates of less than 0.1 nanostrain per year. However, the model is characterized by a secondary peak at higher strain rates $(\approx 2$ nanostrain per year). The Bird model comprises about 14 percent and 8 percent of cells with strain rates of more than 5 and 10 nanostrain per year, respectively.

\section{Calculation of Seismicity Rates from Off-Fault Strain Rates}

We convert off-fault strain rates to moment rates within each cell using Kostrov's (1974) formula, as given by Savage and Simpson (1997). Moment rate is calculated as in equation 1.

$$
\dot{M}_{j}=2 \mu H A \times \max \left(\left|\dot{\varepsilon}_{1}^{j}\right|,\left|\dot{\varepsilon}_{2}{ }^{j}\right|,\left|\dot{\varepsilon}_{1}^{j}+\dot{\varepsilon}_{2}^{j}\right|\right)
$$

where $M o$ refers to moment, overdots indicate time derivatives, $\mu$ is the elastic shear modulus, $H$ is seismogenic thickness, $A$ is the area of the grid cell, and the max notation indicates the maximum of the principal-surface strain rates. Savage and Simpson (1997) refer to the resulting moment-rate estimate as a minimum scalar moment rate. Assuming a shear modulus of $3 \times 10^{10}$ pascal $(\mathrm{Pa})$ and a seismogenic thickness of $11 \mathrm{~km}$, we compute moment rates for all grid points. Total WUS moment rate values associated with the combined-inversion models, excluding California, vary by a factor of about seven $\left(1.1 \times 10^{18}-7.75 \times 10^{18}\right.$, see table E-1). Interestingly, model type (block or fault-based) is not the primary factor in differentiating total moment rates from the models; although the average moment rate from the block models is lower than the average from the fault-based models, the total moment rate of the block model from McCaffrey and the total moment rate of the fault-based model from Bird are comparable. 
Table E-1. Total moment rate (in Newton-meters per year, $\mathrm{Nm} / \mathrm{y}$ ) across all grid cells in the study area from the combined-inversion models. The total moment rate for the updated Zeng and Shen (appendix D) combinedinversion model is given in parentheses (see the section, Updates to Combined-Inversion Models, for details).

\begin{tabular}{lc}
\hline \multicolumn{1}{c}{ Geodetic model } & Moment rate, off-fault (Nm/y) \\
\hline McCaffrey (appendix A) & $7.752 \mathrm{E}+18$ \\
Hammond and Bormann (appendix B) & $1.101 \mathrm{E}+18$ \\
Bird (appendix C) & $7.755 \mathrm{E}+18$ \\
Zeng and Shen (appendix D) & $(8.667 \mathrm{E}+18)$ \\
\hline
\end{tabular}

We convert moment rates to seismicity rates by assuming that the magnitude-frequency distribution for earthquakes is governed by a truncated Gutenberg-Richter distribution (equation 2). To calculate the seismicity rate $\left(10^{a}\right)$, we equate the moment rate from the geodetic models with the moment rate from a truncated Gutenberg-Richter model, assuming a linear factor for aseismic moment release, and solve for the seismicity rate $\left(10^{a}\right)$ in each grid cell (equation 3 ).

$$
\begin{aligned}
& N\left(M_{i}\right)=10^{a-b M_{i}} \\
& 10^{a}{ }_{j}=\left(1-\alpha_{a s e i s}\right) \frac{10^{-9.05} \dot{M o}_{j}{ }^{g}}{\sum_{i}^{M_{\max }} 10^{(1.5-b) M_{i}}}
\end{aligned}
$$

Combining equations 1 and 3 gives the following:

$$
10^{a}{ }_{j}=\left(1-\alpha_{\text {aseis }}\right) \frac{\left(2 \times 10^{-9.05}\right) \mu H A \times \max \left(\left|\dot{\varepsilon}_{1}^{j}\right|,\left|\dot{\varepsilon}_{2}{ }^{j}\right|,\left|\dot{\varepsilon}_{1}{ }^{j}+\dot{\varepsilon}_{2}^{j}\right|\right)}{\sum_{i}^{M_{\max }} 10^{(1.5-b) M_{i}}}
$$

In equations 2-4, $\mathrm{N}\left(M_{i}\right)$ is the rate of earthquakes in magnitude bin $M_{i}$, and $\dot{M} o_{j}{ }_{j}$ and $10^{a}{ }_{j}$ are the geodetic moment rate and seismicity rate, respectively, in cell $j$. Our calculation for seismicity rates assumes an aseismicity factor $\left(\alpha_{\text {aseis }}\right)$ of zero, indicating that all of the geodetically derived moment rate will be released seismically by earthquakes with magnitudes up to $\mathrm{M}_{\max }$. However, we note that the seismogenic thickness used for the calculation of moment rate $(11 \mathrm{~km})$ is thinner than the $15-\mathrm{km}$ seismogenic thickness commonly assumed as the depth limit for brittle fracture. Therefore, the seismogenic thickness used in our calculations may alternatively be interpreted as a $15-\mathrm{km}$ seismogenic thickness with about 27 percent aseismicity. The seismogenic thickness of $11 \mathrm{~km}$ is also consistent with the estimate by Ward (1994) who solved for the seismogenic thickness that would give equal seismic and geodetic moment rates for California. We discuss, below, an additional seismicity-rate normalization, which we use to ensure that the rate of earthquakes does not significantly deviate from the observed rates in the earthquake catalog. However, it is encouraging that our assumptions for the controlling parameters in the seismicity rates calculations yield reasonable values. 
We calculate seismicity rates from the geodetic moment rates assuming regionally uniform maximum magnitudes $\left(M_{\max }=7.5\right)$ and aseismicity factors $\left(\alpha_{\text {aseis }}=0\right)$ for the study area. The seismicity rates are presented in figure E-3. Spatial patterns in seismicity rates are the same as those in the plots of strain rate because seismicity rates and strain rates are linearly related for uniform $M_{\max }, H, A, b$, and $\alpha_{a s e i s}$ (see equation 3 ). Even though spatial variations in these parameters may, and probably do, exist; we have not investigated their variation. 

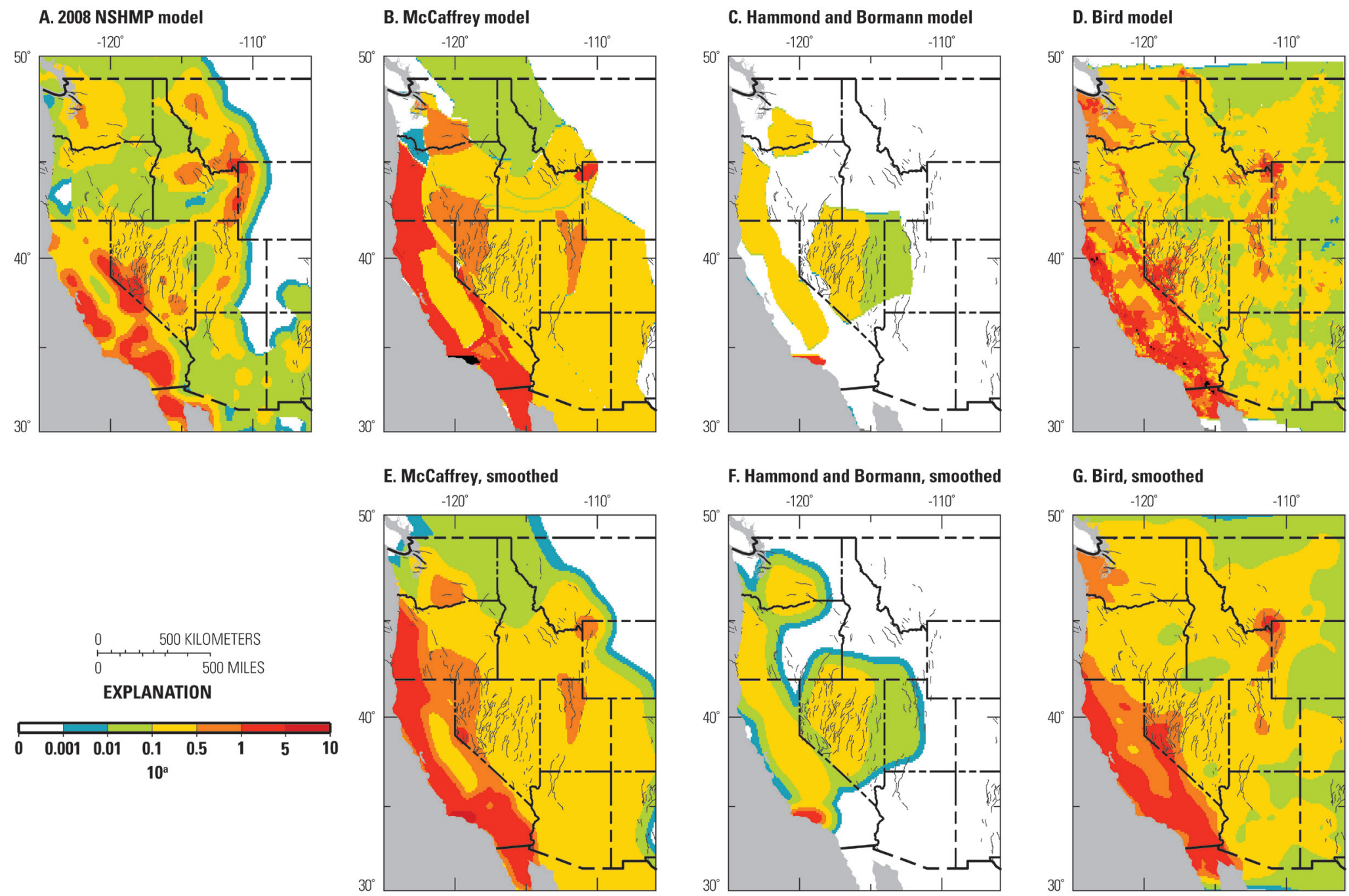

Figure E-3. Comparison of seismicity rates from the $A, 2008$ national seismic hazard maps (Petersen and others, 2008) and the seismicity rates calculated and smoothed from the combined-inversion models of $B$ and $E$, McCaffrey (appendix A), $C$ and $F$, Hammond and Bormann (appendix $B$ ), and $D$ and $G$, Bird (appendix C). Seismicity rates in California are poorly constrained because of the incomplete fault network used in California. 
Because earthquake epicenters are smoothed in order to generate the background seismicity model for the 2008 NSHMP maps (Petersen and others, 2008) and the very short wavelength variations in strain rates from the fault-based models are below the resolving ability of GPS measurements, we smooth the seismicity rates calculated from the combined-inversion models. Smoothed seismicity rates derived from the combined-inversions are plotted in figures E-3E through E-3G. The uniform intrablock strain rates from the block models map into uniform seismicity rates. The smoothed seismicity models derived from the combined-inversion models from Bird and McCaffrey show broad general agreements, though there are considerable differences in small-scale features. The seismicity-rate model from the combined-inversion of Hammond and Bormann yields significantly lower values than the other models and is not considered in the following discussion. WUS seismicity rates from the combinedinversion models are particularly high in three regions: (1) along coastal Washington and Oregon near the Cascadia subduction zone; (2) in western Nevada, locally extending into southeastern Oregon; and (3) at the eastern boundary of the Basin and Range, including the region near Wasatch fault zone.

Comparison of the derived seismicity rates with the observed, smoothed seismicity rates from the 2008 NSHMP maps is presented in figure E-4. Higher seismicity rates are observed in the 2008 NSHMP model, relative to the derived seismicity rates from the combined-inversion models in three regions: (1) along the California-Nevada border, (2) through western Montana, and (3) in southern Nevada. Persistently lower rates in the 2008 NSHMP maps occur through coastal Washington and Oregon and generally within the Cascadia subduction zone.

A. McCaffrey model

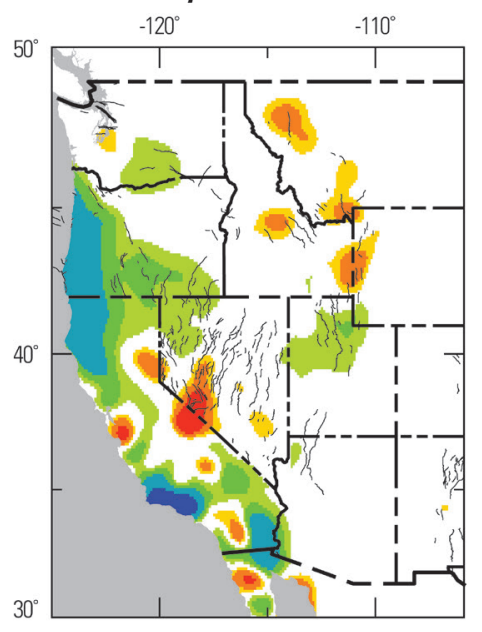

B. Hammond and Bormann model

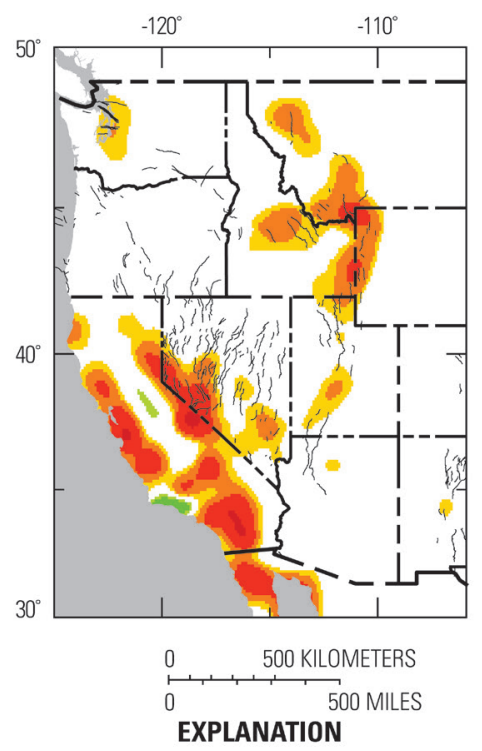

C. Bird model

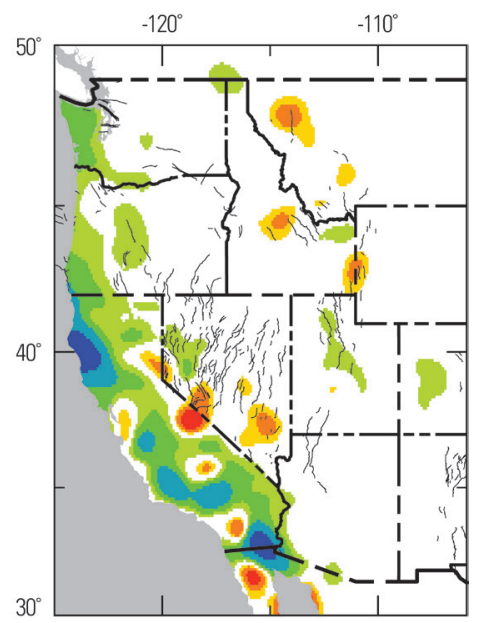

$30^{\circ}$

(1)




\section{Seismic Hazard from Off-Fault Strain Rates}

Based on suggestions from participants at WUS Geodetic workshops (in Newark and Menlo Park, Calif., in 2012 and 2013), we pursued the use of a single combined-inversion model—the Bird model - for hazard sensitivity studies and presentation to the NSHMP Steering Committee. Off-fault seismicity rates calculated from the average block models were not considered, because of concern about the effects of uniform seismicity rates within blocks and their effect on hazard. Whereas future studies with geodetic block models may employ alternative block geometries that allow for higher spatial variability in off-fault strain rates, the fault network prescribed for the 2014 WUS geodetic studies clearly leads to off-fault strain-rate artifacts that cannot be incorporated in the hazard calculation.

We also followed the recommendations from the workshop not to consider the off-fault component from the early version of the Zeng and Shen fault-based model, because of the large moment rate difference that occurred at that time between the Zeng and Shen model and the other combinedinversion models. With the update of the Zeng and Shen model, the total moment rate now falls in-line with the other combined-inversion models.

Because of concerns about the contribution of interseismic surface deformation from the Cascadia subduction zone on the combined-inversion-derived seismicity rates in the U.S. Pacific Northwest, we focused our investigation of the use of off-fault geodetic models for seismic hazard calculations on the Intermountain West (IMW). The combined-inversion models were developed with GPS velocities that had been corrected for the effects of Cascadia subduction; however, residual effects appear to remain and bias the combined-inversion models. We extracted the calculated and smoothed seismicity rates from the Bird model for the IMW region.

Assumptions about the seismic-magnitude-frequency distribution and the appropriate values for seismogenic thickness, elastic shear modulus, the aseismic component of surface deformation, and maximum magnitude strongly affect the seismicity rates calculated from strain rates, and the calculated seismicity rates are linearly related to the seismogenic thickness, aseismicity, and shear modulus. The assumed values are reasonable for the WUS; however, lateral variation is likely to exist leading to laterally variable effects on the seismicity rates calculated from strain rates. Because the GutenbergRichter distribution is known to represent the magnitude-frequency distribution for sufficiently large regions, we apply the Gutenberg-Richter distribution to all grid cells when calculating seismicity rates from strain rates. However, whether Gutenberg-Richter distributions accurately represent magnitudefrequency distributions on such small scales is unknown. Finally, the maximum magnitude $\left(M_{\max }\right)$ for earthquakes that we allow to release geodetic strain rates is inversely related to the calculated seismicity rate; as $M_{\max }$ increases, more moment rate is consumed by large events and the seismicity rate $\left(10^{a}\right)$ decreases to constrain seismic-moment rate.

To further stabilize the seismic hazard calculation, we calculated the regional seismicity rate from the 2008 NSHMP maps and normalized the regional rate from the Bird geodetic model to the observed seismicity rate. Insufficient earthquake numbers are available to constrain spatially variable seismicity rates at the resolution of the combined-inversion models, so we focused our comparisons between observed and geodetically derived seismicity rates on the regional seismicity rate of the IMW. The earthquake catalog for the IMW indicates an annual rate of about 0.062 events with $\mathrm{M} \geq 6$. With the assumed parameters described above, we find a seismicity rate discrepancy from the Bird geodetic model of only about 14 percent. To normalize the seismicity rates from the Bird model to the observed seismicity rates, we increase all of the derived seismicity rates by 14 percent. This normalization ensures that the seismicity rates calculated from off-fault strain rates match the regionally observed values but do not address discrepancies within the IMW. 
We calculated probabilistic seismic hazard using methods described in the documentation for the 2008 NSHMP maps (Petersen and others, 2008) to produce hazard curves at all points within the WUS from the gridded seismicity sources in the IMW region. As previously noted, the combined-inversion model is not well constrained within California, and the modeled and calculated values within California should not be interpreted. We present the hazard maps for 5-Hz response spectral values with a 2-percent probability of exceedance in 50 years, along with the differences and ratios in the probabilistic ground motions in figure E-5. 
A

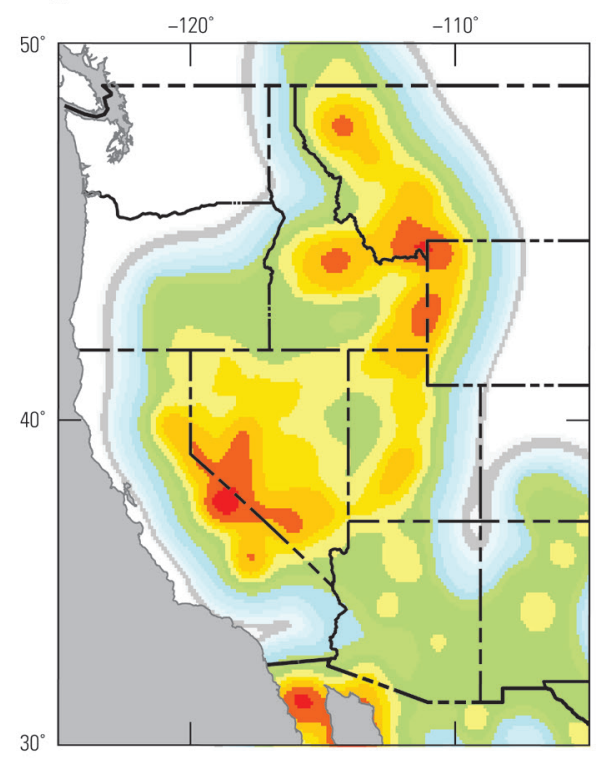

B

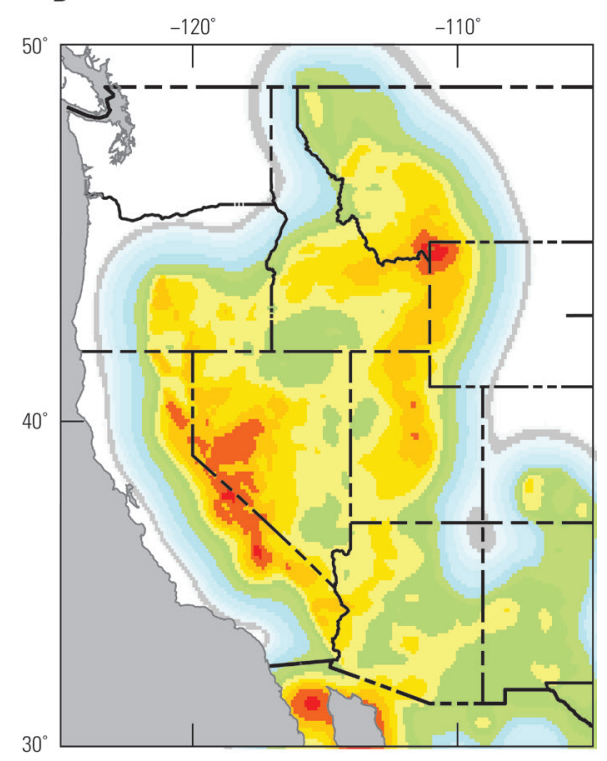

EXPLANATION
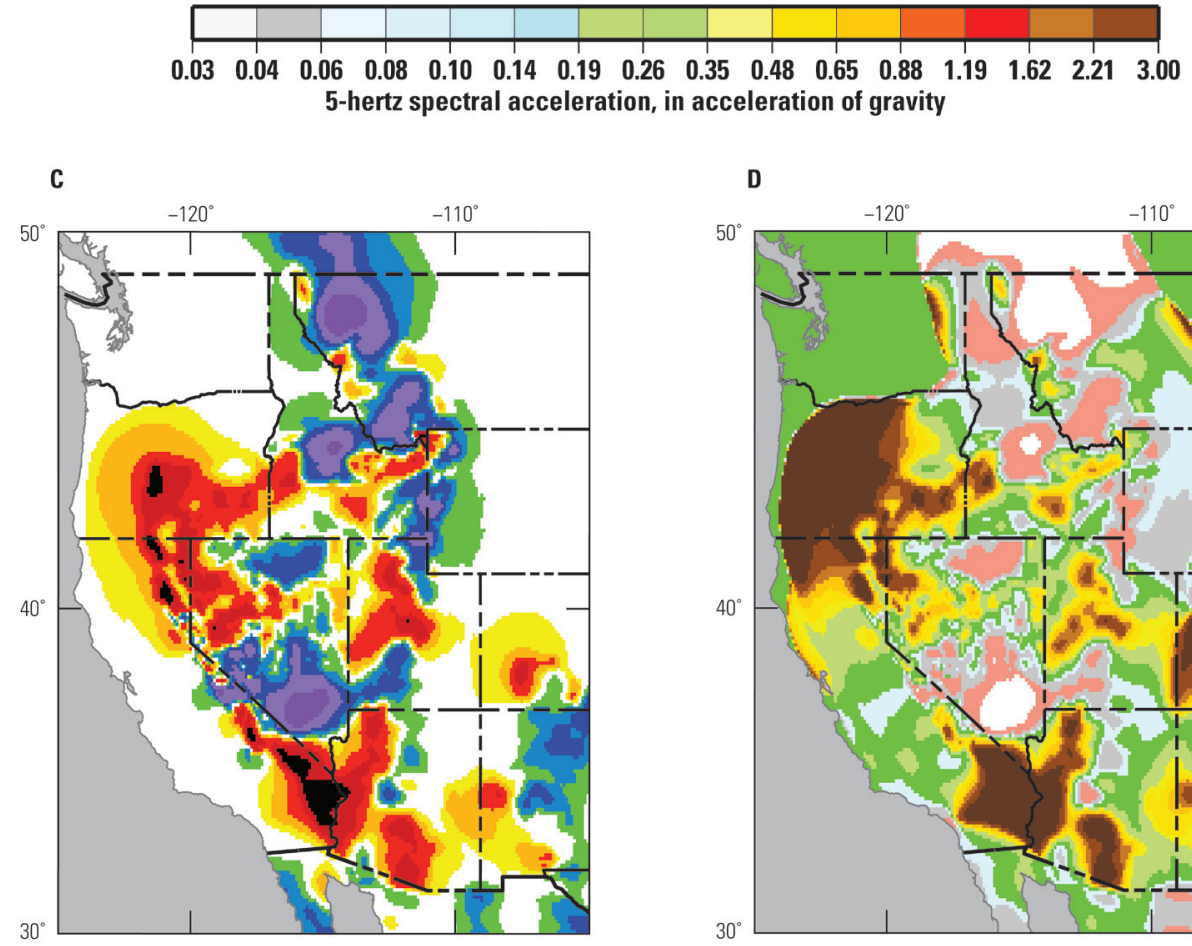

D

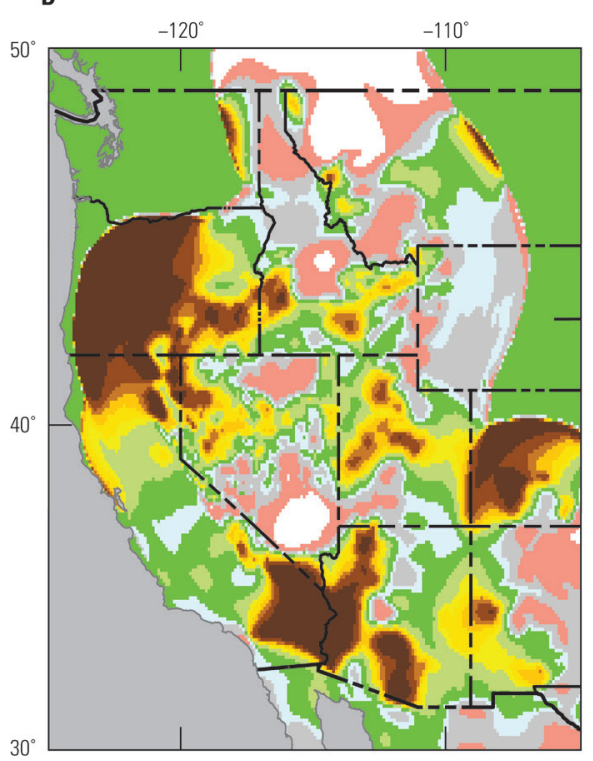

500 KILOMETERS

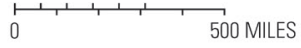

EXPLANATION

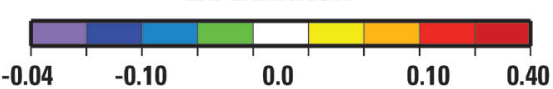

Ground-motion difference at 5-hertz, in acceleration of gravity

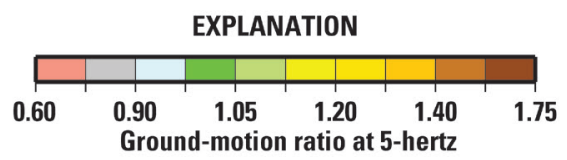

Figure E-5. Comparison of 5-hertz spectral acceleration for 2 percent probability of exceedance in 50 years from $A$, the smoothed seismicity model of the 2008 national seismic hazard maps of Petersen and others (2008) and $B$, the hazard from the seismicity rates calculated from the Bird geodetic model (appendix $C$ ), along with the $C$, 
differences and $D$, ratios of the hazard maps. Seismicity rates employed in the calculation of the seismic hazard were restricted to the Intermountain West region. Rates and hazard values within California, Washington, or parts of Oregon are not accurate, because of the geodetic modeling parameterizations discussed in text.

The hazard maps from the smoothed seismicity (Petersen and others, 2008) and from Bird combined-inversion model exhibit broad general agreement. High seismic hazard exists in western Nevada, throughout the eastern boundary of the Basin and Range province - running from southwest Utah through the Wasatch Range and into western Montana - and in the zone trending approximately east-west across central Idaho.

Smaller scale hazard features in the maps, however, indicate large discrepancies between the observed seismicity and the geodetically derived seismicity. The Bird model indicates higher seismic hazard in southeastern Oregon and running through central Idaho, in western Arizona, through the presumed Yellowstone hotspot track trending northeast, in southwestern Utah, and along a southwestnortheast trending band leading to the Rio Grande rift. The smoothed seismicity from the 2008 NSHMP maps indicates higher hazard in southern Nevada, northwestern Montana, and along the IdahoWyoming border.

\section{Input and Guidance from NSHMP Steering Committee}

The seismic hazard maps calculated using the off-fault component of the Bird combinedinversion model (fig. E-5) were presented to the 2014 NSHMP Steering Committee on May 6-7, 2013, for consideration in the 2014 update to the NSHMP maps. Although the Steering Committee recognized the importance of incorporating geodetic measurements into the NSHMP maps, they recommended against incorporation of the off-fault geodetic strain rates for the NSHMP update. The Steering Committee had three primary concerns with the off-fault strain rates. (1) They reiterated the concern that the attempts to remove surface deformation signals associated with Cascadia subduction had not been completely successful. (2) They expressed concern that high strain rates observed in southeastern California and western Arizona were associated with transient signals. (3) Although the Steering Committee recognized the general importance of alternative seismicity models for hazard calculations, they suggested that future work to compare orientations of the strain-rate tensors with seismic-moment tensors could provide additional confidence in the use of geodetic off-fault strain rates.

\section{Updates to Combined-Inversion Models-Zeng and Shen}

Since the WUS geodetic workshops and the NSHMP Steering Committee meeting, updated offfault strain rates associated with the combined-inversion model of Zeng and Shen have been provided to the NSHM project. Discussion about the Zeng and Shen model presented to the WUS geodetic workshop participants in this appendix refers to the outdated off-fault strain-rate model, except for the updated total moment rate value in table E-1. Although the updated off-fault strain-rate model will not be considered for the 2014 update to the NSHMP maps, we present the updated strain-rate and momentrate values here to enable readers to evaluate the combined-inversion model of Zeng and Shen. 


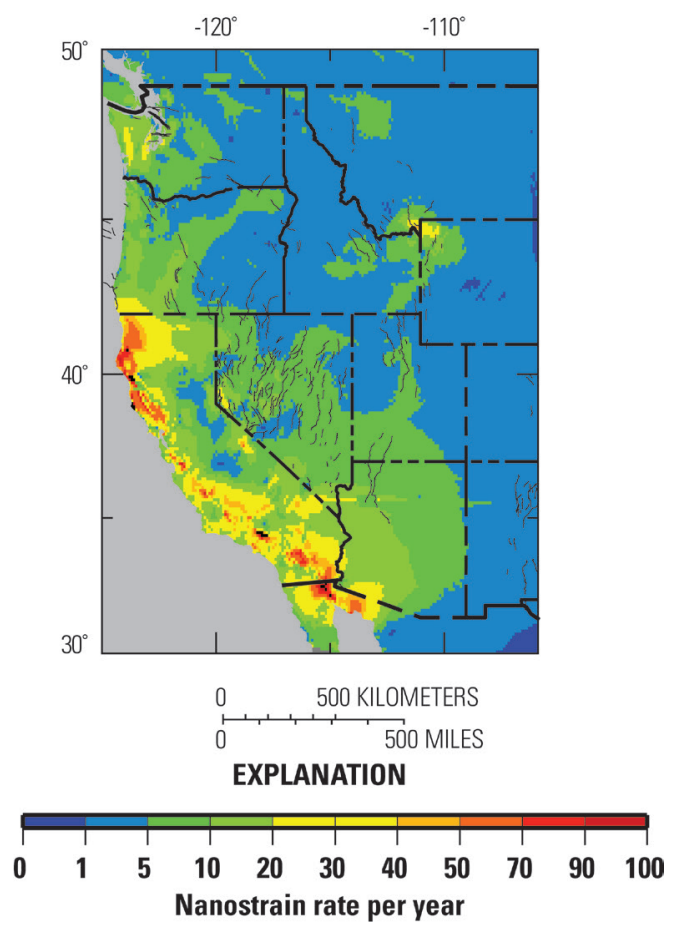

Figure E-6. Plot of updated off-fault strain rates from the Zeng and Shen model (appendix D).

Zeng and Shen's off-fault strain rates consist of a modeled off-fault strain-rate component and an inverted component obtained through fitting the residual GPS velocities. Modeled off-fault strain rates from the previous version of the Zeng and Shen model were biased by including an incorrect contribution from the Cascadia subduction model, which resulted in the high preliminary strain rates and moment rates. Because the Cascadia subduction zone was modeled by using a back-slip model, the residual off-fault strain-rate contribution becomes zero when the locking-depth is brought up to the surface. This correction in the current version of the Zeng and Shen combined-inversion model reduces total off-fault moment rate from $1.189 \times 10^{19}$ to $8.667 \times 10^{18}$ Newton-meters per year. A plot of the updated off-fault strain rates from the Zeng and Shen model is given in figure E-6. Although this model was not available for consideration during the WUS geodetic workshop of the NSHMP Steering Committee meeting, the reduction in total moment rate associated with off-fault deformation brings the total moment rate from the combined-inversion model of Zeng and Shen into agreement with the total moment rates from the other combined-inversion models.

\section{References Cited}

Kostrov, B.V., 1974, Seismic moment and energy of earthquakes, and seismic flow of rock: Izvestiya, Russian Academy of Sciences, Physics of the Solid Earth, v. 1, p. 23-44.

Petersen, M.D., Frankel, A.D., Harmsen, S.C., Mueller, C.S., Haller, K.M., Wheeler, R.L., Wesson, R.L., Zeng, Y., Boyd, O.S., Perkins, D.M., Luco, N., Field, E.H., Wills, C.J., and Rukstales, K.S., 2008, Documentation for the 2007 update of the United States national seismic hazard maps: U.S. Geological Survey Open-File Report 2008-1128, 128 p.

Savage, J.C., and Simpson, R.W., 1997, Surface strain accumulation and the seismic moment tensor:

Bulletin of the Seismological Society of America, v. 87, no. 5, p. 1345-1353.

Ward, S.N., 1994, A multidisciplinary approach to seismic hazard in southern California: Bulletin of the Seismological Society of America, v. 84, no. 5, p. 1293-1309. 